\title{
Three Essays on Capital Structure
}

\author{
by \\ Mona Yaghoubi
}

A thesis

submitted to the Victoria University of Wellington

in fulfilment of the

requirements for the degree of

Doctor of Philosophy

in Finance.

Victoria University of Wellington

2017 
To Mum, Dad, Peyman \& Elara 


\section{Abstract}

This thesis consists of three self-contained essays about the relationship between cash flow and investment volatility and firm capital structure and cash holdings. Capital structure measures sources of financing that allow a firm to operate, invest, and grow.

The first essay reviews the theoretical relationship between firm capital structure and cash flow volatility, develops testable hypotheses, constructs a data set, and then tests the hypotheses using several measures of firm cash flow volatility and econometric methods that account for the non-linear relationship of proportional variables. Overall, the evidence indicates that ceteris paribus, a one standard deviation increase from the mean of cash flow volatility, implies approximately by $24 \%$ decrease in the long-term debt ratio, a $26 \%$ decrease in probability of holding debt with over 10 years to maturity, and a 39\% increase in the probability of not holding either short or long term debt. These findings are novel in the empirical capital structure literature and show the importance of cash flow volatility in firm financial policies.

The second essay studies the financing behaviour of Hospital Corporation of America (HCA) from 1990 to 2013 and demonstrates variation in HCA's market and book leverage ratios due to 1) mergers and acquisitions and divestitures that change the firm's total assets, 2) share buybacks, and 3) leveraged buyouts and public offerings that change the firm's ownership. The paper scrutinizes variation in HCA's market and book leverage ratios independently as well as relative to each other. Our evidence shows that i) HCA's management team used HCA's excess cash from divestitures to repurchase HCA's stock rather than pay off HCA's debt, ii) HCA's market leverage ratio tends to stay in a target leverage zone, and iii) in some years 
HCA's management team used the book leverage ratio as a tool to keep the market leverage ratio inside a target leverage zone.

In the third essay, we investigate the influence of investment volatility on capital structure and cash holdings using a broad definition of investment. Despite theoretical motivation, the relationship between investment volatility and capital structure has not been studied in the empirical literature. All in all, our evidence suggests that i) firms with relatively high capital expenditure and acquisition investment volatility hold relatively higher levels of debt and lower levels of cash, ii) firms fund large capital expenditures and/or acquisition by increasing debt or decreasing cash, and iii) immediately after funding large investment firms reduce debt levels and increase cash holdings. Research and development investment volatility is related to lower debt levels and higher cash levels, and does not exhibit similar investment spike funding. Overall, our results are consistent with parts, but not all, of the DeAngelo, DeAngelo and Whited (2011) model. 


\section{Acknowledgments}

One event could have postponed submitting this thesis; carrying my baby girl Elara that turned into a big motivation.

I am extremely grateful to my supervisors, Michael Keefe and Graeme Guthrie for their patient guidance and excellent advice throughout the course of my dissertation. In particular, I would like to thank Michael for his encouragement and endless support. His input significantly improved the quality of this thesis, any PhD student is lucky to have him as their supervisor. Also, I would like to thank Graeme for his input, comments and ideas regarding HCA's case study. Although it was quite a challenge; with Graeme's help, I enjoyed working on HCA's case and analysing its financing behaviour.

I am enormously thankful to my beloved Mum and Dad, Fahimeh and Asad for their unconditional love and support. Everything I have in my life and the person I am today is the result of their endeavour and values in life. A very special thank you to Peyman the love of my life, whom I met and married while I was doing my PhD. I cannot thank him enough for all he has done for me and his never-ending love and continuous support throughout this journey. I would also like to thank my caring and always supportive brothers Reza and Ehsan, their spouses Maryam and Rebecca and my in-laws Morteza, Minoo and Pouyan who were always there for me.

Also, I must thank all the staff members and fellow PhD students at the School of Economics and Finance for their inspiration and support throughout the past 4 years.

I am also sincerely grateful to my colleagues at the Reserve Bank of New Zealand for their support, encouragement and motivation, especially to Bernard Hodgetts, Steffi Schuster and Daria Kwon. 


\section{Contents}

1 Preliminaries 1

1.1 Thesis Structure . . . . . . . . . . . . . . . . . . . . 1

2 Cash flow volatility \& Debt 4

2.1 Introduction . . . . . . . . . . . . . . . . . . . . 4

2.2 Hypothesis development . . . . . . . . . . . . . . . . 7

2.3 Sample and variable construction . . . . . . . . . . . . . . . . 9

2.3.1 Sample...................... . . . 9

2.3.2 Variable Construction . . . . . . . . . . . 10

2.4 Testing . . . . . . . . . . . . . . . . . . . . . 20

2.4 .1 Testing Hypothesis 1 . . . . . . . . . . . . . 20

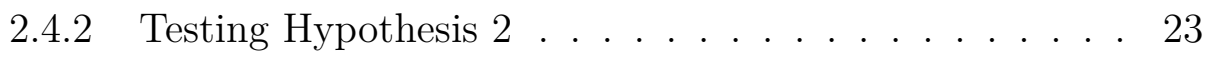

2.5 Discussion and Robustness . . . . . . . . . . . . . . . . 25

2.5.1 Cash Flow Volatility and Other Explanatory Variables 25

2.5.2 Alternative Estimation Methods . . . . . . . . . 26

2.5.3 Robustness to Volatility Measures and Window Lengths 27

2.5.4 Robustness to Different Measures of Debt Maturity . . 28

2.6 Conclusion . . . . . . . . . . . . . . . . . . . 28

2.7 Appendices . . . . . . . . . . . . . . . . . . . 31

2.7.1 Compustat Variable Definitions . . . . . . . . . . 31

2.7.2 Variable Definitions . . . . . . . . . . . . . . 33

2.8 Figures and Tables . . . . . . . . . . . . . . . . . 35

3 Financing Behaviour in Big Events 52

3.1 Introduction . . . . . . . . . . . . . . . . . 52 
3.2 History of $\mathrm{CHC}$ and $\mathrm{HCA} \ldots \ldots \ldots \ldots 5$

$3.2 .1 \mathrm{CHC} \ldots \ldots \ldots \ldots \ldots \ldots 5$

$3.2 .2 \quad \mathrm{HCA} \ldots \ldots \ldots \ldots \ldots \ldots$

3.2.3 Columbia/HCA Healthcare . . . . . . . . . . . 58

3.3 Sample and Variable Construction . . . . . . . . . . . . . . 60

3.3 .1 Sample . . . . . . . . . . . . . . . . 60

3.3.2 Variable Construction . . . . . . . . . . . 60

3.3.3 Decomposition of leverage measure . . . . . . . . . . 61

3.4 Industry Leverage . . . . . . . . . . . . . . . . . . . . . 65

3.5 Findings . . . . . . . . . . . . . . . 67

3.5.1 Market versus Book Leverage Ratio . . . . . . . . . . 67

3.5.2 Changes in a Firm's Total Assets . . . . . . . . . . . . 70

3.5.3 Buyback Programs . . . . . . . . . . . . . . 78

3.5.4 Changes in Ownership . . . . . . . . . . . . . 87

3.6 Discussion and Summary . . . . . . . . . . . . . . . . . . . 91

3.7 Figures and Tables . . . . . . . . . . . . . . . . . . . . . . . . . 94

4 Investment volatility \& Financing 106

4.1 Introduction . . . . . . . . . . . . . . . 106

4.2 Literature review and Hypothesis development . . . . . . . . . 110

4.3 Sample and variable construction . . . . . . . . . . . . . . . . 113

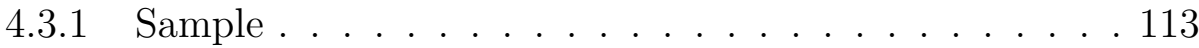

4.3.2 Variable Construction . . . . . . . . . . . . . 113

4.4 Testing . . . . . . . . . . . . . . . . . . . . . . . . . . . . 119

4.4.1 Estimation approach . . . . . . . . . . . . . . 119

4.4.2 Testing Hypotheses 3a and 3b . . . . . . . . . . . 120

4.4.3 Testing Hypotheses 4a and 4b . . . . . . . . . . . . . 122

4.4.4 Testing Hypotheses 5a and 5b . . . . . . . . . . . . . 123

4.5 Discussion and Robustness . . . . . . . . . . . . . . . . . . 125

4.6 Conclusion . . . . . . . . . . . . . . . . . . . . 126

4.7 Appendices . . . . . . . . . . . . . . . . . . . . . . . . . 129

4.7.1 Variable Definitions . . . . . . . . . . . . . . . . 129

4.8 Figures and Tables . . . . . . . . . . . . . . . . . . . . . . . . 132 


\section{List of Tables}

1 Zeroby Maturity Construction . . . . . . . . . . . . 37

2 Empirical Literature Volatility Measures . . . . . . . . . . . . 38

3 Volatility Measures Correlations . . . . . . . . . . . . . . 40

4 Summary of variables . . . . . . . . . . . . . . . . . 41

5 Summary of ZerobyMaturity . . . . . . . . . . . . . . . . . . 42

6 Correlations . . . . . . . . . . . . . . . . . 43

7 Testing Hypothesis $1 \ldots \ldots$. . . . . . . . . . . 44

8 Testing Hypothesis $2 \ldots \ldots \ldots$. . . . . . . . . . . . . 45

9 Predicted ZerobyMaturity . . . . . . . . . . . . . . . 46

10 Capital Structure Variables by Cash Flow Volatility Quantiles 47

11 Robustness to econometric method . . . . . . . . . . . . . . . 48

12 Robustness to volatility measures . . . . . . . . . . . . . . . . 49

13 Robustness to window size . . . . . . . . . . . . 50

14 Robustness to different debt maturity variables . . . . . . . . 51

1 Components of HCA's Book and Market Leverage Ratios . . . 100

2 Empirical Literature - Changes in Assets . . . . . . . . . . . . 102

3 Empirical Literature - Buyback . . . . . . . . . . . . . 103

4 Columbia/HCA buybacks and public offerings from 1990 to $2013 \ldots \ldots \ldots \ldots$. . . . . . . . . . . . . . . . . . . . . . . . .

5 Empirical Literature - Leveraged Buyout . . . . . . . . . . . . 105

1 Summary of variables . . . . . . . . . . . . . . . . . . 132

2 Correlations . . . . . . . . . . . . . . . . . . . 133

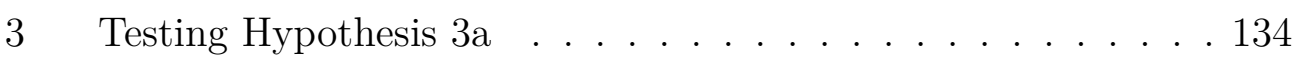




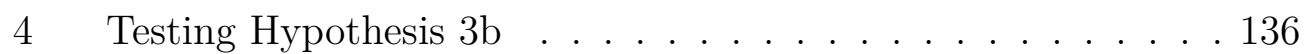

$5 \quad$ Testing Hypothesis $4 a \ldots \ldots$. . . . . . . . . . . . . . . . . . . . 138

6 Testing Hypothesis $4 \mathrm{~b} \ldots \ldots$. . . . . . . . . . . . . . . . . 140

$7 \quad$ Testing Hypothesis $5 \mathrm{a} \quad \ldots \ldots$. . . . . . . . . . . . . 142

8 Testing Hypothesis $5 \mathrm{~b} \ldots \ldots$. . . . . . . . . . . . . . 145

9 Economic importance . . . . . . . . . . . . . . . . . . . 148

10 Robustness . . . . . . . . . . . . . . . . . . . . 149 


\section{List of Figures}

1 Market Debt Ratio and Cash Flow Volatility (Net Assets Scaled) 35

2 Predicted versus actual $M D R 1$. . . . . . . . . . . . 35

3 Actual ZerobyMaturity versus Predicted Probabilities . . . . 36

1 HCA Market Leverage Ratio Decomposition Terms 1993-2004 95

2 HCA Book Leverage Ratio Decomposition Terms 1993-2004 . 95

3 Changes in the HCA's Market and Book Leverage Ratios . . . 96

4 Industry Leverage and Market Leverage Ratio . . . . . . . . . 96

$5 \quad$ Industry Leverage and Book Leverage Ratio . . . . . . . . . . 97

$6 \quad$ HCA Annual Market and Book Leverage 1994-2013 . . . . . . 97

$7 \quad$ HCA Annual Long-term Debt and Retained Earnings 1990-2013 98

8 HCA annual long-term debt issuance and reduction from 1990

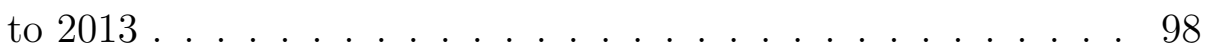

9 HCA $6.5 \%$ coupon bond prices due Feb 15, 2016 . . . . . . . 99

10 HCA Share Price 2006 . . . . . . . . . . . . . . 99 


\section{Chapter 1}

\section{Preliminaries}

This thesis was motivated by the inconclusive results in the empirical literature on the relationship between cash flow and investment volatility and firm financing decisions. Empirical analysis in the thesis focuses on the relationship between a firm's capital structure and cash flow volatility, and the relationship between a firm's level of debt and cash and investment volatility. This thesis also includes a case study about the financing behaviour of Hospital Corporation of America (HCA). The motivation behind this case study is to understand at the firm level how management make their capital structure decisions.

\subsection{Thesis Structure}

The first paper of this thesis investigates the relationship between cash flow volatility and capital structure. Theory suggests volatility is important in explaining firm's capital structure decisions. Although the theoretical literature supports the effect of cash flow volatility on capital structure, the empirical literature on this relationship is inconclusive. The first paper of the thesis re-addresses this important question by carefully developing a set of cash flow volatility measures, conducting tests using methods that account for the non-linearity, and subjecting our analysis to a wide range of capital structure measures, alternative estimation methods, and window sizes. Across all these approaches, we find cash flow volatility is an important determinant of both 
a firm's debt ratio and use of debt of different maturities.

The thesis proceeds with a case study which investigates the financing behaviour of HCA. In empirical studies of capital structure, the scholars examine the relationship the significance between capital structure and a variable of interest. By scrutinizing HCA's financing behaviour in detail, not only do we understand the direction of the relationship, but also we understand managements capital structure decision process. Specifically, the second essay focuses on HCA and its financing behaviour for the years 1990 to 2013. HCA is an interesting case because of tremendous growth over this period. Founded in 1986 with just 150 beds, HCA managed to become one of the largest hospital corporations in the USA. As of date, HCA manages 165 hospitals and 115 freestanding surgery centres in the USA and the UK, which is the results of it vigorous growth strategy. This case study illustrates how firms make capital structure decisions, how they decide between the use of debt and equity financing, how accounting-based measures differ from the market-based measures, and how the management decisions affect these measures. The second essay investigates the capital structure changes of HCA, due to 1) mergers and acquisitions, and divestitures that change a firm's total assets, 2) share buybacks and, 3) leveraged buyouts (LBOs) and public offerings that change a firm's ownership.

Using the evidence from the second paper, the third paper of this thesis empirically tests the relationship between investment volatility and firms' levels of debt and cash. Despite theoretical motivation, this relationship is not studied in the empirical literature. We initially follow DeAngelo et al. (2011) and define investment as capital expenditures plus acquisitions and scale by property, plant and equipment. We also unbundle their definition and define investment as either capital expenditures or acquisitions. We further define research and development as investment. We use two methods to construct our variables of interest. The paper uses estimation methods that consider the fact that the dependent variables are proportional variables and bounded between zero and one, and that the relationship between the dependent variables and control variables is non-linear. Our evidence suggests: i) firms with relatively high capital expenditure and acquisition investment 
volatility hold relatively higher levels of debt and lower levels of cash, ii) firms fund large capital expenditures and/or acquisitions by increasing debt or decreasing cash, iii) immediately after funding large investment firms reduce debt levels and increase cash holdings. Research and development investment volatility is related to lower debt levels, higher cash levels, and does not exhibit similar investment spike funding. 


\section{Chapter 2}

\section{The influence of cash flow volatility on capital structure and zero leverage by maturity}

\section{$2.1 \quad$ Introduction}

Despite the theoretical literature about the relationship between cash flow volatility and a firm's use of debt, there is little empirical evidence. For example, Frank and Goyal (2009) investigate twenty five explanatory variables used in prior studies and find six factors that reliably explain a firm's capital structure, but do not find volatility robustly explains capital structure. Likewise, Leary and Roberts (2005) and Antoniou, Guney and Paudyal (2008) do not find that volatility matters in explaining capital structure. In a seminal study of international firms, Rajan and Zingales (1995) do not include volatility as an independent variable. Also, Leary and Roberts (2014) and Kayhan and Titman (2007) do not include volatility in their studies. Lastly, Friend and Lang (1988) find a positive relationship between volatility and leverage, whereas Bradley, Jarrell and Kim (1984) and Kim and Sorensen (1986) find a negative relationship. In this paper, we re-examine the relationship between cash flow volatility and both a firm's capital structure and use of debt of different maturities. 
The variable of interest in our study is cash flow volatility. To construct our volatility measures, we identify measures used in prior literature and find those studies use a variety of measures. Because of the lack of uniformity, we make several choices. First, we define cash flow as either operating income before depreciation or cash-based operating profit as defined by Ball, Gerakos, Linnainmaa and Nikolaev (2015). Second, we scale each cash flow measure by net assets. Third, we estimate the volatility of each of the two cash flow measures using the panel regression method of De Veirman and Levin (2015), the rolling standard deviation method of Kim and Sorensen (1986) and the rolling standard deviation of first differences method of Stohs and Mauer (1996). Fourth, we choose window sizes of five years or in the case of the De Veirman and Levin (2015) method one or five years. This approach leads to eight measures of cash flow volatility. Lastly, in robustness tests, we evaluate our measures using different window lengths. We find that our volatility measures are similar but not identical and further our conclusions hold regardless of which measure or window is used.

We first study the effects of cash flow volatility on the firm's debt ratio. To test our first question, we consider the fact that our dependent variable (debt ratio) is a proportional variable, and therefore the conditional expectation is a nonlinear function of independent variables. Following Papke and Wooldridge (1996) and Kieschnick and McCullough (2003), we use a GLM (Generalized Linear Model) to test the effect of cash flow volatility on capital structure. We take into account the Welch (2011) critique that some debt ratios implicitly treat non-financial liabilities as equity and construct three book and three market debt ratios where debt is defined as either all liabilities, short and long-term debt, or just long-term debt. For each measure, we find that cash flow volatility has an economically important and statistically significant negative effect on a firm's capital structure. ${ }^{1}$ Our results show that ceteris paribus one standard deviation increase from the mean of cash flow volatility implies an approximate $24 \%$ decrease in the long-term market debt ratio.

Second, we study the relationship between cash flow volatility and the use

\footnotetext{
${ }^{1}$ To control for simultaneity all explanatory variables are lagged.
} 
of debt of different maturities. Prior literature explores the use of zero debt in a firm's capital structure. Implicit in the zero debt question is the accounting rule that distinguishes short-term from long-term debt based upon whether the debt matures in one year. We extend this debate by constructing a measure that places a firm's use of debt into five maturity categories and then test the influence of cash flow volatility on the probability of a firm's use of debt by category.

As a categorical debt by maturity variable is novel, we explain its construction. Using Compustat debt definitions, we define five categories based on a firm using or not using debt with different times to maturity. At one extreme, we place a firm which uses debentures (usually with maturity greater than 10 years) in category one. Likewise, a firm in category two uses notes but not debentures. At the other extreme, we place a firm which uses neither long nor short-term debt in category five. Firms in category four use debt with maturity of less than one year, but do not use long-term debt. Firms in category three use long-term debt with maturity that is not as long as notes. In summary, as the zero by maturity variable increases from one to five, the firm uses less debt of longer maturity.

Using the zero-debt by maturity variable as the dependent variable in an ordered probit model, we find that cash flow volatility has a statistically significant and economically important influence on a firm's use of debt of different maturities. Specifically, the probability of a firm holding debt of longer maturity decreases with cash flow volatility. Similarly, the probability of a firm holding only short maturity debt (or zero-debt) increases with cash flow volatility. Overall, in both absolute and percentage terms, the effect of cash flow volatility on the use of debt of different maturities is strongest at the extremes. Specifically, a one standard deviation increase in cash flow volatility implies a $26 \%$ decrease in the probability of using debt with maturity greater than ten years and a $39 \%$ increase in the probability of neither using long nor short-term debt. Our evidence shows that firms with high cash flow volatility are more likely to use debt in shorter maturity categories.

We employ a series of robustness tests. First, we re-estimate using panel, zero inflated beta and OLS estimation methods. Second, we re-estimate using 
eight different measures of cash flow volatility. Third, we re-estimate using estimation windows for our cash flow volatility measures for one through five years. Lastly, we re-estimate using the debt maturity measure of Barclay and Smith (1995). Across all these robustness tests our findings are qualitatively unchanged.

This paper proceeds as follow, Section 2.2 reviews the literature and develops our hypotheses. Section 2.3 reviews the data, constructs the variables and reports the univariate statistics. Section 2.4 tests the hypotheses and discusses the results. Section 2.5 discusses the relationship between cash flow volatility and the other explanatory variables as well as tests for robustness to other econometric methods and volatility measures. Section 2.6 provides concluding remarks.

\subsection{Hypothesis development}

Using the Black and Scholes (1973) model, we illustrate the positive relationship between cash flow volatility and the cost of debt. Black and Scholes (1973) price a European call option as

$$
\operatorname{Call}_{B S}\left(V_{t}, B, r, T-t, \sigma\right)=V_{t} N\left(d_{1}\right)-B e^{-r(T-t)} N\left(d_{2}\right)
$$

where $V_{t}$ is the value of underlying assets, $B$ is the strike price, $r$ is the annual risk free rate, $T-t$ is the time in years to expiration date, $\sigma$ is the standard deviation of the return of the asset, and

$$
d_{1}=\frac{\left[\ln \left(V_{t} / B\right)+(r+\sigma / 2)(T-t)\right]}{\sqrt{\sigma(T-t)}}
$$

and

$$
d_{2}=d_{1}-\sqrt{\sigma(T-t)}
$$

where $N(d)$ is the cumulative standard normal distribution. ${ }^{2}$

\footnotetext{
${ }^{2}$ We use notation of Sundaresan (2013). See Sundaresan (2013) for a literature review of extensions of Merton's model.
} 
Stoll (1969) shows the relationship between the price of a European call option and a European put option with identical strike price and expiry date as

$$
P u t_{B S}\left(V_{t}, B, r, T-t, \sigma\right)=B e^{-r(T-t)}-V_{t}+\operatorname{Call}_{B S}\left(V_{t}, B, r, T-t, \sigma\right) .
$$

The relationship shown in Equation (2.3) is called put-call parity. Equations (2.1) and (2.3) imply that the price of call and put options increase with volatility $\sigma .^{3}$

Black and Scholes (1973) and Merton (1973) recognize that the option pricing model could be applied to develop a model to price corporate equity and liabilities in general. By following the option pricing model, Merton (1974) develops a model to price the debt and equity of the firm. In Merton's model, equity holders own the firm $V_{T}$ and borrow debt at $t=0$ from debt holders (creditors) with face value $B$ payable at $T$. Due to the limited liability, in the case of default at $T$ when $B \geq V_{T}$, the creditors receive $V_{T}$. Otherwise, the creditors receive $B$. Therefore, the uncertain payoff to the creditors is

$$
D\left(V_{T}, T\right)=\min \left(V_{T}, B\right)
$$

By employing Black and Scholes (1973) formula, Merton (1974) expresses value of the firm as

FirmValue $=\operatorname{Call}_{B S}\left(V_{t}, B, r, T-t, \sigma\right)+B e^{-r(T-t)}-P_{u t_{B S}}\left(V_{t}, B, r, T-t, \sigma\right)$,

where the value of equity is

$$
E\left(V_{t}, t\right)=\operatorname{Call}_{B S}\left(V_{t}, B, r, T-t, \sigma\right),
$$

and the value of debt is

$$
D\left(V_{t}, t\right)=B e^{-r(T-t)}-P u t_{B S}\left(V_{t}, B, r, T-t, \sigma\right)
$$

\footnotetext{
${ }^{3} \nu=\frac{\partial \operatorname{Call}_{B S}}{\partial \sigma}>0$, measures the sensitivity of a call option to volatility.
} 
Equation (2.6) shows that the value of the equity of a levered firm is equivalent to a call option on the assets of the borrowing firm. Equation (2.7) shows that the value of the debt is equal to the value of risk-free debt minus the value of the put option. Because cash flow volatility increases the value of call and put options, higher cash flow volatility increases equity value in Equation (2.6), while it decreases debt value in Equation (2.7), which in turn increases the marginal cost of debt. The cost of debt is

$$
R_{D}=\frac{B}{D\left(V_{t}, t\right)}-1
$$

Because an increase in $\sigma$ decreases $D\left(V_{t}, t\right)$, an increase in $\sigma$ also increases $R_{D}$. Thus, high volatility firms have a relatively high cost of debt, implying:

Hypothesis 1. Firms with high cash flow volatility use less debt.

The application of Black and Scholes (1973) model to a firm's capital structure implies that the cost of debt increases with debt maturity. Equation (2.7) shows the value of debt equals risk free debt minus a put option with the strike price equal to the face. The first term $B e^{-r(T-t)}$ decreases with time to maturity $T$. The second term $P u t_{B S}$ increases with time to maturity. Hence, the value of debt $D\left(V_{t}, t\right)$ decreases with maturity due to both the time value of money (term one) and the issuance (put option) of the debt (term two). Thus, by Equation (2.8) the cost of debt increases with time to maturity.

Hypothesis 2. The probability of a firm using zero debt of longer (shorter) maturity decreases (increases) with cash flow volatility.

\subsection{Sample, variable construction, and uni- variate statistics}

\subsubsection{Sample}

We obtain annual data from 1974 through 2012 of US corporations from the Compustat CRSP Merged database. Following Frank and Goyal (2009), we 
exclude financial firms, firms involved in major mergers (Compustat footnote code $\mathrm{AB}$ ) and firms with missing book value of assets. ${ }^{4}$ We also exclude firms with zero and negative common (ordinary) equity, utility firms, firms with negative total assets or total revenue. We also exclude firms with missing revenue, total liabilities or total assets. We next investigate Compustat debt items that Compustat codes as missing, which are actually zero. Appendix 2.7.1 provides the Compustat definitions of the variables. To illustrate, PFIZER INC (gvkey = 008530) in fiscal year 2009 has long-term debt ( $d l t t)$ of $\$ 43,193$ million, and notes $(d n)$ of $\$ 43,193$ million, but reports missing debentures $(d d)$. Clearly, debentures are not missing, but are zero. Our inspection of $d d 1, d d 2, d d 3, d d 4$ and $d d 5$ shows a similar pattern. To address this issue, we replace missing observations with zero for $d d$ and $d d 1$ through $d d 5$. Consistent with the literature, we also change missing $R n D$ to zero. Due to the previous edits, the change from missing to zero is only done for firms with positive total assets and liabilities.

Following Kale and Shahrur (2007), we winsorize the data at the $1 \%$ level in both tails of the distribution. After variable filtrations, the sample includes 134,581 firm-year observations from 1974-2012. Because we use the lag of all control variables, our sample reduces to 111,496 firm-year observations. Depending on which cash flow volatility measure is used, our sample further reduces to between 89,035 and 109,613 observations.

\subsubsection{Variable Construction}

\section{Capital Structure Measures}

Welch (2011, page 2) states,

There is no universally used measure of leverage. Most researchers probably spend little time pondering their measure and simply copy what their predecessors have adopted. An informal census of the recent literature suggests that about half of all recently published papers have defined leverage as financial-debt

\footnotetext{
${ }^{4}$ Compustat assigns a footnote $\mathrm{AB}$ to total sales (revt) and create variable revt_f $\mathrm{f}$, if sales increase by more than 50 percent in response to a merger or an asset acquisition.
} 
divided by assets $(F D / A T)$. Unfortunately, this measure is incorrect.

The financial-debt-to-asset ratio (FD/AT), implicitly treats non-financial liabilities as equity, which is clearly wrong. We refer to this issue as the Welch (2011) critique.

In constructing our measures of capital structure, we are guided by two questions. First, what liabilities should be included in debt? Most broadly, debt consists of all liabilities including non-financial liabilities. Most narrowly, debt consists of only long-term debt. Debt may also consist of both short-term and long-term debt but exclude non-financial liabilities. Thus, the capital structure may be defined in three ways. Second, should debt be measured using book or market value? Keeping in mind the Welch (2011) critique and addressing both questions, we define three measures of capital structure for both market and book values, which generates six capital structure variables.

The broadest definition of debt includes all liabilities. The Compustat item total liabilities $(l t)$ includes non-financial liabilities. To construct the all liabilities market debt ratio, we follow Rajan and Zingales (1995) and Welch (2011). The numerator is total liabilities and the denominator is total assets minus common shareholders's equity plus market value of common stock. We define the all liabilities market debt ratio as

$$
M D R 1=\frac{l t}{(a t-c e q)+c s h o * p r c c \_f} .
$$

Rajan and Zingales (1995) and Welch (2011) define the all liabilities book debt ratio as the total liabilities in the numerator and total assets in the denominator. We construct the all liabilities book debt ratio as

$$
B D R 1=\frac{l t}{a t} .
$$

Both $M D R 1$ and $B D R 1$ categorize non-financial liabilities as debt.

The second debt ratio includes short-term plus long-term debt. Rajan and Zingales (1995) construct the short and long-term market debt ratio as 
the long plus short-term debt divided by short and long-term debt plus the market value of equity. We define the short-term plus long-term market debt ratio as

$$
M D R 2=\frac{d l t t+d l c}{d l t t+d l c+c s h o * p r c c \_f} .
$$

To construct singular book debt ratio we follow Rajan and Zingales (1995). The numerator of this measure is the short plus long-term debt and the denominator is short plus long-term debt plus common shareholders' equity. We define the short-term plus long-term book debt ratio as

$$
B D R 2=\frac{d l t t+d l c}{d l t t+d l c+c e q}
$$

Both $M D R 2$ and $B D R 2$ are consistent with the Welch (2011) critique as the denominators exclude non-financial liabilities.

The most narrow definition of debt includes only long-term debt in the debt ratio. We follow Bradley et al. (1984) and define the long-term market debt ratio as the total long-term debt over the total long-term debt plus market value of equity. We define the long-term market debt ratio as

$$
M D R 3=\frac{d l t t}{d l t t+c s h o * p r c c \_f} .
$$

To measure the long-term book debt ratio, we construct a long-term book debt ratio as total long-term debt divided by the total long-term debt plus common shareholders' equity. We define the long-term book debt ratio as

$$
B D R 3=\frac{d l t t}{d l t t+c e q} .
$$

Both $M D R 3$ and BDR3 are consistent with the Welch (2011) critique as the denominators exclude non-financial liabilities.

\section{insert Table 1}

To test Hypothesis 2, we construct an ordered categorical variable based on a firm's use of debt at different maturities. To construct the variable, we use Compustat items $d d, d n, d l t t, d l c$ and $d c l o$. Appendix 2.7 .1 pro- 
vides the Compustat definitions of the variables. Table 1 summarizes the ZerobyMaturity variable construction. Table 1 shows that ZerobyMaturity is set to one when a firm uses debentures. Because debentures are a component of long-term debt, a firm that uses debentures also uses long-term debt. Table 1 denotes the use of debentures and long-term debt by a "Yes" in columns (1) and (3). The other debt types are marked "N.A", in columns (2), (4) and (5) as the use of these types of debt is not used to define a firm in Category 1. For example, a firm in Category 1 might use debentures or possibly both debentures and notes. Table 1 shows that firms in Category 2 use notes and hence hold long-term debt, but do not hold debentures. At the other extreme, Table 1 shows firms in Category 5 hold zero long or shortterm debt. Likewise, firms in Category 4 hold debt in current liabilities, but all other debt items are denoted with "No". Category 5 matches the zero debt definitions by Strebulaev and Yang (2013) and Lee and Moon (2011). Lastly, Category 3 represents firms that hold long-term debt but do not hold debentures or notes. This variable shows use of debt with different maturity by firm and does not measure when the debt actually matures. For example, when a firm-year observation includes a debt debenture in its capital structure, our variable does not indicate the years to maturity of the debenture, rather it shows the use of debt debentures by a firm.

In addition to our ZerobyMaturity variable, we test Hypothesis 2 in the robustness section using the Barclay and Smith (1995) measure of debt maturity. To measure the maturity structure of a firm's debt, Barclay and Smith (1995) use the percentage of the firm's total debt that matures in more than three years. We follow Barclay and Smith (1995) and construct

$$
\text { DebtMat_D }=(d l t t-d d 2-d d 3) /(d l t t+d l c),
$$

where the numerator captures debt greater than three years and the denominator includes short and long-term debt. One issue with the Barclay and Smith (1995) debt maturity measure (DebtMat_D) is that it does not include non-financial liabilities in the denominator. As high cash flow volatility firms use non-financial liabilities like trade credit, we construct a debt ma- 
turity measure that includes non-financial liabilities. We measure the percentage of the firm's total liabilities that matures in more than three years as

$$
\text { DebtMat_L }=(d l t t-d d 2-d d 3) /(l t) .
$$

\section{Control Variables}

To test our hypotheses, we use the following Frank and Goyal (2009) most reliable factors as control variables:

i) MarketToBook is the ratio of market value of assets to total assets (proxy of growth opportunities).

ii) IndustLev is the median industry leverage and is the median of total debt to market value of assets by year and four-digit SIC code.

iii) Tangibility is the asset tangibility. It is the ratio of fixed assets-to-total assets.

iv) FirmSize is a proxy for firms' size. It is the natural log of the total assets of the firm.

v) Profitability shows the profitability of a firm and is the ratio of the firm operating income before depreciation to total assets.

vi) Inflation is the expected change in the consumer price index over the coming year.

To lessen the effect of possible omitted variable bias, we also construct five additional explanatory variables.

vii) $\operatorname{LnRnD}$ is the natural logarithm of $(1+$ the ratio of $\mathrm{R} \& \mathrm{D}$ expenses to sale) (Frank and Goyal, 2009).

viii) EquIssue is the net equity issuance of a firm (Lemmon, Roberts and Zender, 2008). 
ix) CreditRating is a dummy variable. It is equal to one if $\mathrm{S} \& \mathrm{P}$ rates the debt as investment grade (BBB) debt and is equal to zero if the firm is rated less than investment grade (Frank and Goyal, 2009).

x) Firm Age computed as the number of years a firm has been listed in the Compustat (Bergstresser and Philippon, 2006).

\section{Key Variable of Interest}

insert Table 2

The key variable of interest in this study is cash flow volatility. Table 2 surveys many of the volatility measures used in the empirical corporate finance literature. A perusal of Table 2 highlights that there are a large number of closely related measures, but no one agreed upon measure. Due to the lack of a standard definition, we estimate several alternative measures. We test using one measure of cash flow volatility in Section 2.4 and test using alternative measures in the robustness section. We review below our approach to constructing our cash flow volatility measures.

First, we need a measure of cash flow. Table 2 shows the prior literature uses several related cash flow measures including ebitda, ebitd, and ebit. Of these measures ebitda excludes interest expense or taxes, which are related to the level of debt (our dependent variable) in the firm, and depreciation and amortization, which are non-cash expenses. Note that Compustat items ebitda (earnings before interest) and oibdp (operating income before depreciation) both represent net sales minus operating expenses. ${ }^{5}$ We use oibdp as our first cash flow measure and denote volatility variables based on it using oi (operating income) in the variable name. For our second measure of cash flow we follow Ball et al. (2015) who adjust op (operating profit)

$$
\text { op }=\text { sale }-\operatorname{cog} s-(x s g a-x r d)
$$

\footnotetext{
${ }^{5}$ Compustat defines ebitda $=$ sale - cogs $-x s g a$ and oibdp $=$ sale $-x o p r$, where $x o p r=\operatorname{cog} s+x s g a$. Therefore, ebitda $=$ oibdp.
} 
using accruals to find cbop (cash-based operating profit)

$$
c b o p=o p-D \cdot r e c t-D \cdot i n v t-D \cdot x p p+D \cdot(d r c+d r l t)+D \cdot a p+D \cdot x a c c .
$$

We use cbop as our second cash flow measure and denote volatility variables based on cash-based operating profit by including cbop in the variable name. Note that operating profit equals ebitda minus xrd (research and development expenses). ${ }^{6}$

Second, most of the volatility measures in Table 2 are scaled by the total assets of a firm. Total assets includes cash. Pinkowitz and Williamson (2007) show that a firm's cash holdings are a function of the volatility of the firm's cash flows. By removing cash from total assets we remove this functional relationship. ${ }^{7}$ We scale volatility measures by net assets (total assets minus cash and marketable securities) of a firm. In addition, scaling by the net assets generates a measure of return, which is comparable across firms. Thus, our volatility measures capture the cash flow return volatility of the net assets of a firm.

Third, in estimating volatility, Table 2 shows the literature uses a variety of different estimation windows. The length of the window ranges from a minimum of five years to twenty eight years. If firms partially adjust towards the target capital structure, a five year window represents a period of time that is plausibly consistent with firms' adjustment policies. ${ }^{8}$ In our robustness checks, we also test using one, two, three and four year windows.

The fourth issue relates to how to measure volatility. Most of the studies listed in Table 2 measure volatility either using the standard deviation of the cash flow or the standard deviation of first differences of the cash flow. We estimate cash flow volatility using three methods. First we follow Kim and Sorensen (1986) and estimate the rolling standard deviation of oi and

\footnotetext{
$\%$.

${ }^{6}$ In untabulated results, we find the correlation coefficient between ebitda and op is 98.8

${ }^{7}$ We thank the referee for this insight.

${ }^{8}$ The Kraus and Litzenberger (1973) trade-off theory and several empirical studies like Jalilvand and Harris (1984), Leary and Roberts (2005), Flannery and Rangan (2006), Harford, Klasa and Walcott (2009) support the existence of an optimal capital structure and firms' tendencies to adjust towards the target.
} 
cbop over the last five years. Second, we follow Stohs and Mauer (1996) and estimate the rolling standard deviation of first differences of $o i$ and $c b o p$ over the last five years. One issue with the first difference approach is that it requires one additional observation. As an alternative to these rolling measures, we estimate cash flow volatility using the method of De Veirman and Levin (2015) and used by De Veirman and Levin (2012) and Keefe and Tate (2013). To denote the method used to construct the cash flow volatility measures, we include $K S, S M$ and $D L$ in the variable names.

To construct the De Veirman and Levin (2015) cash flow volatility measure, we estimate

$$
\omega_{i, t}=\alpha_{i}+Y e a r \beta_{1}+\epsilon_{i, t}
$$

where $\omega_{i, t}$ represents the first difference of operating income $(o i)$ scaled by net assets from $t-1$ to $t$ for firm $i$ and Year is a matrix of year dummies. ${ }^{9}$ The residual $\epsilon_{i, t}$ represents the difference between the observed and the estimated value of operating cash flow of firm $i$ when controlling for time and firm fixed effects. ${ }^{10}$ De Veirman and Levin (2015) show that $\hat{\sigma}_{i, t}$ is an unbiased estimator of the true conditional volatility

$$
\hat{\sigma}_{i, t}=\sqrt{\pi / 2} *\left|\hat{\epsilon}_{i, t}\right|
$$

where $\hat{\epsilon}_{i, t}$ is the estimated residual from Equation (2.15). We estimate Equation (2.16) and define $C F V \_D L \_o i \_1$ as cash flow volatility measured using the method of De Veirman and Levin (2015) using operating income (oi) for one year. We also define $C F V \_D L \_o i \_5$ as the rolling five year average of $\hat{\sigma}_{i, t}$.

Using the guidelines developed above, we estimate eight measures of cash flow volatility. For example, $C F V \_K S \_o i \_5$ represents cash flow volatility measured as the five year rolling standard deviation of cash flow as measured by operating income. $C F V \_K S \_c b o p \_5$ is a similar measure but estimated

\footnotetext{
${ }^{9}$ Total assets is calculated using Compustat items. Total assets $=$ at - che where, at is total assets and che is cash and short-term investment.

${ }^{10} \mathrm{We}$ also control for industry and the results are qualitatively identical.
} 
using cash-based operating profit. Likewise, $C F V \_S M \_o i \_5$ represents cash flow volatility measured as the five year rolling standard deviation of the first differences of operating income. In summary, we construct the following four cash flow volatility measures using operating income: $C F V \_K S \_o i \_5$, $C F V \_S M \_o i \_5, C F V \_D L \_o i \_1$ and $C F V \_D L \_o i \_5$. In addition, we construct the following four volatility measures using cash-based operating profitability: $C F V \_K S \_c b o p \_5, C F V \_S M \_c b o p \_5, C F V \_D L \_c b o p \_1$ and $C F V \_D L \_c b o p \_5$.

To address the effect of outliers, we winsorize each measure at the $1 \%$ level in both tails. To better approximate a normal distribution, we then take the natural $\log$ of all volatility measures. To illustrate, the skewness and the kurtosis of $C F V \_K S \_o i \_5$ is 35 and 2464, respectively. After taking the natural logarithm of the measure the skewness and the kurtosis is 0.62 and 4.7, respectively. ${ }^{11}$ Lastly, to address possible simultaneity issues, we lag the volatility measure by one year in all tests. In Section 2.4, we test our hypotheses using $C F V \_K S \_o i \_5$. In Section 2.5, we explore if our findings are sensitive to the choice of volatility measures.

\section{insert Table 3}

Table 3 reports the pairwise correlations between our eight volatility measures. Table 3 shows that all measures are positively correlated. Furthermore, the cash flow volatility measures tend to be highly correlated if they have the same underlying measure of cash flow. For example, the correlation coefficient between $C F V \_K S \_o i \_5$ and $C F V \_S M \_o i \_5$ is 0.832 and between $C F V \_K S \_o i \_5$ and $C F V \_D L \_o i \_5$ is 0.811 . Also, volatility measures constructed by the same method are highly correlated. For example, the correlation coefficients between $C F V \_K S \_o i \_5$ and $C F V \_K S \_c b o p \_5$ is 0.755 and between $C F V \_K S \_c b o p \_5$ and $C F V \_D L \_c b o p \_5$ is 0.851 . Lastly, volatility variables with one and five year windows have relatively smaller correlation coefficients. Specially, the correlation coefficient between $C F V \_K S \_o i \_5$ and $C F V \_D L \_o i \_1$ is 0.574 .

\footnotetext{
${ }^{11} \mathrm{~A}$ normal distribution has a skewness of 0 and a kurtosis of 3 .
} 


\title{
Univariate Statistics
}

\author{
insert Table 4
}

Table 4 reports the summary statistics. The means of the three categories of capital structure measures show that the more broadly we define the debt, the higher market and book debt ratios. The mean of $M D R 1$, which includes all liabilities of a firm, is greater than the mean of $M D R 2$, which includes the long and short-term debt of a firm, and the mean $M D R 2$ is greater than the mean of $M D R 3$, which includes the long-term debt of a firm. For example the mean of $M D R 1$ is 0.367 , the mean of $M D R 2$ is 0.238 and the mean of $M D R 3$ is 0.194. Book debt ratios follow a similar pattern. The mean of $B D R 1$ is 0.466 , the mean of $B D R 2$ is 0.296 , and the mean of $B D R 3$ is 0.242. The mean of MarketToBook is 1.622 which is consistent with lower market than book debt ratios. The average FirmAge is 9.77 years and the mean of FirmSize is 4.642 million dollars based on total assets.

\section{insert Table 5}

Table 5 reports the categorical variable ZerobyMaturity frequency, percent and cumulative percent. The table shows several empirical regularities. First, in approximately $17.05 \%$ of the sample firm-year observations, firms use long-term debt (e.g. debentures). Second, in approximately $44.67 \%$ of the sample firm-year observations, firms use notes but not debentures. Third, in approximately $18.66 \%$ of the sample firm-year observations, firms use debt with maturity that is not as long as notes but greater than one year. Fourth, in approximately $5.61 \%$ of the sample firm-year observations, firms use debt with maturity of less than one year. Fifth, in approximately $14.02 \%$ of the sample firm-year observations, firms hold neither long nor short-term debt.

\section{insert Table 6}

Table 6 reports the correlation coefficients between explanatory variables. Table 6 shows that cash flow volatility measure is negatively correlated with Profitability, IndusLev, FirmSize and positively correlated with LnRnD, and MarketToBook. The correlation coefficients between 
CFV_KS_oi_5 and FirmSize, Profitability and IndustLev are $-43.6 \%$, $-42.2 \%$ and $-40.4 \%$, respectively. On the other hand, the correlation coefficients between $C F V \_K S \_o i \_5$ and MarketToBook is $42.9 \%$ and LnRnD is $45 \%$. Overall, highly cash flow volatile firms are smaller, less profitable, belong to industries with low levels of debt, have more growth opportunities and spend more on research and development projects.

\section{insert Figure 1}

To depict the relationship between cash flow volatility and the market debt ratios, we construct 20-quantiles of cash flow volatility. Figure 1 plots $M D R 1$ and $M D R 3$ over twenty cash flow volatility quantiles. ${ }^{12}$ In Figure 1, $M D R 1$ declines slowly from quantile 1 to quantile 16 . From quantile 16 to quantile $20, M D R 1$ declines the same amount as in the first sixteen quantiles, which represents a rate of decrease four times as fast as in the first 16 quantiles. In quantile 20 the magnitude of $M D R 1$ drops to approximately $15 \%$, which indicates that firms with very high cash flow volatility continue to use debt, when debt is broadly defined as including all liabilities. MDR3 follows a similar pattern; however the magnitude of $M D R 3$ is less than $5 \%$, indicating firms with very high cash flow volatility use very little long-term debt. Plotting the other market and book debt ratios, show us the same pattern between volatility and debt ratios.

\subsection{Testing}

\subsubsection{Testing Hypothesis 1 - The relationship between cash flow volatility and leverage.}

Frank and Goyal (2009) do not study potential nonlinearities. Frank and Goyal (2009, page 26) write:

There are a number of other things that we have not studied in this paper. We have not allowed for alternative functional

\footnotetext{
${ }^{12}$ All figures in this paper plot the means of every variable in each quantile.
} 
forms and general nonlinearities. ... All of these are potentially interesting, and we hope to explore many of them in the future.

The dependent variable of this study is a proportion variable bounded between zero and one. Cook, Kieschnick and McCullough (2008) address some common specification errors in using a linear prediction equation to model a proportional or fractional variable and show the conditional expectation is a nonlinear function of the independent variables. ${ }^{13}$ To mitigate the estimation problems caused by a bounded dependent variable, we use a GLM (Generalized Linear Model) with a logit link function.

$$
E\left(\text { DebtRatio }_{i, t} \mid X_{i, t-1}, \operatorname{LnCF} V_{i, t-1}\right)=G\left(\alpha+X_{i, t-1} \beta_{1}+\beta_{2} L n C F V_{i, t-1}+\epsilon\right)
$$

where

- $\mathrm{G}($.$) is the logistic link function,$

- DebtRatio ${ }_{i, t}$ is market or book debt ratio, MDR1, MDR2, MDR3, $B D R 1, B D R 2$ and $B D R 3$,

- $X_{i, t-1}$ is a matrix of lagged control variables listed in Section 2.3.2, and

- $L n C F V_{i, t-1}$ is the lag of the natural logarithm of the volatility measure.

$$
\text { insert Table } 7
$$

Table 7 shows GLM estimation results of Equation (2.17) using $C F V \_K S \_o i \_5$ as the variable of interest, with standard errors clustered by firm. The table reports that the coefficients associated with $C F V \_K S \_o i \_5$ are statistically significant at less than the $1 \%$ significance level in explaining all capital structure measures. Columns (1), (3) and (5) show the estimated coefficients using the market debt ratios and Columns (2), (4) and (6) show the estimated coefficients using the book debt ratios. Each coefficient associated with $C F V \_K S \_o i \_5$ is negative, implying that firms with high cash flow volatility use less debt. In addition, Table 7 shows that the magnitude of the coefficients associated with cash flow volatility increases as debt

\footnotetext{
${ }^{13}$ Cook et al. (2008) finding is consistent with Papke and Wooldridge (1996), Cox (1996), Paolino (2001).
} 
is more narrowly defined to include only long-term debt. Specifically, the coefficients associated with cash flow volatility are $-0.203,-0.295$ and -0.309 using $M D R 1, M D R 2$ and $M D R 3$, respectively. This is consistent with high cash flow volatile firms substituting short-term and non-financial liabilities for long-term debt.

To obtain the economic importance of cash flow volatility coefficients in Equation (2.17), we estimate the change in the long-term market debt ratio due to a one standard deviation increase in cash flow volatility. Using the estimated coefficients from Column (5) of Table 7, we predict the long-term market debt ratio evaluated at the mean of $C F V \_K S \_o i \_5$ and the mean plus a one standard deviation of $C F V \_K S \_o i \_5$. All other explanatory variables are evaluated at their means. Table 4 reports the mean and the standard deviation of $C F V \_K S \_o i \_5$ as 1.961 and 0.992 , respectively. Predicted $M D R 3$ evaluated at the mean of $C F V \_K S \_o i \_5$ is equal to 0.153 and at the mean plus a one the standard deviation of $C F V \_K S \_o i \_5$ is equal to 0.116 , implying a one standard deviation increase in cash flow volatility leads to a decrease of $24.18 \%$ in market long-term debt ratio. ${ }^{14}$

Table 7 also reports that the coefficients associated with the reliable factors of Frank and Goyal (2009) are statistically significant at less than the $1 \%$ level. We note Frank and Goyal (2009) did not identify research and development expenses as one of the six reliable factors but we find that the coefficient associated with $R n D$ is statistically significant at less than the $1 \%$ level. This negative coefficient indicates that firms with higher research and development spending employ less debt. We note that the correlation coefficient between $L L n R n D$ and $C F V \_K S \_o i \_5$ is $45 \%$.

\section{insert Figure 2}

To visually show how the GLM (Generalized Linear Model) estimates the relationship between capital structure and the explanatory variables, we use the estimated GLM coefficients to predict $M D R 1$. We then estimate the mean of the predicted $M D R 1$ over twenty cash flow volatility quantiles. Figure 2 plots the mean of predicted versus actual $M D R 1$ over twenty cash

\footnotetext{
${ }^{14}$ PercentageChange $=\frac{0.116-0.153}{0.153}=-24.18 \%$.
} 
flow volatility quantiles. Figure 2 shows the predicted values closely match the actual values. Plots of other predicted market and book debt ratios show fits that are similar to Figure 2. Overall, Figure 2 shows a negative relationship between volatility and the use of long-term debt. Lastly, Figure 2 shows that the use of long-term debt rapidly declines in higher volatility quantiles.

Overall, our evidence supports Hypothesis 1 and suggests that firms with more volatile cash flows use less debt. We suggest two reasons our results differ from Frank and Goyal (2009). First, Frank and Goyal (2009) use the variance of stock returns, whereas we use cash flow volatility. The volatility of stock prices may be caused by many reasons unrelated to a firm's cash flow and is not as direct a measure of the lenders' risk. Second, Frank and Goyal (2009) use OLS, which does not account for non-linear relationship between cash flow volatility and debt ratios. ${ }^{15}$

\subsubsection{Testing Hypothesis 2 - The effects of cash flow volatility on a firm's use of debt of different ma- turities}

We test Hypothesis 2 using an ordered probit model which estimates the relationship between cash flow volatility and our categorical variable debt by maturity. We construct ZerobyMaturity in Section 2.3.2. The ordering starts from firms that hold debt with more than ten years of maturity to firms with no long and short-term debt. The ordered probit model allows us to test the debt maturity hypothesis using five categories of ZerobyMaturity. We estimate

$\operatorname{Pr}\left(Z\right.$ erobyMaturity $\left.>i \mid \kappa, X_{t-1}, v_{j}\right)=\Phi\left(X_{t-1} \beta_{1}+\beta_{2} L n C F V_{t-1}+v_{j}-\kappa_{i}\right)$,

where, residual $v_{j}$ has the standard normal distribution $\mathrm{N}(0,1)$, and $\kappa$ is a set of cut-points, where $i$ is the category number. The model has $\kappa=4$

\footnotetext{
${ }^{15}$ Column (3) of Table 11 reports the estimation results of Hypothesis 1 testing using OLS, the coefficients of cash flow volatility remain statistically significant at the $1 \%$ level, but the magnitude of the coefficients decrease relative to GLM estimation.
} 
cut-points as there are $i=5$ categories of ZerobyMaturity.

insert Table 8

Table 8 reports estimation results of an ordered probit model using CFV_KS_oi_5. Column (1) reports cross-sectional results and Column (2) reports panel results. The coefficients associated with the $C F V \_K S \_o i \_5$ are statistically significant at less than the $1 \%$ level. The positive coefficients of $C F V \_K S \_o i \_5$ suggest that when cash flow volatility increases, the probability of a firm using shorter (longer) maturity debt increases (decreases).

\section{insert Table 9}

To show the economic magnitude of cash flow volatility on the use of debt of different maturities, we calculate the absolute and percentage change in the probability of a firm falling within one of the five categories due to a one standard deviation increase in cash flow volatility. Table 9 reports the economic magnitude by category. For example the probability of using notes but not debentures at the mean of $C F V \_K S \_o i \_5$ is equal to $46.4 \%$ and at the mean plus one standard deviation is equal to $43.3 \%$, implying an absolute decrease of about 0.031 or equivalently a $7 \%$ increase in the probability of using notes but not debentures. In both absolute and percentage terms at the extremes, a one standard deviation increase in cash flow volatility has the largest economic magnitude. In category five a one standard deviation increase implies an approximate 0.046 absolute increase and a 39\% relative increase in the probability of a firm using zero long or short term debt. ${ }^{16}$ At the other extreme (category one), a one standard deviation change in cash flow volatility implies a $4.7 \%$ absolute and a $26 \%$ relative decrease in the probability of using debt with greater than ten years maturity. Overall, our estimation results support Hypothesis 2.

insert Figure 3

\footnotetext{
${ }^{16}$ The $39 \%$ increases matches with using the dichotomous zero short and long-term debt variables, where zero short and long-term debt variables are indicator variables set to one if a firm's long-term plus short-term debt is zero and if a firm's long-term debt equals zero, respectively.
} 
The economic magnitude estimates started at the mean of the explanatory variables. To visualize how a change in the probability of holding debt of different maturities changes by volatility, Figure 3 plots the percentage of the sample firms existing in each debt maturity category relative to the mean of the predicted probability by volatility quantiles using ordered probit model Equation (2.18). As shown in the figure, predicted values closely match the actual values. Overall, consistent with the above analysis of the economic magnitudes, the probability of holding debentures or notes (Categories 1 and 2) decreases with cash flow volatility whereas the probability of holding shortterm debt (Categories 3, 4 and 5) increases with cash flow volatility. Lastly, consistent with the economic magnitude analysis, in high volatility quantiles the magnitude of the slopes in the Category 2 (use notes) and Category 5 (no debt) greatly increase.

\subsection{Discussion and Robustness}

In this section we discuss the relationship between cash flow volatility and our other explanatory variables and evaluate if our findings are robust to alternative estimation methods, volatility measures and window lengths and measures of debt maturity.

\subsubsection{Relationship of Cash Flow Volatility with Other Explanatory Variables}

insert Table 10

In our estimation of the marginal effects, we assume that firm characteristics remain constant as volatility increases. However, based on the correlation analysis firm characteristics also change between quintiles. To illustrate, Table 10 shows the mean of each explanatory variable for each 5-quantiles of cash flow volatility. Column (1) represents the lowest cash flow volatility quintile and Column (5) represents the highest cash flow volatility quintile. To test whether the characteristics of firms differ from one cash flow volatility quintile to another, we test if differences in mean is zero using the first 
versus the fifth, as well as the fourth versus the fifth quintile of cash flow volatility for each variable. As it can be seen in the last two columns of Table 10, the $t$-statistics are very high, showing that there is a statistically significant difference between the mean of each variable in the first and the fifth quintiles as well as the fourth and the fifth quintiles. Overall, the evidence that explanatory variables also change with volatility suggests that our estimates of the economic importance of cash flow volatility represent a lower bound. For example, a high cash flow volatile firm also tends to have less asset tangibility. Higher volatility and lower asset tangibility tend to reduce debt levels, but our marginal effect analysis only considers the direct effect of volatility.

\subsubsection{Alternative Estimation Methods}

insert Table 11

To control for time invariant firm heterogeneity, we follow Flannery and Rangan (2006) and Lemmon et al. (2008) and estimate Equation (2.17) using a panel data method. In keeping with our estimation approach for fractional dependent variables, we use GLM panel data estimation. Column (1) of Table 11 reports the coefficients associated with $C F V \_K S \_o i \_5$ are negative and statistically significant at less than the $1 \%$ level for all six debt ratios. In the panel model, the identification is only through changes within a firm and not across firms. As a result, the magnitude of the coefficients decrease relative to the result in Table 7 .

In addition to the fractional dependent variables issue, some of our proportion dependent variables (short and long-term and long-term book and market debt ratios) contain a considerable number of zero values. To address this issue we follow (Cook et al., 2008) and use a zero-inflated beta model to test Hypothesis 1 as some of the debt ratios may cluster at zero. We do not use the Tobit model because the debt ratios are not censored; rather, firms may simply use zero debt. Column (2) of Table 11 shows negative and statistically significant coefficients at less than the $1 \%$ level associated with the $C F V \_K S \_o i \_5$. These results are qualitatively identical to the main 
results in Table 7. Following Frank and Goyal (2009), we also test using an ordinary least squares (OLS). Column (3) of Table 11 reports that the coefficient associated with the $C F V \_K S \_o i \_5$ is negative and statistically significant at less than the $1 \%$ level. By comparing the coefficients in column (3) with the ones in columns (1) and (2), we can see that the column (3) coefficients are smaller. We interpret the decrease in the size of the coefficients as plausibly due to the inherent non-linearity of the fractional dependent variables.

\subsubsection{Robustness to Volatility Measures and Window Lengths}

insert Table 12

Using all the six debt ratios as the dependent variables, we re-test $\mathrm{Hy}$ pothesis 1 using eight different cash flow volatility measures as defined in Section 2.3.2. Columns (1) to (6) of Table 12 report that coefficients associated with all volatility measures for every debt measures are negative and statistically significant at less than the $1 \%$ level. In addition, we re-test Hypothesis 2 by using an ordered probit model. Column (7) reports the coefficients associated with all volatility measures are positive and statistically significant at less than the $1 \%$ level. Overall, our main results remain qualitatively unchanged due to different measures of volatility.

insert Table 13

Table 13 reports negative and statistically significant coefficients associated with several cash flow volatility measures with different rolling windows. In this table, we test Hypothesis 1 using GLM with a logit link function and $M D R 3$. Rolling measures require five observations. Due to this requirement, the sample size is reduced, leading to possible sample selection bias. In our main results, we used an estimation window of five. For the $K S$ measure, which uses a rolling method, we constructed the measures using a three and four year windows. For the $D L$ measure, we estimate the mean over two, 
three, four and five years. As can be seen in the table, the number of observations increases as the window size decreases. In addition, the magnitude of the coefficients decrease with the window size. For any window size or measure, the coefficient is statistically significant at less than the $1 \%$ level. Overall, our results do not appear to be driven by a sample selection issue.

\subsubsection{Robustness to Different Measures of Debt Ma- turity}

insert Table 14

Table 14 shows estimation results of re-testing Hypothesis 2 using DebtMat_D and DebtMat_L constructed in Section 2.3.2. In Columns (1) and (2) we use GLM with a logit link function. In Columns (3) and (4) we use a zero inflated beta model. The coefficients associated with $L C F V \_K S \_o i \_5$ in all four columns are negative and statistically significant at less than the $1 \%$ level. The negative relationship between cash flow volatility and the use of debt of lower maturity is consistent with our main findings. Columns (1) and (3) of Table 14 test using the strict Barclay and Smith (1995) measure as the dependent variable. Columns (2) and (4) of Table 14 test using our modified measure where long-term debt is scaled by total liabilities. Table 14 shows the coefficients associated with $L C F V \_K S \_o i \_5$ in Columns (2) and (4) are much larger than in Columns (1) and (3). Our interpretation of the original measure is that it understates the effect of volatility on firms substituting non-financial liabilities for debt.

\subsection{Conclusion}

The literature on the relationship between capital structure and cash flow volatility is inconclusive. We re-address this important question by carefully developing a set of cash flow volatility measures, conducting tests using methods that account for the non-linearity, and subjecting our analysis to a wide range of capital structure measures, alternative estimation methods, and window sizes. Across all these approaches, we find cash flow volatility 
is an important determinant of both a firm's debt ratio and use of debt of different maturities.

In testing our first hypothesis, we reject at less than the $1 \%$ level that cash flow volatility does not influence a firm's debt ratio, regardless of how capital structure is measured. The relationship is not only statistically significant, but also economically important. For example, a one standard deviation increase in cash flow volatility implies an approximate $24 \%$ decrease in the long-term market debt ratio. We find the magnitude of the effect is strongest when debt is strictly defined as long term. This finding suggests that high cash flow volatile firms tend to reduce long term debt but continue to use short term and non-financial liabilities. Our results are consistent with several recent working papers like Reindl, Stoughton and Zechner (2013), Levine and Wu (2016) and Chen, Wang and Zhou (2014).

Accounting standards categorize debt into either short (one year or less) or long term (greater than one year). This distinction hides firm heterogeneity in the use of debt of different maturities. In our second hypothesis, we investigate the effect of cash flow volatility on the use of debt of different maturities. Using our constructed categorical variable, we test if cash volatility effects a firm's use of debt in these maturity categories. We reject at less than a $1 \%$ level that cash flow volatility does not influence a firm's use of debt by maturity category. Again, the relationship is economically important, especially at the extremes. For example, a one standard deviation increase from the mean of cash flow volatility implies an approximate $24.18 \%$ decrease in the long-term debt ratio, a $26 \%$ decrease in probability of holding debt with over 10 years to maturity, and a $39 \%$ increase in the probability of holding neither short or long term debt.

In closing, we note that in our testing we control for many explanatory variables that are highly correlated with cash flow volatility. Our analysis suggests a high cash flow volatile firm tends to be smaller, less profitable, have a higher market to book ratio, and spend more on research and development than a low cash flow volatile firm. Nonetheless, even when controlling for all of these characteristics the effect of cash flow volatility on the debt ratio and use of debt of different maturities is both statistically significant and 
economically important. 


\subsection{Appendices}

\subsubsection{Compustat Variable Definitions}

Compustat Variable Definitions

This table provides Compustat variable definitions. Column (1) provides the variable name.

Column (2) defines the variables.

\begin{tabular}{|c|c|}
\hline $\begin{array}{l}\text { Compustat } \\
\text { Variable }\end{array}$ & Compustat Definition \\
\hline$d d$ & $\begin{array}{l}\text { Debt debentures, long-term debt containing a promise to pay a specific } \\
\text { amount of money on a fixed date usually more than } 10 \text { years after is- } \\
\text { suance and a promise to pay interest on stated dates. }\end{array}$ \\
\hline$d d 1$ & $\begin{array}{l}\text { Debt - Due in 1st year, the total long-term debt falling due within the } \\
\text { first year from the balance sheet date, including all long-term bank, } \\
\text { finance lease and etc. }\end{array}$ \\
\hline$d d 2$ through $d d 5$ & $\begin{array}{l}\text { Debt - due in } 2 \mathrm{nd}, 3 \mathrm{rd}, 4 \text { th and } 5 \text { th years, the dollar amount of long- } \\
\text { term debt payable in the second (or third, fourth, or fifth) year from the } \\
\text { balance sheet date. }\end{array}$ \\
\hline$d n$ & $\begin{array}{l}\text { Debt-notes, long-term debt possibly secured by the pledge of property } \\
\text { or securities owned by the company. }\end{array}$ \\
\hline$d l t t$ & $\begin{array}{l}\text { Total long-term debt, debt obligations due more than one year from the } \\
\text { company's balance sheet date. }\end{array}$ \\
\hline$d l c$ & $\begin{array}{l}\text { Total debt in current liabilities, the total amount of short-term notes } \\
\text { and the current portion of long-term debt (debt due in one year). }\end{array}$ \\
\hline dclo & $\begin{array}{l}\text { Debt-capitalized lease obligations, the debt obligation a company incurs } \\
\text { when capitalizing leases. }\end{array}$ \\
\hline$l t$ & $\begin{array}{l}\text { Total liabilities, current liabilities plus long-term debt plus other non- } \\
\text { current liabilities, including deferred taxes and investment tax credit. }\end{array}$ \\
\hline$a t$ & Total assets, the total assets/liabilities of a company at a point in time. \\
\hline$c e q$ & $\begin{array}{l}\text { Total common/ordinary equity, the common shareholders' interest in the } \\
\text { company. }\end{array}$ \\
\hline csho & $\begin{array}{l}\text { Number of common shares outstanding, the net number of all common } \\
\text { shares outstanding at year-end, excluding treasury shares and scrip. }\end{array}$ \\
\hline prec_f & Price close at the end of fiscal year. \\
\hline sale & $\begin{array}{l}\text { gross sales (the amount of actual billings to customers for regular sales } \\
\text { completed during the period) reduced by cash discounts, trade discounts, } \\
\text { and returned sales and allowances for which credit is given to customers, } \\
\text { for each operating segment. }\end{array}$ \\
\hline $\operatorname{cog} s$ & $\begin{array}{l}\text { Cost of goods sold, all costs directly allocated by the company to pro- } \\
\text { duction, such as material, labor and overhead. }\end{array}$ \\
\hline
\end{tabular}




\begin{tabular}{|c|c|}
\hline $\begin{array}{l}\text { Compustat } \\
\text { Variable }\end{array}$ & Compustat Definition \\
\hline$x \operatorname{sga}$ & $\begin{array}{l}\text { Selling, general and administrative expense, all commercial expenses of } \\
\text { operation (i.e., expenses not directly related to product production) in- } \\
\text { curred in the regular course of business pertaining to the securing of } \\
\text { operating income. }\end{array}$ \\
\hline ebitda & $\begin{array}{l}\text { Earnings before interest, the sum of Sales - Net (sale) minus cost of goods } \\
\text { sold (cogs) minus selling, general \& administrative expense (xsga). }\end{array}$ \\
\hline oibdp & $\begin{array}{l}\text { Operating income before depreciation and includes the effects of ad- } \\
\text { justments for }(\operatorname{cogs}) \text { of goods sold and selling, general \& administrative } \\
\text { expense }(x s g a) \text {. }\end{array}$ \\
\hline ebit & $\begin{array}{l}\text { Earnings before interest and taxes, the sum of Sales - Net (sale) minus } \\
\text { cost of goods sold (cogs) minus selling, general \& administrative expense } \\
(x \text { sga) minus depreciation/amortization }(d p) \text {. }\end{array}$ \\
\hline$x o p r$ & $\begin{array}{l}\text { Total operating expense, the sum of different components based on the } \\
\text { format the company uses to report its income account. }\end{array}$ \\
\hline$x r d$ & $\begin{array}{l}\text { Research and development expense, all costs incurred during the year } \\
\text { that relate to the development of new products or services. }\end{array}$ \\
\hline xacc & Accrued expenses, expenses incurred with the passage of time. \\
\hline rect & $\begin{array}{l}\text { Total receivables, claims against others, after applicable reserves, col- } \\
\text { lectible in money, generally within one year. }\end{array}$ \\
\hline invt & $\begin{array}{l}\text { Total inventories, this item represents merchandise bought for resale and } \\
\text { materials and supplies purchased for use in production of revenue. }\end{array}$ \\
\hline$x p p$ & $\begin{array}{l}\text { Prepaid expenses, advance payments for services or benefits that are to } \\
\text { be received within one operating cycle. }\end{array}$ \\
\hline$d r c$ & $\begin{array}{l}\text { Current deferred revenue, revenue which has not yet been earned, but is } \\
\text { expected to be classified as earned during the current year. }\end{array}$ \\
\hline$d r l t$ & Long-term deferred revenue, revenue which has not yet been earned. \\
\hline$a p$ & $\begin{array}{l}\text { Accounts payable - trade, this item represents only trade obligations due } \\
\text { within one year or the normal operating cycle of the company. }\end{array}$ \\
\hline che & $\begin{array}{l}\text { Cash and short-term investments, cash and all securities readily trans- } \\
\text { ferable to cash as listed in the Current Asset section. }\end{array}$ \\
\hline
\end{tabular}




\subsubsection{Variable Definitions}

Variable Definitions

This table provides variable definitions. Column (1) provides the variable name. Column (2) defines the variable. Column (3) shows the variable construction using system variable names. Column (4) provides the data source.

\begin{tabular}{|c|c|c|c|}
\hline Variable & Definition & Construction & $\begin{array}{l}\text { Data } \\
\text { Sources }\end{array}$ \\
\hline$M D R 1$ & $\begin{array}{l}\text { The ratio of total liabilities to total } \\
\text { assets minus common shareholders } \\
\text { equity plus market value of } \\
\text { common stock, (Rajan and } \\
\text { Zingales, 1995; Welch, 2007). }\end{array}$ & $\frac{l t}{\frac{(a t-c e q)+c s h o * p r c c \_f}{f}}$ & Compustat \\
\hline$B D R 1$ & $\begin{array}{l}\text { The ratio of total liabilities to total } \\
\text { assets, (Rajan and Zingales, 1995; } \\
\text { Welch, 2011). }\end{array}$ & $\frac{l t}{a t}$ & Compustat \\
\hline$M D R 2$ & $\begin{array}{l}\text { The ratio of short plus long-term } \\
\text { debt to short plus long-term debt } \\
\text { plus common shareholder equity, } \\
\text { (Rajan and Zingales, 1995). }\end{array}$ & $\frac{d l t t+d l c}{d l t t+d l c+c s h o * p r c c \_f}$ & Compustat \\
\hline$B D R 2$ & $\begin{array}{l}\text { The ratio of total liabilities to total } \\
\text { assets, (Rajan and Zingales, 1995). }\end{array}$ & $\frac{d l t t+d l c}{d l t t+d l c+c e q}$ & Compustat \\
\hline$M D R 3$ & $\begin{array}{l}\text { The ratio of long-term market debt } \\
\text { ratio over the total long-term debt } \\
\text { plus market value of equity, } \\
\text { (Bradley et al., 1984). }\end{array}$ & $\frac{d l t t}{d l t t+c s h o * p r c c \_f}$ & Compustat \\
\hline$B D R 3$ & $\begin{array}{l}\text { The ratio of total long-term debt } \\
\text { over total long-term debt plus } \\
\text { common share holder equity }\end{array}$ & $\frac{d l t t}{d l t t+c e q}$ & Compustat \\
\hline$C F V \_K S \_o i \_5$ & $\begin{array}{l}\text { Natural logarithm of cash flow } \\
\text { volatility. }\end{array}$ & Section 2.3 .2 & Compustat \\
\hline Tangibility & $\begin{array}{l}\text { The assets tangibility of a firm is } \\
\text { the ratio of(ppent) net property, } \\
\text { plant, and equipment(at) toatal } \\
\text { assets, (Lemmon et al., 2008) and } \\
\text { (Frank and Goyal, 2009). }\end{array}$ & $\frac{p p e n b}{a t}$ & Compustat \\
\hline IndustLev & $\begin{array}{l}\text { The median industry leverage of } \\
\text { the sector which a firm is classified } \\
\text { by four-digit SIC code, (Frank and } \\
\text { Goyal, 2009). }\end{array}$ & $\begin{array}{l}\text { The median of } \\
\frac{L T}{M V A} 17\end{array}$ & Compustat \\
\hline
\end{tabular}

\footnotetext{
${ }^{17}$ Market value of assets $(M V A)=$ debt in current liabilities $(d l c)+$ long-term debt $(d l t t)+$ preferred stock $(p s t k l)+$ market value of equity $(c s h o * p r c c-f)-$ balance sheet deferred taxes and investment tax credit (txditc).
} 


\begin{tabular}{|c|c|c|c|}
\hline Variable & Definition & Construction & $\begin{array}{l}\text { Data } \\
\text { Sources }\end{array}$ \\
\hline FirmSize & The proxy for a firm size. & $\ln (a t)$ & Compustat \\
\hline Profitability & Shows the profitability of a firm. & $\frac{\text { oibdp }}{a t}$ & Compustat \\
\hline MarketToBook & $\begin{array}{l}\text { The proxy for a firm's growth } \\
\text { opportunities and is the ratio of } \\
\text { market value of asset to total } \\
\text { assets. }\end{array}$ & $\frac{M V A}{a t}$ & Compustat \\
\hline Inflation & $\begin{array}{l}\text { The expected change in the } \\
\text { consumer price index (CPI) over } \\
\text { the coming year, (Frank and Goyal, } \\
2009 \text { ). }\end{array}$ & 18 & $\begin{array}{l}\text { Livingston } \\
\text { Survey }\end{array}$ \\
\hline $\operatorname{LnRnD}$ & $\begin{array}{l}\text { The ratio of } \mathrm{R} \& \mathrm{D} \text { expenses to sale } \\
\text { of a firm, (Frank and Goyal, 2009). }\end{array}$ & $\ln \left(1+\frac{x r d}{r e v t}\right)$ & Compustat \\
\hline EquIssue & $\begin{array}{l}\text { The split-adjusted change in shares } \\
\text { outstanding times the } \\
\text { split-adjusted average stock price } \\
\text { dividend by the end of year t-1 } \\
\text { total assets, (Lemmon et al., 2008). }\end{array}$ & 19 & Compustat \\
\hline CreditRating & $\begin{array}{l}\text { Indicator variable: One if a firm is } \\
\text { listed as investment grade by } \mathrm{S} \& \mathrm{P} \text {, } \\
\text { and zero otherwise. }\end{array}$ & $\begin{array}{l}=1 \text { if SPLTICRM } \\
\text { or SPSDRM }<13\end{array}$ & Compustat \\
\hline FirmAge & $\begin{array}{l}\text { The number of years a firm has had } \\
\text { data in Compustat. }\end{array}$ & $\begin{array}{l}\text { fyear-First year in } \\
\text { Compustat }\end{array}$ & Compustat \\
\hline ZerobyMaturity & $\begin{array}{l}\text { An ordered categorical variable } \\
\text { based on debt maturity }\end{array}$ & $\begin{array}{l}\text { Section } 2.3 .2 \\
\text { defines the five } \\
\text { categories of } \\
\text { ZerobyMaturity. }\end{array}$ & Compustat \\
\hline$\overline{D e b t M a t \_D}$ & $\begin{array}{l}\text { The percentage of a firm's total } \\
\text { debt that matures in more than } \\
\text { three years, (Barclay and Smith, } \\
\text { 1995). }\end{array}$ & $\frac{d l t t-d d 2-d d 3}{d l t t+d l c}$ & Compustat \\
\hline DebtMat_L & $\begin{array}{l}\text { The percentage of a firm's total } \\
\text { liabilities that matures in more } \\
\text { than three years }\end{array}$ & $\frac{d l t t-d d 2-d d 3}{l t}$ & Compustat \\
\hline
\end{tabular}

\footnotetext{
18 Forecast 12 Month-BasePeriod

${ }^{19}$ EquIssue $_{i, t}=\left[\left(\right.\right.$ csho $\left.\left._{t}-\operatorname{csho}_{t-1}\right) *\left(\operatorname{adjex}_{t-1} / \operatorname{adjex} f_{t}\right)\right] *\left[\left(\operatorname{prccf}_{t}-\operatorname{prccf}_{t-1}\right) *\right.$ $\left.\left(\operatorname{adjex} f_{t} / \operatorname{adjex} f_{t-1}\right)\right] /$ at.
} 


\subsection{Figures and Tables}

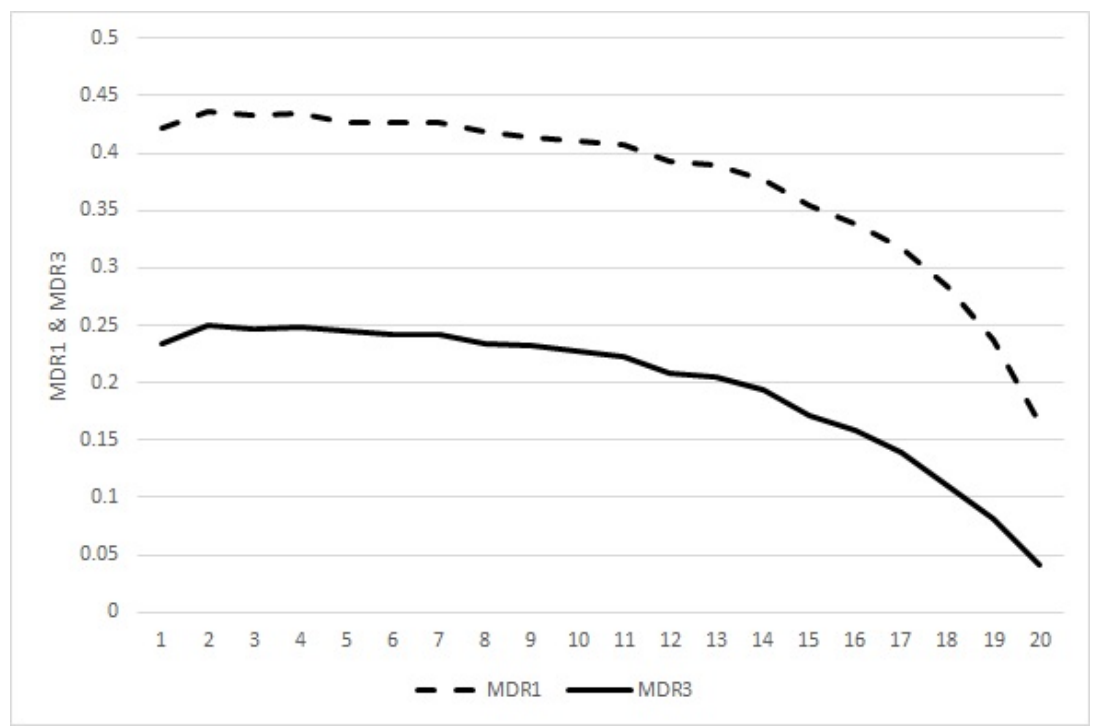

Figure 1: The horizontal axis shows the 20-Quantiles of $C F V \_K S \_o i \_5$. The vertical axis shows the debt ratio. The figure plots the mean of $M D R 1$ and $M D R 3$ in each volatility quantile.

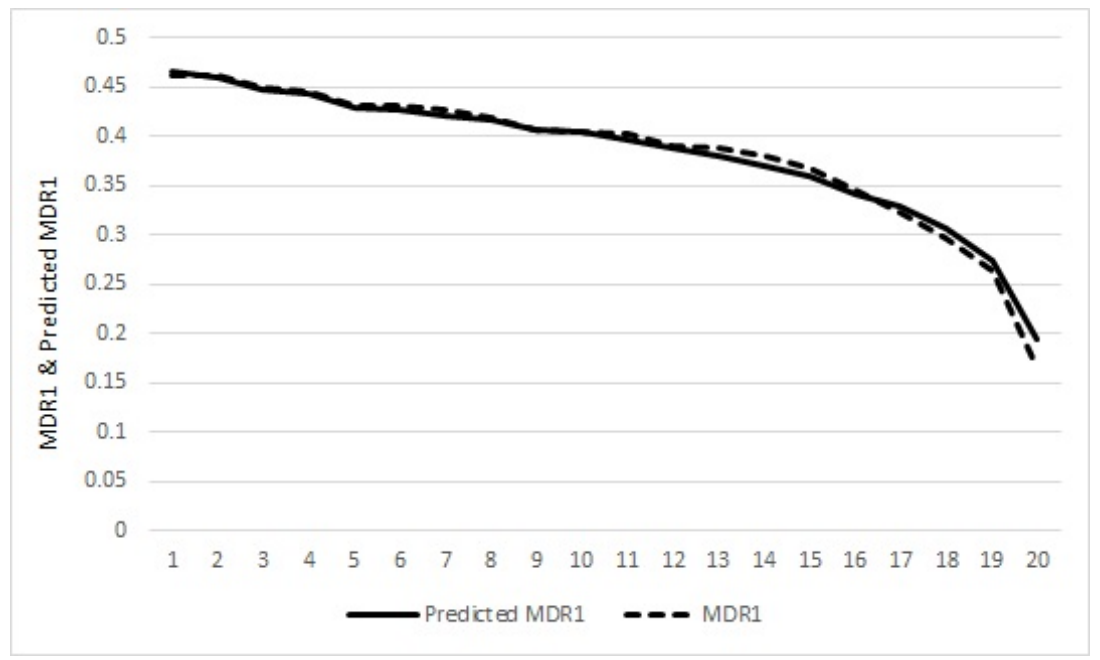

Figure 2: The horizontal axis shows the 20-Quantiles of $C F V \_K S \_$oi_5. The vertical axis shows the debt ratio. The figure plots by quantile the mean of actual versus predicted $M D R 1$. MDR1 predicted values are obtained using GLM with a logit link function shown in Equation (2.17). 


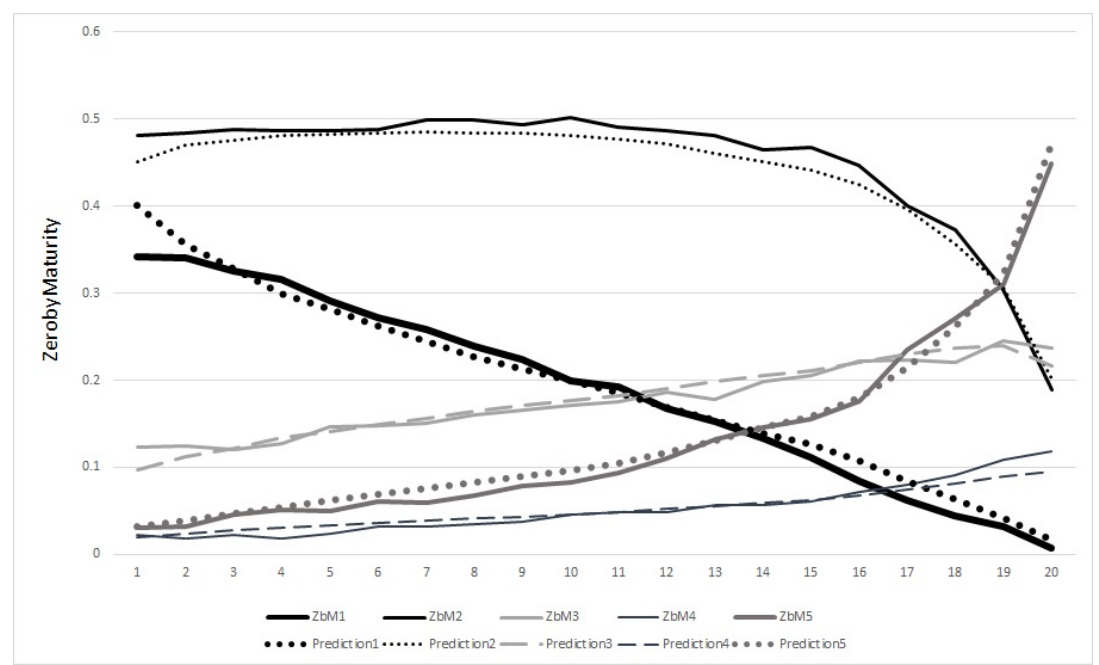

Figure 3: The horizontal axis shows the 20-Quantiles of $C F V \_K S \_o i \_5$. The vertical axis shows the percentage of the sample firms in the each category of ZerobyMaturity ( $Z b M 1$ to $Z b M 5$, where for example $Z b M 1$ represents the percentage of the sample firms existing in the first category ZerobyMaturity=1). The figure plots by quantile the predicted mean probability and actual percentage for each maturity category. Predicted mean probabilities are obtained from the ordered probit model shown in Equation (2.18). From the top, first, second, third, fourth and fifth set of lines depicts second, first, third, fifth and fourth categories of ZerobyMaturity, respectively. 


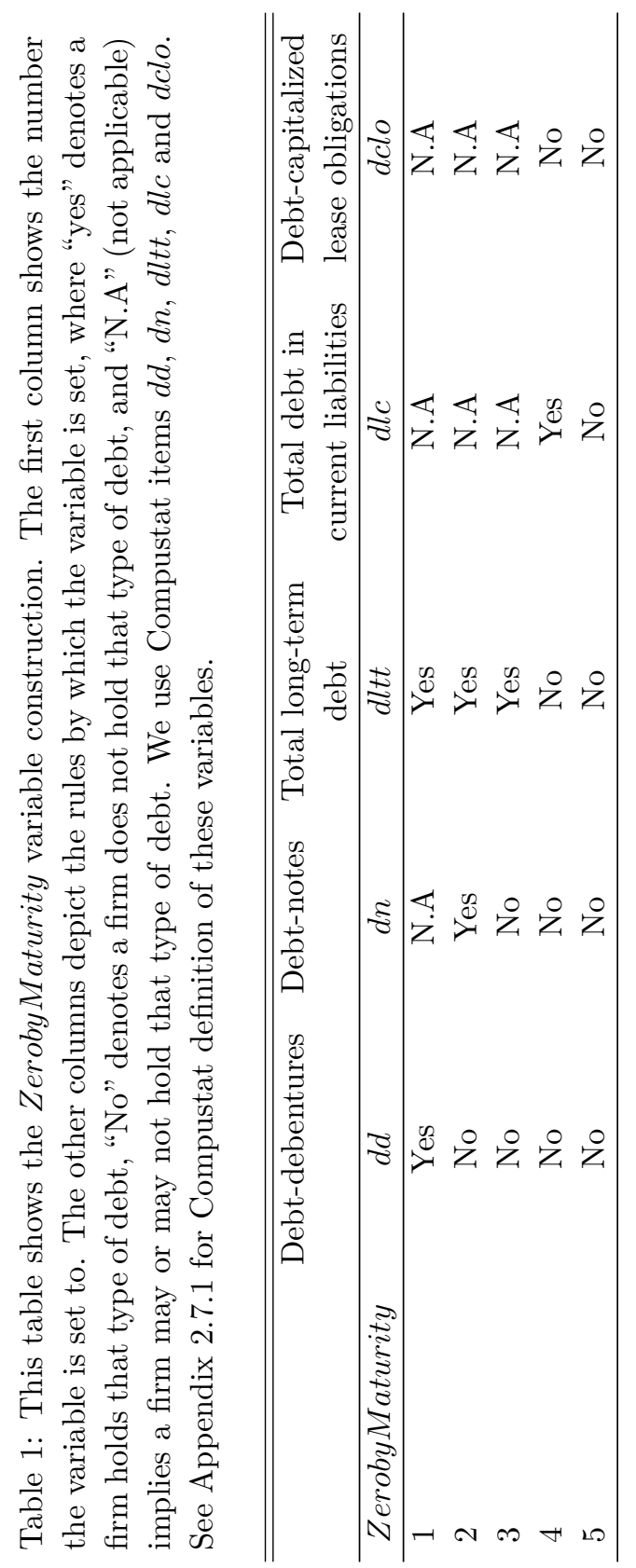




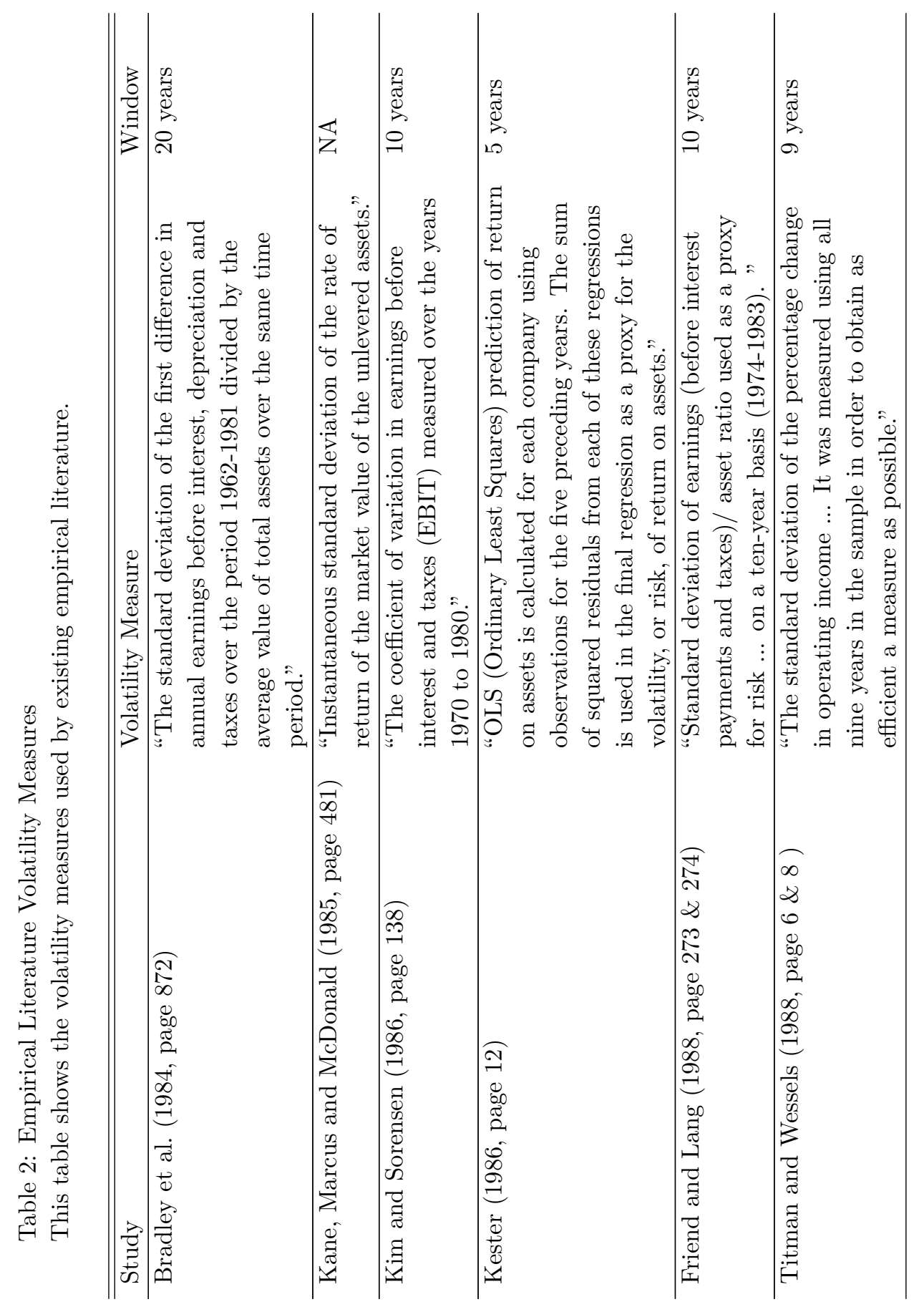




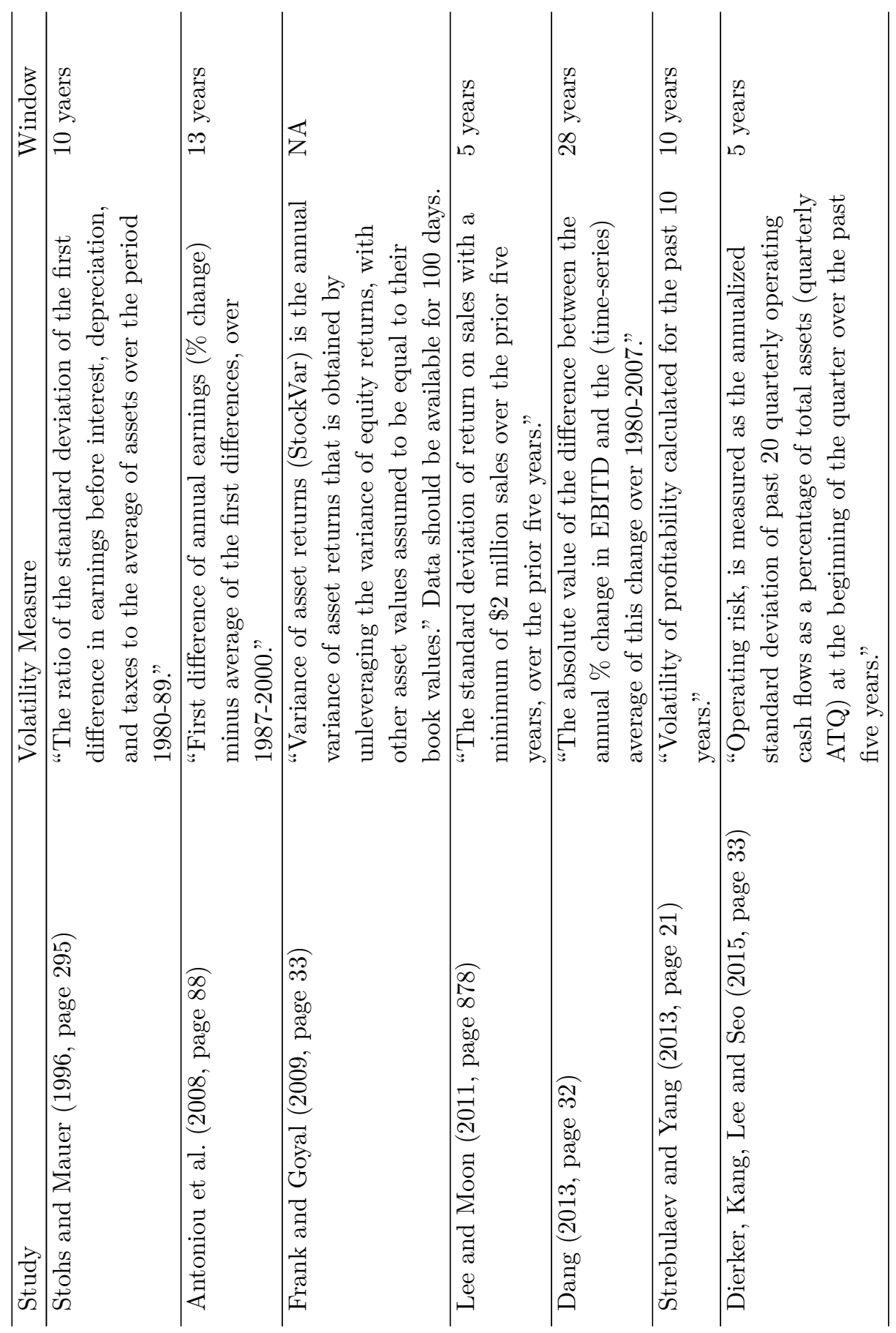


Table 3: Volatility Measures Correlations

This table shows the pairwise correlations between volatility measures. See Section 2.3.2 for the discussion on the volatility measures. Reference numbers in columns and rows refer to the variables associated with the pairwise correlation.

\begin{tabular}{lcccccccc}
\hline \hline Pairwise Correlations & & & & & & & & \\
Volatility Measures & $(1)$ & $(2)$ & $(3)$ & $(4)$ & $(5)$ & $(6)$ & $(7)$ & $(8)$ \\
\hline (1) $C F V \_K S \_o i \_5$ & 1 & & & & & & & \\
(2) $C F V \_K S \_c b o p \_5$ & 0.755 & 1 & & & & & & \\
(3) $C F V \_S M \_o i \_5$ & 0.832 & 0.692 & 1 & & & & & \\
(4) $C F V \_S M \_c b o p \_5$ & 0.632 & 0.875 & 0.715 & 1 & & & & \\
(5) $C F V \_D L \_o i$ 1 & 0.574 & 0.482 & 0.606 & 0.461 & 1 & & & \\
(6) $C F V \_D L \_c b o p \_1$ & 0.422 & 0.556 & 0.444 & 0.589 & 0.396 & 1 & & \\
(7) $C F V \_D L \_o i 5$ & 0.811 & 0.689 & 0.893 & 0.669 & 0.704 & 0.473 & 1 & \\
(8) $C F V \_D L \_c b o p \_5$ & 0.655 & 0.851 & 0.698 & 0.922 & 0.514 & 0.650 & 0.748 & 1 \\
\hline
\end{tabular}


Table 4: Summary Statistics

This table shows summary statistics of variables of the study for non-financial and non-utility US companies during 1974-2012. All the variables are winsorized at $1 \%$ level in both tails of the distribution before the summary statistics are calculated. The table reports the number of observations, mean, 25th percentile, median, 75 th percentile and standard deviation. Appendix 2.7.2 defines the variables.

\begin{tabular}{lcccccc}
\hline \hline Variable & $\mathrm{N}$ & $\mathrm{mean}$ & $\mathrm{p} 25$ & $\mathrm{p} 50$ & $\mathrm{p} 75$ & $\mathrm{sd}$ \\
\hline MDR1 & 134581 & 0.367 & 0.160 & 0.338 & 0.549 & 0.241 \\
BDR1 & 134581 & 0.466 & 0.299 & 0.472 & 0.621 & 0.216 \\
MDR2 & 134581 & 0.238 & 0.0236 & 0.167 & 0.389 & 0.238 \\
BDR2 & 134581 & 0.296 & 0.0562 & 0.270 & 0.471 & 0.250 \\
MDR3 & 134581 & 0.194 & 0.00454 & 0.113 & 0.319 & 0.219 \\
BDR3 & 134581 & 0.242 & 0.0116 & 0.191 & 0.399 & 0.237 \\
Tangibility & 134367 & 0.283 & 0.110 & 0.231 & 0.398 & 0.219 \\
FirmSize & 134581 & 4.642 & 3.162 & 4.500 & 6.003 & 2.060 \\
FirmAge & 134581 & 9.779 & 3 & 7 & 14 & 8.851 \\
Profitability & 134034 & 0.0718 & 0.0385 & 0.117 & 0.179 & 0.208 \\
MarketToBook & 130515 & 1.622 & 0.714 & 1.054 & 1.794 & 1.682 \\
EquIssue & 134576 & 0.523 & 0 & 0 & 0.163 & 2.914 \\
IndustLev & 134581 & 0.344 & 0.232 & 0.338 & 0.446 & 0.142 \\
LnRnD & 132772 & 0.0796 & 0 & 0 & 0.0437 & 0.263 \\
Inflation & 134581 & 0.0454 & 0.0260 & 0.0394 & 0.0601 & 0.0247 \\
CreditRating & 134581 & 0.0681 & 0 & 0 & 0 & 0.252 \\
CFV_KS_oi_5 & 104408 & 1.961 & 1.302 & 1.876 & 2.512 & 0.992 \\
CFV_KS_cbop_5 & 97960 & 2.229 & 1.670 & 2.169 & 2.708 & 0.853 \\
CFV_SM_oi_5 & 97377 & 1.854 & 1.125 & 1.776 & 2.484 & 1.071 \\
CFV_SM_cbop_5 & 91394 & 2.397 & 1.806 & 2.349 & 2.920 & 0.893 \\
CFV_DL_oi_1 & 131119 & 1.885 & 0.986 & 1.916 & 2.837 & 1.552 \\
CFV_DL_cbop_1 & 124281 & 2.263 & 1.476 & 2.364 & 3.161 & 1.413 \\
CFV_DL_oi_5 & 97327 & 2.135 & 1.410 & 2.002 & 2.724 & 1.061 \\
CFV_DL_cbop_5 & 91373 & 2.543 & 1.945 & 2.479 & 3.066 & 0.893 \\
\hline & & & & & & \\
\hline & & & & & &
\end{tabular}


Table 5: Summary of ZerobyMaturity

This table shows summary of ZerobyMaturity for non-financial and non-utility US companies during 1974-2012. The table reports the number of observations, the frequency and the percentage of the sample firms existing in the each category of ZerobyMaturity. Appendix 2.7.2 defines the variables.

\begin{tabular}{lcccc}
\hline \hline Category & Description & Freq. & Percent & Cum. \\
\hline 1 & Debt maturity more than ten years & 22,944 & 17.05 & 17.05 \\
2 & Zero debt that matures in more than ten years & 60,117 & 44.67 & 61.72 \\
3 & Zero debt that matures in five to ten years & 25,110 & 18.66 & 80.38 \\
4 & Zero total long term debt & 7,548 & 5.610 & 85.98 \\
5 & Zero long-term and short-term debt & 18,862 & 14.02 & 100 \\
Total & & 134,581 & 100 & \\
\hline
\end{tabular}




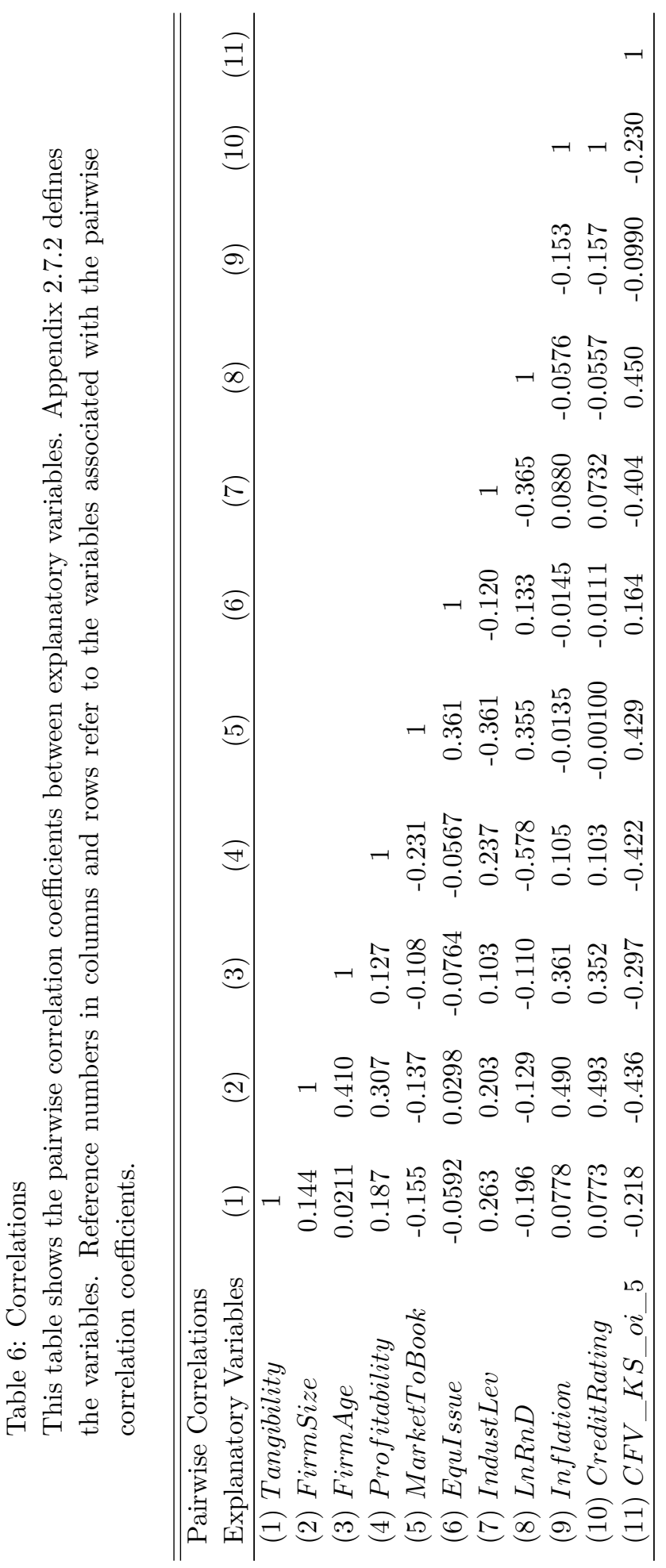


Table 7: Testing Hypothesis 1 - The effects of cash flow volatility on capital structure This table shows estimation results of Equation (2.17) using GLM with a logit link function. All explanatory variables are lagged by one year. Columns (1) to (6) show estimation results using the different capital structure measures as the dependent variable and $L C F V \_K S \_o i \_5$ as the variable of interest. Appendix 2.7.2 defines the variables. Clustered standard errors by firm are shown in parentheses with $1 \%, 5 \%$ and $10 \%$ significance level denoted by ${ }^{* * *},{ }^{* *}$ and ${ }^{*}$, respectively.

\begin{tabular}{|c|c|c|c|c|c|c|}
\hline & (1) & $(2)$ & (3) & $(4)$ & $(5)$ & (6) \\
\hline VARIABLES & $M D R 1$ & $B D R 1$ & $M D R 2$ & $B D R 2$ & $M D R 3$ & $B D R 3$ \\
\hline \multirow[t]{2}{*}{$\overline{L C F V \_K S \_o i \_5}$} & $-0.203^{* * *}$ & $-0.106^{* * *}$ & $-0.295^{* * *}$ & $-0.223^{* * *}$ & $-0.309^{* * *}$ & $-0.234^{* * *}$ \\
\hline & $(0.00721)$ & $(0.008)$ & $(0.0108)$ & $(0.0106)$ & $(0.0114)$ & $(0.0112)$ \\
\hline \multirow[t]{2}{*}{ LTangibility } & $0.204^{* * *}$ & $0.290^{* * *}$ & $0.784^{*}$ & $0.930^{* * *}$ & $1.089^{* * *}$ & $1.218^{* * *}$ \\
\hline & $(0.0298)$ & $(0.0321)$ & $(0.0439)$ & $(0.0437)$ & $(0.0470)$ & $(0.0465)$ \\
\hline \multirow[t]{2}{*}{ LFirmSize } & $0.0404^{* * *}$ & $0.0772^{* * *}$ & $0.0276^{* * *}$ & $0.0539 * * *$ & $0.0782^{* * *}$ & $0.106^{* * *}$ \\
\hline & $(0.00391)$ & $(0.00423)$ & $(0.00584)$ & $(0.00592)$ & $(0.00619)$ & $(0.00628)$ \\
\hline \multirow[t]{2}{*}{ LFirmAge } & $-0.0105^{* * *}$ & $-0.00595^{* * *}$ & $-0.0178^{* * *}$ & $-0.0125^{* * *}$ & $-0.0182^{* * *}$ & $-0.0128^{* * *}$ \\
\hline & $(0.000798)$ & $(0.000880)$ & $(0.00122)$ & $(0.00125)$ & $(0.00128)$ & $(0.00131)$ \\
\hline \multirow[t]{2}{*}{ LProfitability } & $-1.483^{* * *}$ & $-1.180 * * *$ & $-1.761^{* * *}$ & $-1.512^{* * *}$ & $-1.516^{* * *}$ & $-1.270^{* * *}$ \\
\hline & $(0.0400)$ & $(0.0377)$ & $(0.058$ & & & \\
\hline \multirow[t]{2}{*}{ LMarketToBook } & $-0.478^{* * *}$ & $-0.0671 * * *$ & $-0.522^{* * *}$ & $-0.0918^{* * *}$ & $-0.523^{* * *}$ & $-0.0876^{* * *}$ \\
\hline & $(0.00725)$ & $(0.004$ & $(0.010$ & $(0.006$ & $(0.0122)$ & $(0.00$ \\
\hline \multirow[t]{2}{*}{$L \operatorname{LnRnD}$} & $-0.682^{* * *}$ & $-0.512^{* * *}$ & $-1.070 * * *$ & $-0.630^{* * *}$ & $-0.863^{* * *}$ & $-0.450 * * *$ \\
\hline & $(0.0422)$ & $(0.03$ & $(0.113)$ & $(0.0687)$ & $(0.126)$ & $(0.0$ \\
\hline \multirow[t]{2}{*}{ LEquIssue } & 0.00138 & $-0.00224^{*}$ & -0.00235 & -0.000987 & -0.00332 & -0.000769 \\
\hline & $(0.00140)$ & $(0.00125)$ & $(0.00191)$ & $(0.00189)$ & $(0.00207)$ & $(0.00204)$ \\
\hline \multirow[t]{2}{*}{ LIndustLev } & $1.690^{* * *}$ & $1.223^{* * *}$ & $2.030^{* * *}$ & $1.603^{* * *}$ & $2.017 * * *$ & $1.583^{* * *}$ \\
\hline & $(0.0540)$ & $(0.0557)$ & & & & \\
\hline \multirow[t]{2}{*}{ LInflation } & $3.318^{* * *}$ & $1.858^{* * *}$ & $3.143^{* * *}$ & $1.958^{* * *}$ & $3.129^{* * *}$ & $1.700^{* * *}$ \\
\hline & & & & & & \\
\hline \multirow[t]{2}{*}{ LCreditRating } & $-0.0860^{* * *}$ & $0.207^{* * *}$ & $-0.119 * * *$ & $0.232^{* * *}$ & $-0.233^{* * *}$ & $0.0939^{* * *}$ \\
\hline & $(0.0202)$ & $(0.0243)$ & & & $(0.0328)$ & \\
\hline \multirow[t]{2}{*}{ Constant } & $-0.208^{* * *}$ & $-0.588^{* * *}$ & $-0.834^{* * *}$ & $-1.233^{* * *}$ & $-1.451^{* * *}$ & $-1.843^{* * *}$ \\
\hline & $(0.0385)$ & $(0.0392)$ & $(0.0576)$ & $(0.0554)$ & $(0.0617)$ & $(0.0594)$ \\
\hline Observations & 95,244 & 95,244 & 95,244 & 95,244 & 95,244 & 95,244 \\
\hline
\end{tabular}


Table 8: Testing Hypothesis 2 - The effects of cash flow volatility on maturity of debt

This table shows estimation results of Equation (2.18) using an ordered probit model. The dependent variable is the categorical variable ZerobyMaturity. Columns (1) and (2) report the estimation results using a cross-sectional and a panel ordered probit model, respectively. Appendix 2.7.2 defines the variables. Clustered standard errors by firm are shown in parentheses with 1\%, $5 \%$ and $10 \%$ significance level denoted by ${ }^{* * *}, * *$ and ${ }^{*}$, respectively.

\begin{tabular}{lcc}
\hline \hline & Dependent variable $=$ ZerobyMaturity & \\
VARIABLES & $(1)$ & $(2)$ \\
\hline LCFV_KS_oi_5 & Cross-sectional & Panel \\
LTangibility & $0.238^{* * *}$ & $\left(0.181^{* * *}\right.$ \\
& $(0.00511)$ & $-1.658^{* * *}$ \\
LFirmSize & $-0.936^{* * *}$ & $(0.0763)$ \\
& $(0.0172)$ & $-0.173^{* * *}$ \\
LFirmAge & $-0.125^{* * *}$ & $(0.0113)$ \\
& $(0.00241)$ & $0.0234^{* * *}$ \\
LProfitability & $-0.00229^{* * *}$ & $(0.00214)$ \\
& $(0.000493)$ & $0.319^{* * *}$ \\
LMarketToBook & $0.419^{* * *}$ & $(0.0567)$ \\
& $(0.0263)$ & $0.0374^{* * *}$ \\
LLnRnD & $0.0594^{* * *}$ & $(0.00635)$ \\
& $(0.00303)$ & $0.213^{* * *}$ \\
LEquIssue & $0.0570^{* * *}$ & $(0.0485)$ \\
& $(0.0203)$ & $-0.00660^{* * *}$ \\
LIndustLev & $-0.00907^{* * *}$ & $(0.00191)$ \\
& $(0.00153)$ & $-2.475^{* * *}$ \\
LInflation & $-0.897^{* * *}$ & $(0.117)$ \\
LCreditRating & $(0.0294)$ & $-7.053^{* * *}$ \\
Observations & $-13.24^{* * *}$ & $(0.436)$ \\
& $(0.173)$ & $-0.535^{* * *}$ \\
& $-0.718^{* * *}$ & $(0.0650)$ \\
& $(0.0168)$ & 95,235 \\
\hline
\end{tabular}




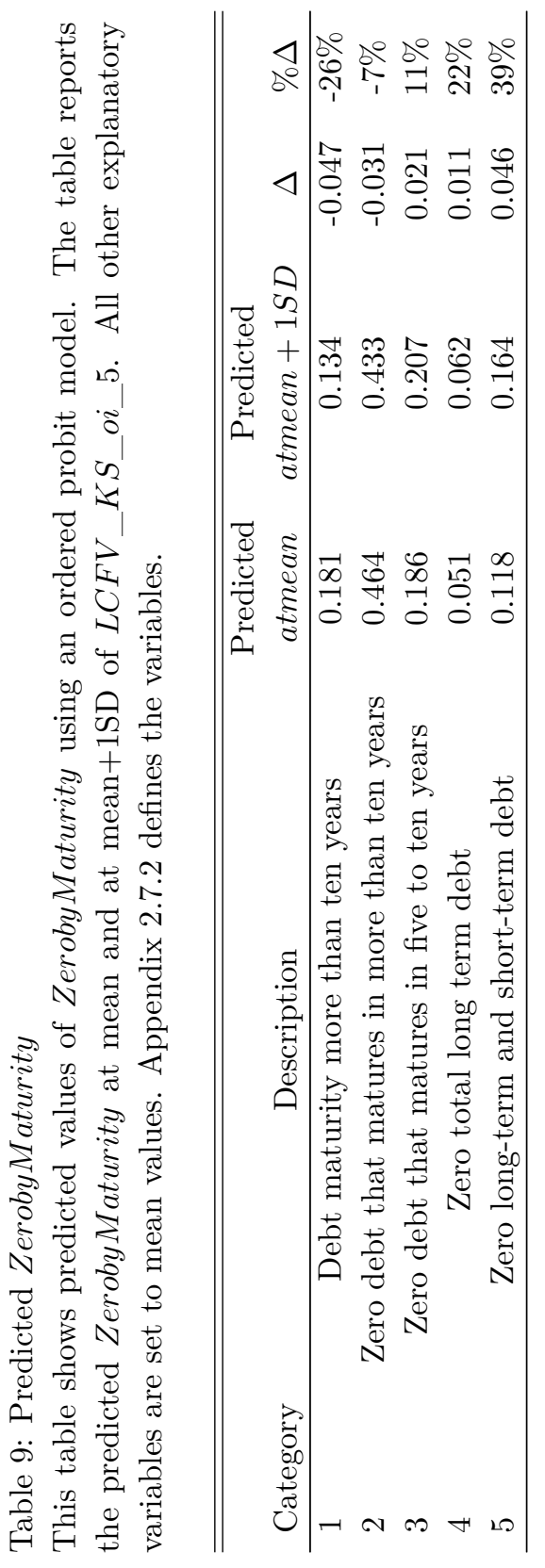


Table 10: Capital Structure Variables by Cash Flow Volatility Quantiles

This table shows the mean of the capital structure control variables by 5 -quantiles of cash flow volatility. Column 1 represents the lowest cash flow volatility quantile and Column 5 represents the highest cash flow volatility quantile. The $t$-test columns show the $t$-stat of the difference in the mean between the first versus the fifth quantiles and the fourth versus the fifth quantiles. Note that the $P$-values are less than 0.01 for every test. Appendix 2.7.2 defines the variables.

\begin{tabular}{l|ccccc|cc}
\hline \hline \multicolumn{7}{c}{ Cash Flow Volatility Quantiles } \\
\hline VARIABLES & 1 & 2 & 3 & 4 & 5 & $t$-stat & $t$-stat \\
& Low & & & & High & 1 vs 5 & 4 vs 5 \\
\hline Tangibility & 0.327 & 0.317 & 0.309 & 0.286 & 0.197 & 63.77 & 43.6715 \\
FirmSize & 6.043 & 5.247 & 4.699 & 4.126 & 3.394 & 145.53 & 44.16 \\
FirmAge & 13.64 & 11.46 & 9.876 & 8.378 & 6.124 & 92.81 & 33.2 \\
Profitability & 0.132 & 0.135 & 0.134 & 0.112 & -0.0530 & 83.99 & 71.45 \\
MarketToBook & 1.031 & 1.164 & 1.339 & 1.659 & 2.873 & -99.12 & -61.2 \\
LnRnD & 0.0137 & 0.0194 & 0.0271 & 0.0498 & 0.262 & -73.47 & -60.92 \\
EquIssue & 0.204 & 0.292 & 0.412 & 0.552 & 1.203 & -39.11 & -22.65 \\
IndustLev & 0.409 & 0.384 & 0.364 & 0.329 & 0.251 & 128.84 & 63.24 \\
Inflation & 0.0464 & 0.0498 & 0.0504 & 0.0491 & 0.0418 & 26.34 & 34.25 \\
CreditRating & 0.19 & 0.103 & 0.06 & 0.028 & 0.009 & 61.26 & 13.75 \\
\hline
\end{tabular}


Table 11: Robustness to econometric method

This table reports the coefficients associated with $L C F V \_K S \_o i \_5$ using different econometric procedures. Column (1) uses the GLM panel data model, Column (2) uses the zero inflated beta model, and Column (3) uses OLS (ordinary least squares). Appendix 2.7.2 defines the variables. Clustered standard errors by firm are shown in parentheses with $1 \%, 5 \%$ and $10 \%$ significance level denoted by $* * *, * *$ and *, respectively.

\begin{tabular}{lccc}
\hline \hline \multirow{2}{*}{$\begin{array}{c}(1) \\
\text { Dependent }\end{array}$} & $\begin{array}{c}(2) \\
\text { GLM panel } \\
\text { variables }\end{array}$ & $\begin{array}{c}\text { Zero inflated } \\
\text { data model }\end{array}$ & OLS \\
\hline$M D R 1$ & $-0.162^{* * *}$ & $-0.205^{* * *}$ & $-0.0489^{* * *}$ \\
& $(0.00571)$ & $(0.00345)$ & $(0.00159)$ \\
BDR 1 & $-0.0447^{* * *}$ & $-0.101^{* * *}$ & $-0.0254^{* * *}$ \\
& $(0.00567)$ & $(0.00346)$ & $(0.00179)$ \\
$M D R 2$ & $-0.200^{* * *}$ & $-0.246^{* * *}$ & $-0.0522^{* * *}$ \\
& $(0.00786)$ & $(0.00469)$ & $(0.00177)$ \\
$B D R 2$ & $-0.109^{* * *}$ & $-0.162^{* * *}$ & $-0.0419^{* * *}$ \\
& $(0.00773)$ & $(0.00479)$ & $(0.00201)$ \\
$M D R 3$ & $-0.212^{* * *}$ & $-0.237^{* * *}$ & $-0.0470^{* * *}$ \\
& $(0.00834)$ & $(0.00490)$ & $(0.00164)$ \\
$B D R 3$ & $-0.121^{* * *}$ & $-0.154^{* * *}$ & $-0.0381^{* * *}$ \\
& $(0.00819)$ & $(0.00502)$ & $(0.00187)$ \\
\hline
\end{tabular}




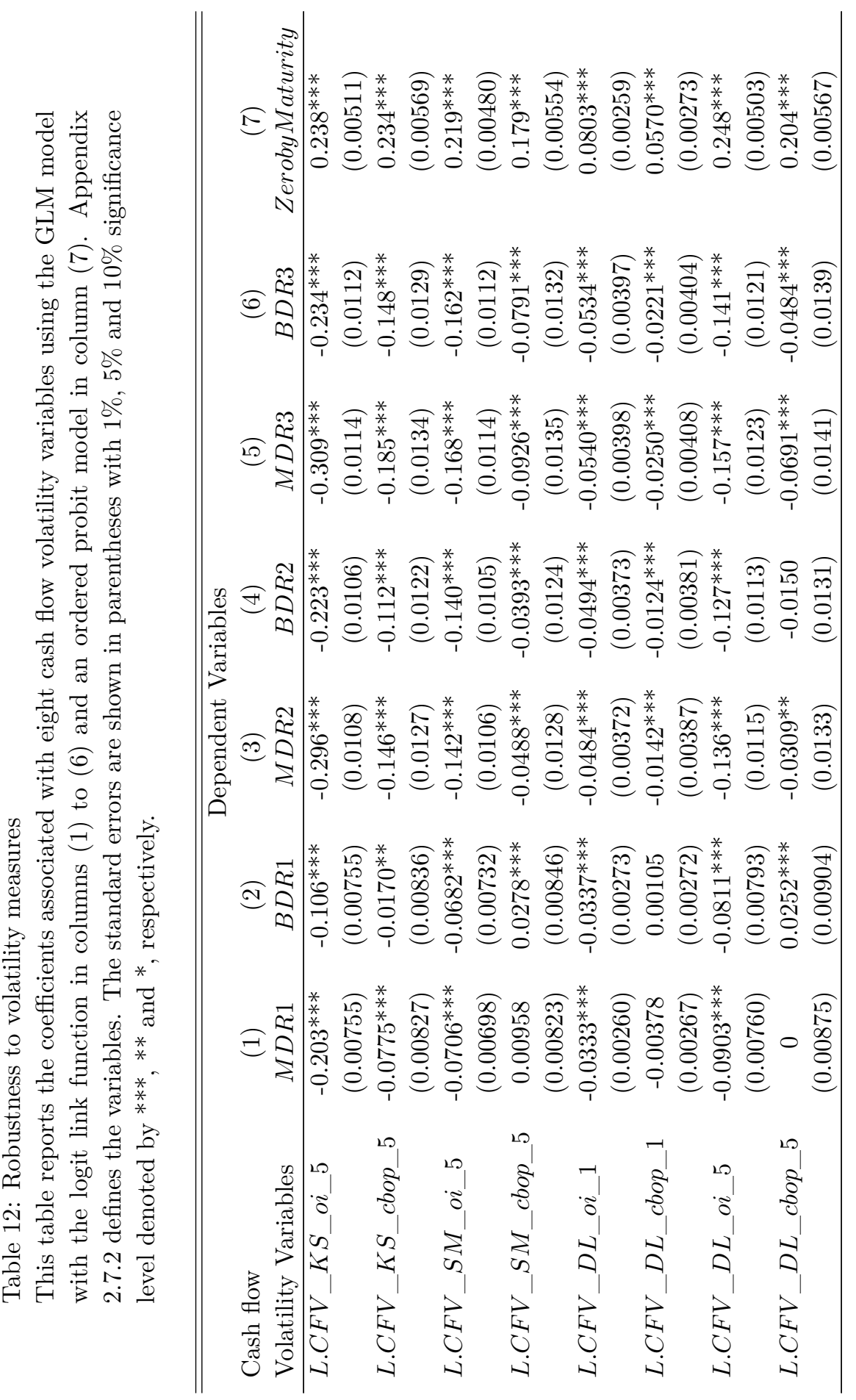




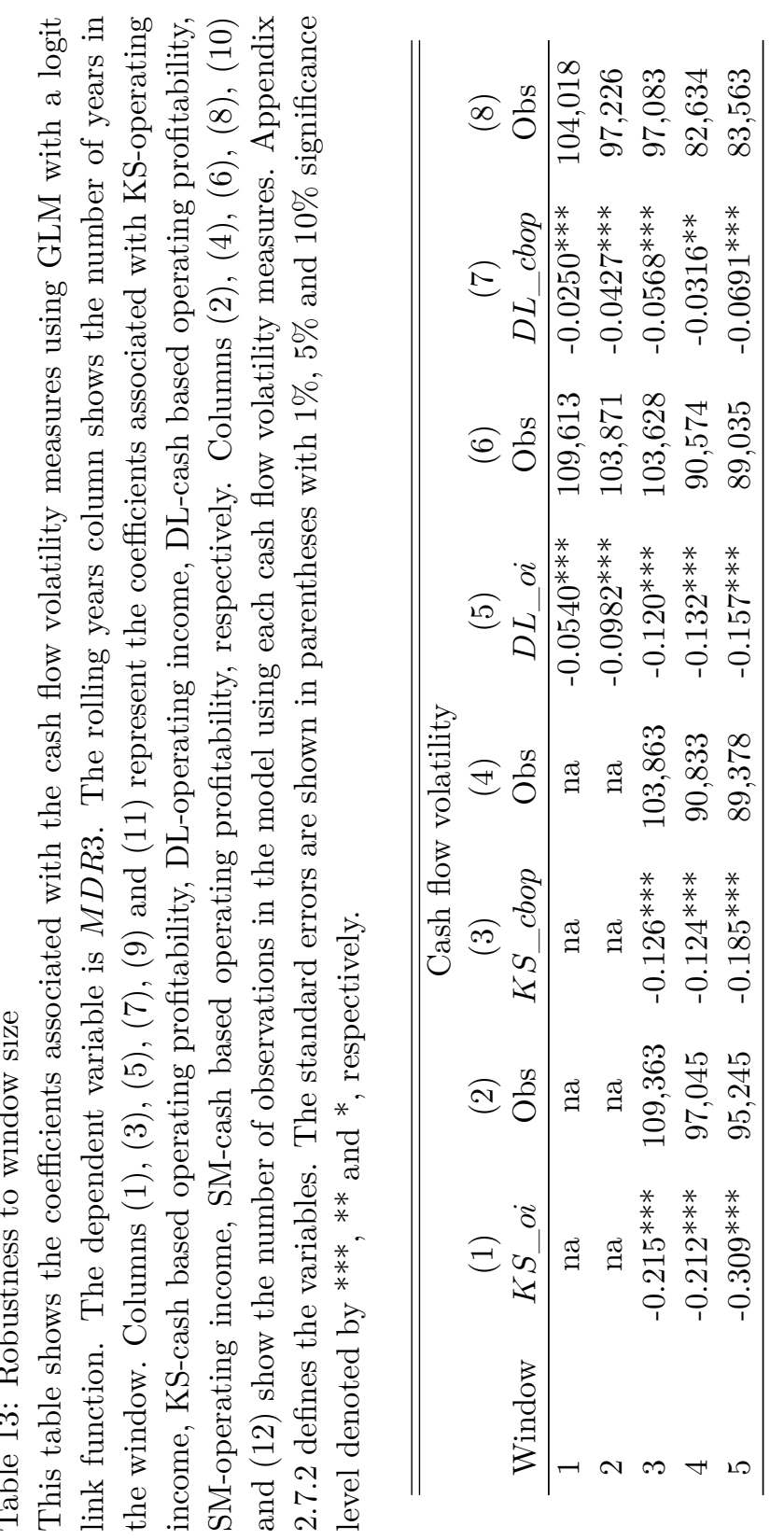


Table 14: Robustness to different debt maturity variables

This table shows estimation results of re-testing Hypothesis 2 with alternative debt maturity variables using the $L C F V \_K S \_o i \_5$ as the variable of interest. The alternative debt maturity variables are constructed in Section 2.3.2. In columns (1) and (2) we use GLM with a logit link function. In columns (3) and (4) we use zero inflated beta model. Appendix 2.7.2 defines the variables. The standard errors are shown in parentheses with $1 \%, 5 \%$ and $10 \%$ significance level denoted by $* * *, * *$ and ${ }^{*}$, respectively.

\begin{tabular}{|c|c|c|c|c|}
\hline \multirow[b]{3}{*}{ VARIABLES } & \multicolumn{2}{|c|}{ GLM } & \multicolumn{2}{|c|}{ Zero Inflated Beta } \\
\hline & (1) & $(2)$ & $(3)$ & (4) \\
\hline & DebtMat_D & DebtMat_L & DebtMat_D & DebtMat_L \\
\hline \multirow[t]{2}{*}{$L C F V_{-} K_{\perp} S_{-} i_{-} 5$} & $-0.0687^{* * *}$ & $-0.222^{* * *}$ & $-0.0640^{* * *}$ & $-0.143^{* * *}$ \\
\hline & $(0.0114)$ & $(0.0112)$ & $(0.00667)$ & $(0.00555)$ \\
\hline \multirow[t]{2}{*}{ LTangibility } & $0.910^{* * *}$ & $1.465^{* * *}$ & $0.698^{* * *}$ & $1.207^{* * *}$ \\
\hline & $(0.0492)$ & $(0.0481)$ & $(0.0223)$ & $(0.0183)$ \\
\hline \multirow[t]{2}{*}{ LFirmSize } & $0.228^{* * *}$ & $0.130^{* * *}$ & $0.187^{* * *}$ & $0.112^{* * *}$ \\
\hline & $(0.00676)$ & $(0.00625)$ & $(0.00307)$ & $(0.00251)$ \\
\hline \multirow[t]{2}{*}{ LFirmAge } & $-0.00650^{* * *}$ & $-0.0153^{* * *}$ & $-0.00495^{* * *}$ & $-0.00909^{* * *}$ \\
\hline & $(0.00126)$ & $(0.00128)$ & $(0.000619)$ & $(0.000519)$ \\
\hline \multirow[t]{2}{*}{ LProfitability } & $0.345^{* * *}$ & $-0.367^{* * *}$ & $0.377^{* * *}$ & $-0.0977 * * *$ \\
\hline & $(0.0649)$ & $(0.0619)$ & $(0.0399)$ & $(0.0325)$ \\
\hline \multirow[t]{2}{*}{ LMarketToBook } & 0.0111 & $-0.0326^{* * *}$ & $0.0152^{* * *}$ & $-0.0109 * * *$ \\
\hline & $(0.00755)$ & $(0.00730)$ & $(0.00447)$ & $(0.00362)$ \\
\hline \multirow[t]{2}{*}{$L \operatorname{LnR} R D$} & $0.306^{* * *}$ & 0.103 & $0.211^{* * *}$ & $0.213^{* * *}$ \\
\hline & $(0.0531)$ & $(0.0672)$ & $(0.0320)$ & $(0.0268)$ \\
\hline \multirow[t]{2}{*}{ LEquIssue } & 0.00136 & $0.00606^{* * *}$ & 0.00304 & 0.00164 \\
\hline & $(0.00238)$ & $(0.00209)$ & $(0.00211)$ & $(0.00173)$ \\
\hline \multirow[t]{2}{*}{ LIndustLev } & $0.460 * * *$ & $0.749^{* * *}$ & $0.477^{* * *}$ & $0.718^{* * *}$ \\
\hline & $(0.0844)$ & $(0.0891)$ & $(0.0373)$ & $(0.0315)$ \\
\hline \multirow[t]{2}{*}{ LInflation } & $6.290^{* * *}$ & $3.963^{* * *}$ & $5.313^{* * *}$ & $5.329 * * *$ \\
\hline & $(0.377)$ & $(0.329)$ & (0.198) & $(0.161)$ \\
\hline \multirow[t]{2}{*}{ LCreditRating } & $-0.0798^{* *}$ & -0.0440 & $-0.0725^{* * *}$ & 0.0199 \\
\hline & $(0.0376)$ & $(0.0323)$ & $(0.0185)$ & $(0.0155)$ \\
\hline \multirow[t]{2}{*}{ Constant } & $-1.662^{* * *}$ & $-2.190 * * *$ & $-1.507^{* * *}$ & $-2.196^{* * *}$ \\
\hline & $(0.0592)$ & $(0.0589)$ & $(0.0297)$ & $(0.0246)$ \\
\hline Observations & 82,510 & 95,244 & 82,510 & 95,244 \\
\hline
\end{tabular}




\section{Chapter 3}

\section{How do firms make capital}

structure decisions when facing

\section{big events?}

\section{The case of Hospital}

\section{Corporation of America (HCA)}

\subsection{Introduction}

In this chapter we investigate the financing behaviour of Hospital Corporation of America (HCA) for the years 1990 to 2013. In the capital structure empirical studies, the scholars examine the positive or negative sign and the significance of the relationship between capital structure and a variable of interest. In such studies, with thousands of firms in the sample, we do not take a close look at the reasons behind the financing behaviour of firms. By taking a closer look at one firm's financing behaviour, not only do we understand the sign of the relationship, but also we figure out how management of firms makes their capital structure decisions and how they decide what to do, and how they do it. To do so, this paper focuses on a specific firm, and is a case study on HCA and its financing behaviour for the years 1990 to 
2013. HCA is an interesting case to look at in detail because of its history and tremendous growth period. Founded in 1986 with just 150 beds, HCA managed to become one of today's largest hospital corporations in the USA. HCA currently manages 165 hospitals and 115 freestanding surgery centres in the USA and the UK, which is the results of it vigorous growth strategy.

This case study helps us to understand how firms make capital structure decisions, how they decide between use of debt or equity financing in different events, how the behavior of the accounting-based data is different from the market-based data, and how the management decisions affect the data. In Chapter 2 of this dissertation, we use a firm's debt ratio as the dependent variable and test the effect of cash flow volatility and other explanatory factors on a firm's use of debt. In this chapter, we investigate the capital structure changes of one corporation, HCA, due to 1) mergers and acquisitions, and divestitures that change a firm's total assets, 2) buybacks and, 3) leveraged buyouts (LBOs) and public offerings that change a firm's ownership.

The empirical studies on dynamics of capital structure explore whether firms' capital structures vary over time and what factors affect the capital structure variations. Frank and Goyal (2007) look at leverage ratios in a study spanning 1900-2002 and found that the aggregate balance sheet data show stable leverage ratios. They state that although leverage ratios had been fluctuating during 1900-2002, firms keep their leverage ratios in narrow bounds. Lemmon et al. (2008) find that variations in firms' leverage ratios are mainly explained by firms' fixed-effects and they tend to keep their leverage ratios as they are (low or high) for more than 20 years. Graham and Leary (2011) also emphasize the influence of firms' fixed-effects on the capital structure. Alternatively, Flannery and Rangan (2006) show that firms have target capital structure and each year they close the gap between the actual and the target capital structure with rapid adjustment speed. Their result is consistent with Jalilvand and Harris (1984) and Leary and Roberts (2005). Fischer, Heinkel and Zechner (1989), Leary and Roberts (2005), and Strebulaev (2007) find that firms have an optimal capital structure range and try to stay in that optimal leverage zone. In addition to the target cap- 
ital structure literature, a recent paper by DeAngelo and Roll (2015) finds temporary capital structure stability.

Along with the dynamics of capital structure studies' diversified results, the way that these studies define their leverage ratios in terms of using market or book values is different. Frank and Goyal (2009) review different arguments on using the book or the market leverage ratios and provide their concluding remarks based on the market leverage ratio. They state the book leverage ratios take into account what took place in the past, not in the present or in the future. The supporters of market leverage ratios claim that the book value of equity is just a balance sheet number and it could be negative in some cases (Welch, 2004). On the other hand, the supporters of the book leverage ratios argue that, first, book leverage ratios are widely employed by firms' managers as a firm's debt is guaranteed by assets already in place, rather than by future growth opportunities (Myers, 1977). Second, large market fluctuations stop firms' managers from making their capital structure decisions based on market value of equity. We consider both stances towards the leverage measures and scrutinize both HCA's market and book leverage ratios' variations independently as well as relative to each other during the same periods of time.

As we know, debt is a part of capital structure and it disciplines managers because making interest payments to debt holders is a firm's obligation. Through this obligation firms can control managers. Although a firm's management team has the option to use the excess cash to decrease the amount of corporate debt or payout dividend, in some cases they prefer to use the excess cash to repurchase the firm's share. Our evidence of how HCA's management team used HCA's excess cash from divestitures to repurchase stock rather than pay off debt or dividends is consistent with Stephens and Weisbach (1998) and Brav, Graham, Harvey and Michaely (2005).

Harford et al. (2009) show that firms have target capital structure and when it comes to finance mergers and acquisitions, over leveraged firms prefer equity financing rather than debt financing to stay close to their target capital structure. Consistent with Harford et al. (2009), our finding shows that HCA's management team kept HCA's leverage ratio in the target leverage 
zone and financed the HCA deals by the combination of debt and equity. Not being over-leveraged let HCA's management team increase the firm's longterm debt. In addition to our findings in this chapter, we empirically test the effect of volatility in acquisition expenditure on a firm's capital structure in chapter 4. All in all, our evidence indicates that

i) HCA's management team used HCA's excess cash from divestitures to repurchase HCA's stocks rather than pay off HCA's debt,

ii) During 1998-2000, the HCA's market leverage ratio was decreasing while the book leverage ratio was increasing,

iii) HCA's market leverage ratio tends to stay in a target leverage zone, and

iv) in some years HCA's management team used the book leverage ratio as a tool to keep the market leverage ratio inside a target leverage zone.

This chapter proceeds as follows: Section 3.2 reviews the history of Columbia Hospital Corporation (CHC) and HCA. Section 4.3 reviews the data, constructs the variables, and shows the market and book leverage ratios' decompositions. Section 3.5 reports the findings of the paper. Section 3.6 provides discussion on the findings and presents concluding remarks.

\subsection{History of Columbia Hospital Corpora- tion ( $\mathrm{CHC}$ ) and Hospital Corporation of America (HCA) ${ }^{1}$}

\subsubsection{CHC}

CHC was founded in 1987 by Richard Scott and Richard Rainwater. Scott started his journey to create a national healthcare provider network by teaming up with Rainwater who was a director on HCA's board. For their first move, Columbia's management team purchased two hospitals in Texas that were poorly managed and reformed the operations of these hospitals. After-

\footnotetext{
${ }^{1}$ Readers may refer to "International Directory of Company Histories" as a general source for the history of CHC and HCA.
} 
wards, they formed a limited partnership with a group of physician investors and named it El Paso Healthcare System, Ltd. (EPHS). The new partnership acquired the two Columbia owned hospitals and some other diagnostic centres owned by physicians in exchange for EPHS shares. Columbia's growth continued by purchasing two medical centres and consolidating them with EPHS hospitals through transferring these two medical centres' equipment and patients and selling their buildings. Columbia's management team pursued its expansion by opening Sun Tower Behavioral Healthcare in 1988, which increased the Columbia average daily census. The EPHS growth plan was a success between 1988 and 1990. EPHS management team increased its total average daily census to 303 from 174 patients and EPHS revenue jumped to $\$ 135$ million in 1990 from $\$ 113$ million in 1989 (Pederson, 2001).

Scott and his team's expansion plans were not limited to EPHS. Columbia continued its growth and entered other markets by purchasing nearly bankrupt hospitals in other states. They followed the same strategy as before, forming limited partnerships with physician investors. For their next steps, Columbia merged with Smith Laboratories and its subsidiary Sutter Corp in 1990 which led Columbia to go public, and then in a landmark joint venture Columbia's management team built a $\$ 50$ million hospital with Medical Care America of Dallas. ${ }^{2}$ Columbia's management team chased their growth strategy by acquiring local hospitals from 1990 to 1992. By the end of 1992 the number of Columbia's hospitals increased to 24 (Pederson, 2001).

Scott shook up the general medical and surgical hospital industry twice between 1993 and 1994. The first big change in Columbia Corporation occurred in 1993, when Columbia merged with Galen Health Care and renamed itself Columbia Healthcare Corporation (COL) (Reuters News, 10 June 1993). This $\$ 3.2$ billion stock swap merger increased Columbia's network to 94 hospitals in 19 states, as well as Switzerland and England. Not long after its merger with Galen Health Care, in October 1993 Columbia shocked the industry again by announcing a $\$ 5.7$ billion stock swap merger with HCA (The New York Times, 3 October 1993). The merger created the

\footnotetext{
${ }^{2}$ Columbia had three more deals in 1990. It acquired HEI Corporation for $\$ 22$ million in cash, Reef Hospital for $\$ 18$ million in cash and notes and then, Southside Community Hospital for $\$ 5$ million.
} 
$\$ 10.25$ billion Columbia/HCA Healthcare Corporation, the largest hospital chain in the USA with its 190 hospitals in 26 states, as well as Switzerland and England.

\subsubsection{HCA}

Founded in 1968 by a small group including Dr. Thomas Frist, Sr., his son Dr. Thomas Frist, Jr. and Jack Massey, HCA was one of America's first hospital companies. Dr. Thomas Frist, Sr. called "the father of modern for-profit hospital system" by the New York Times (1998), emphasized the role of Dr. Thomas Frist, Jr. his son, on the establishment of HCA. Gilpin (January 8, 1998, part 1) reported:

In an oral history on file at the American Hospital Association, the elder Dr. Frist quoted his son as having said: "Banks are together, filling stations are together, grocery stores are together, why can't we put hospitals together? Economy of scale means so much."

HCA's first initial public offering (IPO) was conducted in 1969 with 11 hospitals on the New York Stock Exchange. By the end of 1969, HCA increased the number of its hospitals to 26.

The 1970s and the early 1980s had been the golden years for HCA due to remarkable growth by acquiring hundreds of hospitals across the US. During this period the HCA's management team acquired General Care Corporation, Hospital Affiliates International, General Health Services and Health Care Corporation, which increased the number of HCA hospitals (owned and managed) to 349. In 1987, Dr. Thomas Frist, Jr. took over as HCA's chief executive officer after which HCA spun off Healthtrust, one of its subsidiaries with 104 hospitals. One year later, in 1988, HCA went private by a $\$ 5.1$ billion management buyout followed by a successful IPO in 1992 (HCA History, 2015).

Frist, Jr., who designed HCA's private LBO in 1988, considered the early 1990s's serious reforms in the health industry as a growth opportunity and tried to team up with HCA's biggest competitors. His first target was Galen 
Health Care, which was a result of the early 1993 Humana spin off. However, Frist would rather use HCA's cash to repay HCA's debt which was increased as a result of $1988 \mathrm{LBO}$. In the meantime, Scott the CEO of Columbia, proposed a merger to Galen, and Galen took it. Frist, who has been watching Columbia, found this to be a good opportunity to merge with Columbia and build the nation's largest hospital. In October 1993, HCA and CHC announced a tax-free stock-for-stock merger agreement which created a $\$ 10$ billion corporation (Norris, October 6, 1994). ${ }^{3}$ The new corporation was called Columbia/HCA Healthcare Corporation and its board of directors included 4 HCA current directors and Columbia's 11 directors (The New York Times, 3 October 1993).

\subsubsection{Columbia/HCA Healthcare}

In October 1993, Columbia and HCA jointly announced their $\$ 5.7$ billion stock swap merger. The merger was completed in February 1994 and made a $\$ 10$ billion corporation (Flower, 1995). The newly formed company was renamed the Columbia/HCA Healthcare Corporation, Scott was named CEO, and Frist, Jr. became chairman. Pursuing Scott's joint ventures and acquisitions strategies, Columbia/HCA acquired the Cedars Medical Center of Miami which was followed by purchasing Medical Care America, Inc. in May 1994 (Myerson, May 24, 1994). Columbia/HCA also created joint ventures with several teaching hospitals and medical schools. ${ }^{4}$ Scott's next big step was to acquire Healthtrust for $\$ 5.6$ billion which was announced in October 1994 and was completed in April 1995 (Flower, 1995). The Healthtrust merger increased Columbia/HCA hospitals to 311 (Associated Press, October 05, 1994). Along with the Healthtrust merger, Columbia/HCA acquired several other hospitals from 1994 to $1995 .^{5}$ Scott also announced acquisition of several hospitals in different states. Columbia/HCA growth continued

\footnotetext{
${ }^{3}$ The merger was the seventh-largest merger since 1981.

${ }^{4}$ For example the University of Louisville, University of Miami, Emory University, Tulane University, the Medical College of Virginia, and the Medical University of South Carolina (Columbia/HCA Healthcare Corporation, 1996).

${ }^{5}$ Including St. Francis Hospital of Charleston, Colorado-based Rose Healthcare System, West Virginia, and Angelo Community Hospital of San Angelo, Texas (Pederson, 2001).
} 
from 1996 through 1997 by several acquisitions. ${ }^{6}$

The company's growth strategy stopped when a Columbia/HCA facility in El Paso became the subject of a federal healthcare fraud investigation in March 1997 (Reuters News, March 21, 1997c). Following the fraud investigation, Scott was forced to resign in July 1997 and Frist, Jr., who was the CEO of HCA Corporation before its merger with Columbia, was named the CEO. Scott was paid $\$ 9.88$ million to settle and kept 10 million shares of Columbia/HCA stock worth over $\$ 350$ million (Reuters News, July 26, 1997b).

The new CEO, who was against Scott's growth strategies, immediately guided Columbia /HCA in a new direction. He announced Columbia/HCA's new strategy in August 1997. Frist stopped working with physicians who owned Columbia/HCA shares, as he believed that being a physician and having ownership of the company made physicians bring the money-making patients to the company and refer the other ones to competitors. Another new strategy was selling Columbia/HCA's home care division, which was investigated during the fraud investigation (Reuters News, August 7, 1997a). ${ }^{7}$

As a result of Frist's modifications, Columbia/HCA became smaller in size and more focused in markets. By January 1999 the corporation sold more than 33 surgery centres, 44 hospitals and all its home care related centres. Frist changed the name of the corporation back to HCA Inc. in 1999. In 2002, HCA's fraud case was settled with a $\$ 1.7$ billion payment which made it the largest fraud settlement inUSAhistory (Department of Justice, June $26,2003)$.

This was not the end of HCA's lawsuit story. In July 2005, two weeks before reporting HCA financial results to the market, senator Frist (Frist, Jr.'s brother) sold all his HCA shares, as did other executives. Two weeks later, after the disappointing financial results, HCA was sued by shareholders claiming that the company increased the price of stocks by false claims about HCA's profit. The case was settled in 2007 by paying $\$ 20$ million to the

${ }^{6}$ Central Health Services, Inc. was acquired in November 1996 (PRNewswire, November 5, 1996), and Value Health, Inc. merger was completed in August 1997 (BIIDEP, July 18, 1997).

${ }^{7} \mathrm{HCA}$ was shrinking in size for the years 1998 to 2000. 
shareholders (Modern Healthcare, August 15, 2007).

In November 2006, a group of investors, including the Frist family, acquired the company for $\$ 31.6$ billion, making HCA privately held again after its first public offering in 1992. The company was privately held during 2006 through 2011, and went public in March 2011. HCA currently manages 165 hospitals and 115 freestanding surgery centres in the USA and the UK (HCA History, 2015).

\subsection{Sample and Variable Construction}

\subsubsection{Sample}

We study CHC and HCA from 1990 through 2013. We obtain data from different databases. For the stock data we use the Compustat CRSP Daily Stock database and for the debt issuance data we use the Bloomberg database. We also obtain $\mathrm{HCA}$ and $\mathrm{CHC}$ news releases from Factiva and their financial statements or any other reports or news from their SEC filings.

Due to the merger of HCA and CHC in 1994, no data are available for HCA for 1993; the 1993 and 1992 reported data in Compustat for HCA are the CHC data. ${ }^{8}$ It looks like HCA and CHC merged in 1994, and then Compustat goes back and overwrites the data in the years 1993 and 1992 based on CHC data. Despite overwriting HCA data on 1992, we find both HCA and CHC data for the years 1990 to 1992. In addition, for the years when HCA was privately held (2006-2011), no market data are available and we obtain the book data from the HCA's annual reports.

\subsubsection{Variable Construction}

To study variations in HCA's capital structure over time, we use market and book long-term leverage ratios. We define this study's variables as follows:

\footnotetext{
${ }^{8}$ We could not find HCA annual reports before 1994, therefore for the years 1990-1994, we trust the Compustat database; for 1994-2013, we check both annual reports and the Compustat data.
} 
i) $\left(L_{t}\right)_{\text {Market }}$ is the ratio of long-term market debt over the total long-term debt plus market value of equity at $t .^{9}$

$$
\left(L_{t}\right)_{\text {Market }}=\frac{D_{t}}{D_{t}+N_{t} * P_{t}}
$$

ii) $\left(L_{t}\right)_{\text {Book }}$ is the ratio of total long-term debt over total long-term debt plus common share holder equity at $t$.

$$
\left(L_{t}\right)_{B o o k}=\frac{D_{t}}{D_{t}+c e q_{t}}
$$

iii) $D_{t}$ is the firm's long-term debt at $t .^{10}$

iv) $P_{t}$ is the price per share at $t .^{11}$

v) $N_{t}$ is the number of shares outstanding at $t .^{12}$

vi) $C e q$ is the the common/ordinary equity and $C e q=c s t k+c a p s+r e-$ tstk, where cstk is common /ordinary stock (capital), caps is capital surplus/share premium reserve, re is retained earnings and tstk is total treasury stock.

vii) SHEquity is the market value of shareholders' equity and SHEquity $=P_{t}^{*} N_{t}$.

viii) Diffshrout is the number of the buy-backed shares and Diffshrout= $N_{t-1}-N_{t}$.

\subsubsection{Decomposition of leverage measure}

Generally, the capital structure of a firm is measured by its leverage ratio, defined as debt over debt plus equity of a firm. By this definition any variation in the numerator or the denominator changes the capital structure. To

\footnotetext{
${ }^{9} t$ can represent both year and day.

${ }^{10}$ Compustat item dltt.

${ }^{11}$ Compustat item prec_f.

${ }^{12}$ Compustat item csho.
} 
find how public offerings, share buyback programs, LBOs, and mergers and acquisitions that deal with long-term debt which can affect the capital structure measure, we decompose the market and book leverage measures into different components following Fahlenbrach and Stulz (2009). ${ }^{13}$ In Section 2.3.2 of Chapter 2 we construct several market and book debt ratios. For this chapter, we use the narrowest definition of debt, which includes only long-term debt:

$$
L_{t}=\frac{D_{t}}{D_{t}+E_{t}}
$$

where $L_{t}$ is either market or book long-term leverage ratio, $D_{t}$ is the longterm debt value and $E_{t}$ is the equity value of a firm at $t . E_{t}$ is SHEquity = $P_{t} N_{t}$ for market leverage ratio where $P_{t}$ is the price per share and $N_{t}$ is the number of shares outstanding, and $E_{t}=C e q_{t}$ for book leverage ratio, where $\mathrm{Ceq}$ is the common/ordinary equity. ${ }^{14}$ Recalling from Section 3.3.2,

$$
\begin{aligned}
& \left(L_{t}\right)_{\text {Market }}=\frac{D_{t}}{D_{t}+P_{t} N_{t}} \\
& \left(L_{t}\right)_{\text {Book }}=\frac{D_{t}}{D_{t}+C e q_{t}}
\end{aligned}
$$

where $\left(L_{t}\right)_{\text {Market }}$ is the market leverage ratio and $\left(L_{t}\right)_{\text {Book }}$ is the book leverage ratio.

By definition, the change in leverage ratio from $t$ to $t+1\left(\Delta L_{t}\right)$ is:

$$
\Delta L_{t}=\frac{D_{t+1}}{D_{t+1}+E_{t+1}}-\frac{D_{t}}{D_{t}+E_{t}}
$$

\footnotetext{
${ }^{13}$ Fahlenbrach and Stulz (2009) look at the separate effects of changes in numerator and denominator of the CEO's percentage ownership stake. We use their model to show the separate effects of total assets and total liabilities on leverage changes.

${ }^{14}$ Compustat item $C e q=c s t k+c a p s+r e-t s t k$, where $c s t k$ is common /ordinary stock (capital), caps is capital surplus/share premium reserve, re is retained earnings and tstk is total treasury stock.
} 


$$
\begin{aligned}
\Delta L_{t} & =\frac{D_{t+1}}{D_{t+1}+E_{t+1}}-\frac{D_{t+1}-\Delta D}{D_{t}+E_{t}} \\
& =\frac{\Delta D}{D_{t}+E_{t}}+\frac{D_{t+1}\left(D_{t}+E_{t}\right)}{\left(D_{t+1}+E_{t+1}\right)\left(D_{t}+E_{t}\right)}-\frac{D_{t+1}\left(D_{t+1}+E_{t+1}\right)}{\left(D_{t+1}+E_{t+1}\right)\left(D_{t}+E_{t}\right)} \\
& =\frac{\Delta D}{D_{t}+E_{t}}-\frac{\left(D_{t+1}\right)\left(-D_{t}+D_{t+1}-E_{t}+E_{t+1}\right)}{\left(D_{t+1}+E_{t+1}\right)\left(D_{t}+E_{t}\right)} \\
& =\frac{\Delta D}{D_{t}+E_{t}}-\frac{\left(D_{t+1}\right) \Delta D}{\left(D_{t+1}+E_{t+1}\right)\left(D_{t}+E_{t}\right)}-\frac{\left(D_{t+1}\right) \Delta E}{\left(D_{t+1}+E_{t+1}\right)\left(D_{t}+E_{t}\right)} \\
& =\Delta D\left(\frac{1}{D_{t}+E_{t}}-\frac{\left(D_{t+1}\right)}{\left(D_{t+1}+E_{t+1}\right)\left(D_{t}+E_{t}\right)}\right)-\frac{\left(D_{t+1}\right) \Delta E}{\left(D_{t+1}+E_{t+1}\right)\left(D_{t}+E_{t}\right)} \\
& =\Delta D\left(\frac{D_{t+1}+E_{t+1}-D_{t+1}}{\left(D_{t+1}+E_{t+1}\right)\left(D_{t}+E_{t}\right)}\right)-\frac{\left(D_{t+1}\right) \Delta E}{\left(D_{t+1}+E_{t+1}\right)\left(D_{t}+E_{t}\right)} \\
& \left.=E_{t+1} \frac{\Delta D_{t+1}}{\left(D_{t+1}+E_{t+1}\right)\left(D_{t}+E_{t}\right)}-D_{t+1}+E_{t+1}\right)\left(D_{t}+E_{t}\right)
\end{aligned}
$$

where $\Delta D=D_{t+1}-D_{t}$, and $\Delta E=E_{t+1}-E_{t}$, and for market leverage ratio,

$$
\begin{aligned}
& \Delta E=E_{t+1}-E_{t} \quad \text { where } E_{t}=P_{t} N_{t} \\
& \Delta E=P_{t+1} N_{t+1}-P_{t} N_{t} \\
& \Delta E=P_{t} \Delta N_{t}+N_{t} \Delta P_{t}+\Delta P_{t} \Delta N_{t}
\end{aligned}
$$

By plugging $\Delta E=P_{t} \Delta N_{t}+N_{t} \Delta P_{t}+\Delta P_{t} \Delta N_{t}$ into the last line of Equation $(3.2)$,

$$
\begin{aligned}
\Delta\left(L_{t}\right)_{\text {Market }} & =P_{t+1} N_{t+1} \frac{\Delta D}{\left(D_{t+1}+P_{t+1} N_{t+1}\right)\left(D_{t}+P_{t} N_{t}\right)} \\
& -D_{t+1} P_{t} \frac{\Delta N}{\left(D_{t+1}+P_{t+1} N_{t+1}\right)\left(D_{t}+P_{t} N_{t}\right)} \\
& -D_{t+1} N_{t} \frac{\Delta P}{\left(D_{t+1}+P_{t+1} N_{t+1}\right)\left(D_{t}+P_{t} N_{t}\right)} \\
& -D_{t+1} \frac{\Delta P \Delta N}{\left(D_{t+1}+P_{t+1} N_{t+1}\right)\left(D_{t}+P_{t} N_{t}\right)},
\end{aligned}
$$

Equation (3.4) shows changes in market leverage are related to variations in 
debt, the number of shares outstanding, and price per share of a firm. The first term explains the changes in leverage due to variations in long-term debt $(\Delta D)$, the second term explains the changes in leverage due to variations in the number of shares outstanding $(\Delta N)$, the third term explains the changes in leverage due to variations in price per share $(\Delta P)$, and the fourth term explains the changes in leverage due to the interaction between variations in price per share and the number of shares outstanding $(\Delta P \Delta N)$. The effects of the number of shares outstanding and share price are trivial for small changes in the number of shares outstanding and price but are remarkable in the following two circumstances: 1) when a firm repurchases or offers a large number of shares; and 2) when there is a notable increase (decrease) in share price. Therefore, we study different causes that change long-term debt, the number of shares outstanding, and the price per share to scrutinize variations in HCA's market leverage ratios over time.

\section{insert Figure 1}

Figure 1 plots the first to the fourth terms of Equation (3.4). As can be seen in the figure, the fourth term, which is the interaction between changes in the share price and the number of shares outstanding, is close to zero. Therefore, we can simplify Equation (3.4) as:

$$
\begin{aligned}
\Delta\left(L_{t}\right)_{\text {Market }} & =P_{t+1} N_{t+1} \frac{\Delta D}{\left(D_{t+1}+P_{t+1} N_{t+1}\right)\left(D_{t}+P_{t} N_{t}\right)} \\
& -D_{t+1} P_{t} \frac{\Delta N}{\left(D_{t+1}+P_{t+1} N_{t+1}\right)\left(D_{t}+P_{t} N_{t}\right)} \\
& -D_{t+1} N_{t} \frac{\Delta P}{\left(D_{t+1}+P_{t+1} N_{t+1}\right)\left(D_{t}+P_{t} N_{t}\right)}
\end{aligned}
$$

To find book leverage ratio variations, we plugged $\Delta E=\Delta C e q=C e q_{t+1}$ - Ceq into the last line of Equation (3.2),

$$
\begin{aligned}
\Delta\left(L_{t}\right)_{\text {Book }} & =C e q_{t+1} \frac{\Delta D}{\left(D_{t+1}+C e q_{t+1}\right)\left(D_{t}+C e q_{t}\right)} \\
& -D_{t+1} \frac{\Delta C e q}{\left(D_{t+1}+C e q_{t+1}\right)\left(D_{t}+C e q_{t}\right)} .
\end{aligned}
$$


Equation (3.6) shows changes in book leverage are due to changes in longterm debt $(\Delta D)$ and changes in common/ordinary equity $(\Delta C e q)$. Therefore, we study different causes that change long-term debt and common/ordinary equity to study variations in book leverage ratios over time.

insert Figure 2

Figure 2 plots the first and second terms of Equation (3.6). The figure shows that the effect of the first term (variations in the long-term debt) is more than the second term (variations in the shareholders' equity) on the book leverage ratio changes.

insert Figure 3

Figure 3 plots the changes in the HCA's market leverage ratio of Equation (3.4), and the changes in the HCA's book leverage ratio of Equation (3.6). The figure shows that the changes in market and book leverage ratios $(\Delta L=$ $\left.L_{t+1}-L_{t}\right)$ were bounded between -0.2 and +0.2 for the years 1993-2004, no public offerings or LBOs period.

Overall, considering the fact that the changes in long-term debt are due to both debt issuance and debt retirement, the dynamics of capital structure (taking into account both market and book leverage ratios) occur due to variations in the number of shares outstanding either through the stock buyback program (decrease in the number of shares outstanding - equity repurchases) or share offerings (increase in the number of shares outstanding - equity issuance), share price increase or decrease, changes in common/ordinary equity, debt issuance and debt retirement. ${ }^{15}$

\subsection{Industry Leverage}

Before starting with the changes in the HCA capital structure, we check how the capital structure changes of the firms in the "Hospitals" industry compare with the variations in the median industry leverage. In Chapter 2 we

\footnotetext{
${ }^{15}$ Debt retirement includes both calling the callable bonds before their maturity date and debt repayment at maturity.
} 
use median industry leverage as an explanatory variable and show that there is a statistically significant and positive relationship between the median industry leverage and the debt ratio. In this chapter, we want to see how many of the deviations in debt ratios are in line with the changes in industry leverage trends versus the firms' effect.

First, we obtain annual data from the Compustat-CRSP merged data base for the years 1990 to 2013 and keep theUSAfirms within the "Hospitals" industry that is SIC codes 8060 to 8069 . Then, we define two variables, 1) Industry $M D R$ which is the median industry leverage using the $L_{t_{M} \text { arket }}$ ratio and 4-digit SIC code, and 2) IndustryBDR which is the median industry leverage using $L_{t B o o k}$ ratio and 4-digit SIC code. To find out how the variations in industry leverage affect the variations in debt ratios, we estimate:

$$
\Delta L_{i, t}=\beta_{1} \Delta \text { IndustryLEV } V_{i, t}+\epsilon_{i, t}
$$

where, $\Delta$ is the first difference operator, $L_{i, t}$ represents either market or book debt ratio of firm $i$, Industry $L E V_{, i t}$ is either market or book industry leverage and $\epsilon_{i, t}$ represents the part of the variation in $\Delta L_{i, t}$ which has not been explained by the $\Delta$ IndustryLE $V_{i, t}$.

Using the OLS model in Stata, we then predict $\Delta L_{i, t}$ and the residual $\epsilon_{i, t}$. Considering $\Delta$ IndustryLEV $V_{i, t}$ as an $\mathrm{x}$-axis variable, we plot the predicted $\Delta L_{i, t}$ and $\epsilon_{i, t}$ where the x-axis shows the 20-quantile of $\Delta \operatorname{Industry} L E V_{i, t}$.

\author{
insert Figure 4 \\ insert Figure 5
}

As can be seen in Figures 4 and 5, the residuals, which are the firms specific characteristics, are quite large in both figures. We can also see that the residuals match the $\Delta L_{t \text { Market }}$ or $\Delta L_{t \text { Book }}$ better than the predicted $\Delta L_{t \text { Market }}$ or $\Delta L_{t \text { Book }}$ values. Therefore, we conclude that most of the variations in either market or book debt ratios are the result of the firm's effects rather than the industry effects. 


\subsection{Findings}

As discussed in Section 3.3.3, there are several causes that can change the capital structure of a corporation. In this section, we explain each of these causes and how they affect the CHC, HCA and Columbia/HCA capital structure. We choose six events by which a firm's capital structure can be changed. We study HCA's capital structure changes as a result of 1) mergers and acquisitions (M\&As) and divestitures, 2) buybacks, and 3) LBOs and public offerings.

In this section we first study HCA's market and book leverage ratios' behaviours. Then, we explore the effects of the events on HCA's capital structure. We first discuss HCA's M\&As as they mostly took place from 1994 up to 1998, followed by the 1998 to 2000 HCA divestitures as well as buybacks which led to a smaller but more focused HCA. Then, we discuss the LBO in 2006 followed by 2011 IPO.

\subsubsection{Market versus Book Leverage Ratio}

insert Table 1

Table 1 shows the components of HCA's book and market leverage ratios from 1990 to 2005 and from 2011 to 2013 . There are three sets of accounting information in this table. The first set is HCA's data from 1990 to 1992. The second set is CHC's accounting information from 1990 to 1992. The third set includes the consolidated accounting information of HCA and Columbia in 1993 one year before their merger, and the accounting information of the merged Columbia/HCA from 1994 to 2013. The common component in the market and the book leverage ratios is the long-term debt $(D)$. The main components of the book leverage ratio are common shareholders' equity or deficit $(c e q)$ where, $c e q=c s t k+$ caps + re - tstk. cstk is the common stock, caps is the capital surplus, re is the retained earnings, and tstk is the treasury stock. ${ }^{16}$ All these components go into the calculation of either book or market leverage ratios.

\footnotetext{
${ }^{16} \mathrm{HCA}$ 's $t$ stk is equal to zero for the years 1990 to 2013.
} 
insert Figure 6

Figure 6 shows HCA's annual market and book leverage ratios from 1990 to 2013. Annual market leverage ratios are missing from 1990 to 1992 and from 2007 through 2011, when HCA was privately held. The book leverage ratios are available for all years from 1990 to 2013 as the book leverage ratio components can be found in annual reports. Figure 6 shows that HCA's market leverage ratio had been between 0.2 and 0.4 from 1992 up to 2006, and has been decreasing since the 2011 IPO to get to the 0.2 to 0.4 zone. This HCA market leverage ratio behaviour could be seen as HCA's tendency to stay in a target market leverage ratio zone. The decreasing trend of the leverage ratio after a big jump is consistent with Denis and McKeon (2012). In addition, Figure 6 shows that HCA's market and book leverage ratios appear to follow a similar trend from 1992 to 2006 except for the years 1998 to 2000. The figure also shows neither leverage ratio experienced dramatic fluctuations from 1992 to 2006. Then, the book leverage ratio increased drastically in 2006 as a result of the LBO. ${ }^{17}$

Figure 6 also shows HCA's book debt ratio increased to 1.67 after the 2006 LBO, and has been more than one since then. The unusual HCA book leverage ratio is a result of the negative common equity in its balance sheets after the 2006 LBO. ${ }^{18}$ When the group of private equity firms and the Frist family acquired HCA in 2006, they paid the total market value of assets which was far more than HCA's book value of assets. Generally, LBOs are financed by a large amount of debt. In HCA's case, more than $75 \%$ of the $\$ 21.5$ deal (excluding HCA's $\$ 11.7$ billion existing debt) was financed by borrowings and the rest was financed by cash.

$$
\begin{aligned}
& \text { BookValueof Assets = Liabilities }+ \text { CommonEquity } \\
& \text { CommonEquity = BookValueof Assets }- \text { Liabilities }
\end{aligned}
$$

Note that here the value of liabilities is equal to the sum of $75 \%$ of the market value of assets and HCA's current debt. Therefore, the amount of

\footnotetext{
${ }^{17}$ Annual market leverage ratios are not available for the years 2006 to 2011 when HCA was privately held.

${ }^{18}$ Book value of equity could be negative sometimes (Welch, 2004).
} 
HCA's liability is much greater than its book value of assets, which makes the common equity (ceq) of HCA a negative number. When $c e q$ is negative, it makes the numerator of the book leverage ratio greater than its denominator and makes the book leverage ratio greater than one.

Baker and Wurgler (2002)'s market timing theory suggests that historical market value significantly affects a firm's current capital structure. In other words, firms' managers repurchase the stock when they perceive their stock is undervalued, and alternatively they tend to issue equity rather than debt when they believe their stock is overvalued. The market value measure of leverage is a function of share price, the number of shares outstanding, and long-term debt which could be affected by both outsiders' valuation as well as a firm's decision to signal information to the market. On the other hand, the book measure of leverage is a function of long-term debt and common/ordinary equity which is not affected by the variations in market share price or the number of shares outstanding and is only affected by a firm's decisions. Therefore, in our discussion about capital structure changes we should consider the differences in market and book leverage ratios and if they will be changed by firms' managers' decisions, or by the market effects due to outsiders' valuation. If the management team of a firm intentionally decides to vary the firm's leverage ratio, the managers may use individual market or book leverage ratio components listed in Table 1 to change the market or book leverage ratios. By looking at each component's behavior when there is an upward or downward jump in the leverage ratios, we understand what exactly $\mathrm{HCA}$ did in order to manage its leverage ratios for the years 1990-2014.

\section{insert Figure 7}

Figure 7 plots HCA annual long-term debt $(D)$ and retained earnings (re) from 1990 to 2013. Along with the jump in HCA's leverage in 2006, the total long-term debt $(D)$ increased and the retained earnings $(r e)$ decreased. These two components had not been changing radically between 1993 and 2006 but then experienced considerable change due to the 2006 LBO. The upward trends of HCA's long-term debt $(D)$ and downward trend of its retained 
earnings (re), along with the fairly stable trends of the other market and book leverage components, show that HCA's managers changed long-term debt and retained earnings more than other components to manage HCA's leverage ratio and finance 2006 buyout.

\subsubsection{Changes in a Firm's Total Assets}

In this section we study a firm's financing behavior in events like M\&As and divestitures, which in fact affect a firm's total assets. M\&A is a term referring to the act of several firms consolidating either by joining each other or a firm being purchased by another firm. In a merger, two firms combine to jointly form a new corporation. In an acquisition, one firm will be purchased by another firm. On the other hand, divestiture is a technique by which a firm jettisons a business unit or a part of it through exchange, sale or in some other way, in order to focus on its core competencies. A spinoff is a form of divestiture by which the parent company distributes shares of its subsidiaries to the parent company shareholders. Then, shares of the newly independent spun off corporation will be publicly traded in the market.

\section{insert Table 2}

Table 2 reports some of the literature on M\&As and divestitures. Kummer and Steger (2008) state firms' tendency to grow, outsiders' pressure on firms to grow, elimination of competition, and the history of other firms' successful M\&As as reasons why firms tend to merge with other firms or to acquire other firms. Firms continuously search for growth by which they can create value. Therefore, they follow any value creating tactics like M\&As to have larger market shares and gain more profit. Although, firms' managers are supposed to follow value creating M\&As, Morck, Shleifer and Vishny (1990) find that a firm's value may be reduced as a result of an acquisition which has been derived by managerial objectives, not shareholders interests.

This section answers the question "how do mergers and acquisitions affect a firm's capital structure?" DeAngelo et al. (2011) study the dynamics of capital structure and find that firms permanently diverge from their target capital structure to finance their investments. They show that firms with 
high investment shock volatility keep their leverage low to preserve their debt capacity to meet their future financing needs. The DeAngelo et al. (2011) results suggest that firms consider the debt issuance as a source of financing to invest in opportunities like M\&As. On the other hand, Harford et al. (2009) find that firms have target capital structure and when it comes to financing M\&As, over leveraged firms prefer equity financing to debt financing to stay close to their target capital structure. Uysal (2011) shows that over-leveraged firms are less likely to initiate acquisitions; managers in such firms try to re-balance their capital structure if they are aware of a future acquisition opportunity. The Uysal (2011) result is in line with the DeAngelo et al. (2011) finding, as they both suggest that firms preserve their debt capacity to meet future financing needs. As can be seen in Table 2 and from the literature, there are several factors affecting a firm's decision to initiate a M\&A and how to finance it. In this section we explain how M\&As change HCA's capital structure and how HCA decides about financing its M\&As taking account of its circumstances?

When it comes to acquiring a company, a firm with low debt, a strong cash flow and substantial assets is a good target. By acquiring a target firm, the acquirer capital structure varies due to 1) long-term debt or equity issuance in order to finance the deal, 2) increase in the total debt and the total equity of the acquirer due to consolidation of the acquirer and the target firm. When two firms combine, the newly formed firm's total book assets and long-term debt will be the sum of the total book assets value and the sum of the total long-term debt value of the two combined firms, respectively. Besides, the market value of the newly formed firm will be the new number of shares outstanding times the new share price. The leverage decomposition in Section 3.3.3 shows that a firm's capital structure changes due to the capital 
structure component variations as

$$
\begin{aligned}
\Delta\left(L_{t}\right)_{\text {Market }} & =P_{t+1} N_{t+1} \frac{\Delta D}{\left(D_{t+1}+P_{t+1} N_{t+1}\right)\left(D_{t}+P_{t} N_{t}\right)} \\
& -D_{t+1} P_{t} \frac{\Delta N}{\left(D_{t+1}+P_{t+1} N_{t+1}\right)\left(D_{t}+P_{t} N_{t}\right)} \\
& -D_{t+1} N_{t} \frac{\Delta P}{\left(D_{t+1}+P_{t+1} N_{t+1}\right)\left(D_{t}+P_{t} N_{t}\right)} \\
\Delta\left(L_{t}\right)_{\text {Book }} & =C e q_{t+1} \frac{\Delta D}{\left(D_{t+1}+C e q_{t+1}\right)\left(D_{t}+C e q_{t}\right)} \\
& -D_{t+1} \frac{\Delta C e q}{\left(D_{t+1}+C e q_{t+1}\right)\left(D_{t}+C e q_{t}\right)} .
\end{aligned}
$$

Equation (3.5) shows that M\&As might change the market leverage by causing variations in i) the long-term debt $(D)$, ii) the number of shares outstanding $(N)$, and iii) the price per share $(P)$. Alternatively, Equation (3.6) shows that M\&As might change the book leverage ratio due to variations in i) the long-term debt $(D)$, ii) the common/ordinary stock (cstk), iii) the capital surplus/share premium reserve (caps), and iv) the retained earnings (re). ${ }^{19}$

To discuss HCA's mergers and acquisitions, we divide the period of this study into two periods: first, 1990 to 1994 which is the period before merging with Columbia (the mega merger); and second, 1994 to 1997 which is the period after the mega merger and before the 1997 fraud investigation. The divestitures period is the period after the fraud investigation, Scott's resignation, and modification in HCA's strategy.

The early 1990s' serious reform in the health care industry was considered to be a great growth opportunity for the main players in the USA health care industry; as a result, the biggest competitors tried to team up with each other to take advantage of the synergistic effect of their mergers. First, HCA went public in a successful IPO in 1992. One year later, CHC merged with Galen Health Care in a $\$ 3.2$ billion stock swap merger in early 1993 and formed Columbia Healthcare Corporation (COL). Then, HCA and COL jointly an-

\footnotetext{
${ }^{19}$ If two firms have quite similar book leverage ratios, the book leverage ratio of the newly formed firm will be close to their book leverage ratios.
} 
nounced the largest merger in the history of HCA which was completed in 1994 and created the $\$ 10.25$ billion Columbia/HCA Healthcare Corporation, the largest hospital chain in the USA (Flower, 1995).

Figure 6 shows that from 1990 to 1994 HCA's book leverage ratio was almost halved from 0.93 to 0.49 , despite the large debt issuance in 1993. The reason is HCA's 1992 IPO after its management buyout in 1988, along with the 1993 debt reduction which is close to the 1993 debt issuance. The figure also shows that HCA's market debt ratio remained largely unchanged after its merger with Columbia, whereas HCA's book debt ratio slightly decreased from 0.49 to 0.43 in 1994 after the merger. ${ }^{20}$

Figure 3 does not show extreme changes in HCA's market leverage ratio for 1994 compared to that for 1995. Recalling Equation (3.5) terms and referring to Figure 1, we can see that the small variation in the market leverage ratio is due to the fact that the increase in the first term of Equation (3.5) is offset by an increase in the third and second terms of Equation (3.5). Note that the second and the third terms of Equation (3.5) have negative signs. Therefore, the market leverage ratio remained largely unchanged. Figure 3 also plots a small increase in HCA's book leverage ratio in 1994 compared to 1995. Recalling Equation (3.6) terms and referring to Figure 2, we can see that the variation in Equation (3.5) is due to the fact that a part of the increase in the first term of Equation (3.6) is offset by an increase in the second term of Equation (3.6). ${ }^{21}$ Therefore, the book leverage ratio did not change as much as the amount of debt increased in 1994.

Considering the available market data and the fact that HCA is not over leveraged, our conjecture is that, consistent with Harford et al. (2009), HCA's management team kept HCA's leverage ratio in the target leverage zone and financed the deal by the combination of debt and equity. Not being over leveraged allowed HCA's management team to increase the firm's long-term

\footnotetext{
${ }^{20}$ The existence of no considerable variation in market leverage could be due to the fact that the reported accounting information for the year 1993 is extracted from the consolidated Columbia and HCA financial statements, and not HCA's performance on its own in 1993.

${ }^{21}$ Note that the second term of Equation (3.6) has a negative sign.
} 
debt. ${ }^{22}$ Figure 7 shows that HCA's long-term debt had a decreasing trend from 1990 to 1992. Therefore, we can also say that, consistent with DeAngelo et al. (2011) and Uysal (2011), HCA decreased its level of debt to preserve its debt capacity to meet future financing needs.

In 1994, HCA and COL announced their mega merger after which Scott became the $\mathrm{CEO}$ of $\mathrm{COL} / \mathrm{HCA}$. The new HCA's CEO strategy involved significant healthcare facility acquisition and consolidation activities. ${ }^{23}$ The three largest mergers and acquisitions during this period are: the 1994 merger with Medical Care of America which was financed by issuance of 21.1 million shares of HCA common stock, the 1995 merger with Healthtrust which was financed by issuance of 80.412 million HCA voting common stock, and the Value Health merger in 1997 by which Value Health stockholders received $\$ 20.50$ in cash for each Value Health common stock and HCA financed it by issuing debt. Interestingly, this period's M\&As had been financed mainly by issuing equity, and debt was used as a second source of financing. This is not consistent with DeAngelo et al. (2011).

Figure 6 shows despite Columbia/HCA numerous mergers and acquisitions for the years 1994-1996, both market and book leverage ratios have been moderately stable. Interestingly, Figure 6 shows HCA capital structure did not fluctuate significantly and book leverage ratio was bounded between 0.43 and 0.50 , and market leverage ratio was about 0.2 for the years 1994 up to the 1997 expansion period when Scott was the CEO. This moderately stable trend in the leverage ratios during HCA's intensive expansion and acquisitions period could be due to the fact that the 1994 and 1995 mergers were financed by issuing common stock and not debt.

We recall Figure 1 and Equation (3.5) to see which terms of the Equation (3.5) caused variations in HCA's market leverage ratio in comparison with the following year. For the period 1995-1996 the second term with a positive sign $(\Delta N)$ and the third term $(\Delta P)$ with a negative sign affected the market leverage ratio the most. The negative sign of the third term shows the

\footnotetext{
${ }^{22}$ Note that as debt issuance occurred in February, Compustat reports the debt as the year 1993's debt. This is why we do not see a considerable change in the HCA's long-term debt from 1993 to 1994.

${ }^{23}$ From HCA's 1994 annual report.
} 
outsiders' valuation effect. The Healthtrust merger in 1995 caused a share price increase which was offset in 1996. For the period 1996-1997, the first term with a positive sign $(\Delta D)$ and the third year with a negative sign $(\Delta P)$ had the most influence on Equation (3.5). The increase in the long-term debt was due to the Value Health merger which was financed by issuing debt, and the decrease in the share price was due to the 1997 fraud investigation, which overall caused an increase in the market leverage ratio.

Figure 2, along with Equation (3.6), shows that for the period 1995-1996 the book leverage ratio was affected by the second term (increase in $\Delta c e q$ ) which was due to this period's mergers. For the period 1996-1997, the first term of Equation (3.6) with positive sign and the second term with a negative sign increased the book leverage ratio. For the year 1997, the large amount of first term (increase in $\Delta D$ ) along with a small decrease in the second term, increased the book leverage ratio.

All in all, HCA's M\&As financing behavior shows the HCA's managers' tendency to keep its capital structure in a target leverage zone and financing its M\&As mainly with equity issuance. In one case in 1997, HCA issued debt to finance its merger with Value Health. We think the reason for issuing debt rather than equity to finance this merger is the 1997 fraud investigation. Due to the HCA fraud investigation, HCA's stock was undervalued. Therefore, HCA issued debt, not equity, to finance the deal. To also empirically test this relationship, Chapter 4 of this dissertation tests the effect of acquisition's volatility as a measure of investment volatility on the use of debt.

Following the 1997 fraud investigation, HCA's share price declined, Scott was forced to resign, and COL/HCA modified its strategy and tried to refocus on its core competencies. Hite and Owers (1983) show that the share price increases due to spin-offs and Nanda and Narayanan (1999) find that when a firm is undervalued, selling it as business units may make the market give a more accurate valuation. On the other hand, when overvalued firms face an under-performing division, they use external financing to raise capital. 
Subsequent to fundamental changes in HCA's strategies, HCA started to divest some of its hospitals and business units. ${ }^{24}$

Figure 6 shows HCA's book leverage ratio in 1998 was their lowest book leverage ratio since 1990. After experiencing a trough in 1998, HCA's book leverage ratio showed an increasing trend. The main reason behind the sharp decrease in the book and market leverage ratios in 1998 is a $39 \%$ decrease in the total debt.

For the year 1998, Figure 3 shows a small increase in the book leverage ratio, and a close to zero variation in the market leverage ratio since the year 1999. Recalling Equation (3.5) terms and referring to Figure 1, we can see that the close to zero variation in the market leverage ratio is there because of the small decreases in the first term $(\Delta D)$ and second term $(\Delta N)$ of Equation (3.5), and a small increase in the third term which is due to variations in the share price. Therefore, the market leverage ratio remained largely unchanged. In addition, the 1998 book leverage ratio variations shown in Figure 3 were caused by a small decrease in the first term $(\Delta D)$ and a larger decrease in the second term $(\Delta c e q)$ of Equation (3.6). Note that as the second term of Equation (3.6) is negative, it essentially causes an increase in $\Delta\left(L_{t}\right)_{\text {Book }}$

\section{insert Figure 8}

Figure 8 plots HCA long-term debt issuance and reduction. It shows that despite the nontrivial debt reduction in 1998, HCA debt issuance is very small. Debt payoff without issuing new debt is a result of the 1998 divestitures, which were used as a source of financing to reduce the corporation's total debt.

The year 1998 is a turning point for the book leverage ratio. Figure 6 shows that for the years 1998 up to 2001, which we call the HCA shrinking period, the book leverage ratio was increasing while the market leverage ratio was decreasing. This is the only period from 1990 to 2013 where the market

\footnotetext{
${ }^{24} \mathrm{HCA}$ disposed of more than 33 surgery centres, 44 hospitals and all its home care related centres by selling them off or through spinoffs. Some of the HCA's divestitures between 1998 and 2000 are LifePoint and Triad spin offs, Selling Value Behavioral Health, and Value Rx which were the Value Health business units (HCA's 2000 annual report).
} 
and the book leverage ratios have different upward/downward slopes. As the total long-term debt, which is the book and market leverage ratios' common component, was fairly stable we need to look at the market and the book leverage ratios' decomposition terms in Figures 1 and 2. The figures show that for the years 1998 up to 2001, the increase in the book leverage ratio was due to the second term of Equation (3.6)'s negative sign (decrease in $c e q$ ), whereas, at the same period the market leverage ratio was decreasing due to the increase in the third term of Equation (3.5), i.e. increase in the share price.

Section 3.3.3 explains that equity value of a firm is price per share times the number of shares outstanding for the market leverage ratio and is the common/ordinary equity (ceq) for the book leverage ratio. During the shrinking period, HCA common/ordinary equity was decreasing due to a huge decrease in capital surplus and common/ordinary stock. As a result, the book leverage ratio was increased because of the decrease in its denominator. On the other hand, HCA's price per share times the number of shares outstanding was increased despite the decreases in the number of shares outstanding due to a considerable increase in the share price from $\$ 24.75$ in 1998 to $\$ 40.01$ in 2000. The increase in the share price due to spin-offs is consistent with Hite and Owers (1983). In addition, the share price increase was caused by the market reaction to HCA's several buybacks and HCA's settlement with the USA Department of Justice on its 1997 fraud investigation. Therefore, the market leverage ratio decreased because of increases in its denominator.

As a result of this period of divestitures, the amount of HCA's cash increased as HCA sold some of its business units in cash. The excess cash could be used to decrease the amount of corporate debt, but because debt disciplines managers as interest payments to debtholders are a firm obligation, firms prefer to use the excess cash to repurchase shares than pay off debt. My conjecture is that, if a firm is not in the target leverage zone and is a highly levered firm it may use the excess cash to pay off some of its debt and reduce its leverage ratio. On the other hand, if the firm is in its target leverage zone it can use the excess cash to buy back its stock. Since HCA was in its target leverage zone and was not highly over-levered, it spent 
the excess cash to buy back some of its stocks which we discuss in the next section.

For the years 2001 to 2005, both market and book leverage ratios show upward sloping trends. Despite the same book leverage trends (both increasing) in the late 90s and the early to mid-2000s, these trends are fundamentally different. The late 90s' upward trend was due to a decrease in the denominator (HCA common/ordinary equity), and the early to mid-2000s increasing trend was caused by an increase in the HCA's total long-term debt. In the late 90s, HCA was performing several divestitures and was shrinking in size, whereas in the early to mid-2000s HCA was a stable firm whose fraud investigation was settled, and which was financing several buybacks by issuing debt and firm free cash flows.

\subsubsection{Buyback Programs}

In this section, we discuss how share buybacks changed COL/HCA's capital structure, and the reasons behind HCA's buyback decisions.

\section{insert Table 3}

Buyback is a payout policy and refers to repurchase of a firm's shares outstanding in order to reduce the number of a firm's stock in the market. Table 3 reports some of the buyback literature and indicates why firms choose buyback as a payout policy. Skinner (2008) indicates that the number of firms using share buyback instead of dividend payments as their payout policy is increasing. A firm may choose a share buyback strategy for several reasons. Pettit (2001) suggests that firms benefit from buyback in two ways: 1) signaling, and 2) in the case of financing the buyback by debt, buyback is like exchanging equity for debt and there will be a tax benefit of debt. Dann and Mikkelson (1984), DeAngelo, DeAngelo and Rice (1984) and Asquith and Mullins (1986) show that a stock repurchase announcement can cause a stock price increase; therefore, a firm's management team may follow the stock repurchase strategy to increase the firm's current share value available in the market. In addition, Bagwell (1991) finds that firms can decrease the 
threat of hostile takeovers by choosing share buyback as their payout policy. Firms can also eliminate the threat of shareholders who have the desire for the controlling stake by share buyback. Firms may also use the buyback program to increase earnings per share (Hribar, Jenkins and Johnson, 2006; Almeida, Fos and Kronlund, 2013). Furthermore, Kahle (2002) finds that firms follow a buyback strategy when employees have a large amount of currently exercisable options. In addition to these motives, Dittmar (2000) shows that changing the capital structure could be one of the reasons for a share buyback. Tsetsekos, Kaufman Jr and Gitman (2011) report the findings of a mail questionnaire and show that the managers of a firm are motivated to use share buyback to change the firm's capital structure as well as to signal information to the market.

How does a share buyback change the capital structure? Recalling Equations (3.5) and (3.6), the leverage decomposition in Section 3.3.3 shows that a firm's capital structure changes due to the capital structure components variations as

$$
\begin{aligned}
\Delta\left(L_{t}\right)_{\text {Market }} & =P_{t+1} N_{t+1} \frac{\Delta D}{\left(D_{t+1}+P_{t+1} N_{t+1}\right)\left(D_{t}+P_{t} N_{t}\right)} \\
& -D_{t+1} P_{t} \frac{\Delta N}{\left(D_{t+1}+P_{t+1} N_{t+1}\right)\left(D_{t}+P_{t} N_{t}\right)} \\
& -D_{t+1} N_{t} \frac{\Delta P}{\left(D_{t+1}+P_{t+1} N_{t+1}\right)\left(D_{t}+P_{t} N_{t}\right)} \\
\Delta\left(L_{t}\right)_{\text {Book }} & =C e q_{t+1} \frac{\Delta D}{\left(D_{t+1}+C e q_{t+1}\right)\left(D_{t}+C e q_{t}\right)} \\
& -D_{t+1} \frac{\Delta C e q}{\left(D_{t+1}+C e q_{t+1}\right)\left(D_{t}+C e q_{t}\right)} .
\end{aligned}
$$

We need to seek the dynamics of capital structure due to variations in 1) long-term debt, 2) the number of shares outstanding, 3) share price, and 4) common/ordinary equity. Firms have several options to finance their share buybacks including issuing debt and using their free cash flows. When firms repurchase shares with their excess cash, they give up the option of using the excess cash to payoff the existing debt or payout dividends. In the former case, they forgo the option of decreasing their leverage ratio. Altogether, 
when a firm repurchases its stock, the capital structure dynamics are due to variations in its number of shares outstanding, share price, long-term debt, and common/ordinary equity.

One of the reasons that a firm considers a share buyback could be its undervalued stock (Stephens and Weisbach, 1998). The announcement of share buyback will be considered to be a good sign by the market and consequently increases a firm's share price. This normally happens 2 to 3 days before the buyback. Therefore, if we look at daily changes in the capital structure and consider buyback day as (t) and the day before the buyback as ( $\mathrm{t}-1)$, the share price variation is trivial as the share price has already increased on the announcement day. As a result, the changes in capital structure from day t-1 to day $t$ occur due to the reduction in the number of shares outstanding at day t which leads to a decrease in shareholders' equity and an increase in capital structure from day $\mathrm{t}-1$ to $\mathrm{t}$.

An improving measure of reported financial statements can also be a good motivation for a share buyback (Allen and Michaely, 2003; Brav et al., 2005). Generally, a share buyback increases return on assets (ROA), return on equity (ROE), and earnings per share (EPS) in financial statements. After a share buyback, ROA (a ratio of net income over total assets) increases as the firm's excess cash, which is a part of a firm's total assets, has been used for the share buyback leading to a smaller denominator in ROA; ROE (a ratio of net income over total shareholders' equity) increases due to a decrease in total shareholders' equity following a buyback; EPS (a ratio of earnings over the number of shares outstanding) also increases because the same earnings will be divided among the fewer number of shares outstanding.

\section{insert Table 4}

Panel A of Table 4 reports Columbia /HCA buybacks during 1990-2013. Columns (1) to (5) represent the date of buyback, the number of shares outstanding, price per share, market shareholders' equity and the number of the repurchased shares, respectively. The number of repurchased shares is calculated by the difference between the number of shares outstanding from day t-1 to day t. The negative signs in Column (5) show decreases in the 
shares outstanding from the previous day. Interestingly, all HCA's buybacks occurred at the end of the monthly period from 28th to 31st, showing report purpose as one of the share buyback motivations.

We start with the largest buyback that changed HCA's capital structure. We study the dates of buyback where capital structure increases or decreases more than $2 \%$.

Panel A of Table 4 shows that the largest buyback in Columbia/HCA history from 1990 to 2013 took place on Oct 31, 2011 when HCA repurchased 80.771 million of its outstanding shares owned by the Bank of America at the closing price of NYSE on September 14, 2011. ${ }^{25}$ HCA financed the buyback by cash in hand and some borrowings. The announcement of this share buyback raised the HCA share price from $\$ 18.61$ per share to $\$ 20.84$ per share. Both the increase in the share price and the decrease in the shares outstanding, as well as the increase in HCA's borrowings led to HCA's capital structure change. ${ }^{26}$ The reason for this buyback was the Bank of America's decision to focus on its core business. ${ }^{27}$

This event affected both market and book leverage ratios. The market ratio was affected by an increase in the long-term debt (Equation (3.5)'s first term), the decrease in the number of shares outstanding (Equation (3.5)'s second term) and the increase in share price (Equation (3.5)'s third term) due to outsiders' valuation after the news release, and not by HCA's intention to signal information to the market. The book ratio was affected by the increase in HCA's borrowings (Equation (3.6)'s first term) in order to finance the share buyback, as well as the decrease in the common shareholders' equity

\footnotetext{
${ }^{25}$ StreetInsider (September 15, 2011) reported a HCA announcement of 80,771,143 share repurchase owned by the Bank of America at the closing price of NYSE on September 14, 2011.

${ }^{26}$ This share buyback was completed 6 days later on September 21, 2011 but Compustat dataset reports $80,771,143$ decline in the number of shares outstanding on Oct 31, 2011. The motivation for not reporting the buyback in September could be due to HCA's forthcoming quarterly report. HCA's third quarter report was released in November and included the financial statements up to the end of September. Not reporting the buyback in September, shows that HCA did not want to include the buyback in its third quarter report, and deferred it to the 2011 annual report.

${ }^{27}$ Bank of America, the lead underwriter in HCA's 2006 IPO, was holding $15.6 \%$ stake after acquiring Merrill Lynch one of the private equity firms involved in HCA's 2006 LBO (Ma, 15 Sep 2011).
} 
(Equation (3.6)'s second term) due to the decrease in the number of shares outstanding.

Despite the share price increase after the buyback, President Obama's plan to make Medicare more efficient dropped the HCA share price on Sep $19,2011{ }^{28}$ All in all, the negative effects of news regarding HCA's spending on lobbying and the Robbins Geller's class action suit on HCA's market price could have reduced the HCA share price significantly, but the buyback moderated the effects of the bad news. In addition, following the $\$ 1.45$ billion payment to Colorado Health Foundation, HCA's earnings per share in the forthcoming quarterly report could have been dropped. ${ }^{29}$ The buyback helped HCA to maintain its earnings per share in the next financial report as the buyback reduced the number of shares outstanding. Hribar et al. (2006) and Almeida et al. (2013) find that firms' management teams tend to repurchase shares in order to increase EPS.

The second largest buyback occurred on May 28, 1999 with buyback of 74.159 million shares, which was financed by cash in hand and debt issuance. This buyback was a result of the 1997 fraud investigation after which Scott was forced to resign and Columbia/HCA modified its growth strategy and tried to refocus on its core competencies. This buyback caused an $8 \%$ increase in the market leverage ratio. The increase in the market leverage ratio was due to an increase in debt as well as a decrease in the the number of shares

${ }^{28}$ MarketWatch (September 20, 2011) reported:

HCA Holdings Inc. (HCA, US), which tried to win back investors with a buyback plan last week, lost ground on Monday, dropping nearly $7 \%$ to $\$ 19.81$ at the close.

${ }^{29}$ Several events occurred in October 2011. HCA purchased full ownership of HCAHealthOne in Denver that increased its share price by 92 cents, to close at $\$ 22.05$ on October 14, leading to a close buy imbalance of 91,300 shares on October 18 . Later in October, Bewley (October 28, 2011) reported that HCA is one of the 200 companies that tried to lobby Congress by spending thousands of dollars.

Business Wire (October 29, 2011) reported:

Robbins Geller Rudman \& Dowd LLP files class action suit against HCA Holdings, Inc.

On Oct 31, 2011 on the same day as HCA's largest buyback, the Colorado Health Foundation announced that they received $\$ 1.45$ billion from HCA in order to complete the purchase of HCA-HealthOne. 
outstanding in Equation (3.5). ${ }^{30}$

During April and May 1999, HCA was experiencing an unsteady situation as a result of the fraud trial process and a new lawsuit, which decreased HCA's share price to $\$ 23.31$, the lowest for the last month. HCA perceived its stock to be undervalued and repurchased $\$ 74.159$ million of its shares on May 28, 1999. Therefore, along with refocusing on core competencies after Scott's resignation, HCA's intention to repurchase stock was to signal information to the market. The day after the buyback on May 29, the share price started to increase. ${ }^{31}$

The third largest buyback (39.645 million shares) of HCA occurred on January 31, 2005 and caused a 6\% increase in HCA's market leverage ratio. This buyback and the buyback of January 2006 were the only HCA's share buybacks in January. HCA's strategy on no buybacks in January could be due to the January effect and the fact that prices of most publicly traded stocks increase during the month of January (Haug and Hirschey, 2006).

\footnotetext{
${ }^{30} \mathrm{By}$ recalling the discussion on using the spent cash on the buyback to repay some of the corporation debt, another HCA management team option was to decrease the market leverage instead of increasing it. The HCA's management team chose the buyback over debt repayment; as a result, the market leverage ratio was increased.

${ }^{31}$ Reuters News (21 April, 1999a) reported a $63 \%$ increase in HCA's net profits regardless of lower revenues in the first quarter; the news caused a $12 \%$ increase in HCA's share price on the same day. Ten days later, Zengerle (May 2, 1999b) reported the commencement of COL/HCA's ex-executives' fraud trial, as the outcome of June 1997 fraud investigation which caused May 3, 1999 share price escalation. Such bad news should have decreased the share price, yet the stock price was increased from $\$ 24.68$ on April 30, to $\$ 27.75$ on May 3. The reason for the share price surge was the possible settlement with the government. Another explanation could be the repurchase of 3.272 million shares on April 30, 1999 which gave a positive sign to the market. We could also suppose that the potential settlement with government was the main reason for the April 30, 1999 share buyback. Because of the asymmetric information regarding the settlement with the government, HCA's management team repurchased 3.272 million shares. The stock price kept appreciating to 28.63 on May 5, 1999, then followed a decreasing trend after the testifying of Steve Dudley, the government's first witness. Zengerle (May 5, 1999a) reported:
}

Executives from hospital giant Columbia/HCA Healthcare Corp. misstated interest expenses to suck excess funds from government insurance programmes, a key government witness alleged during their trial on Wednesday.

Another lawsuit against HCA on May 26, 1999 caused a 4\% decrease in HCA's share price. On May 26, Reuters News (May 26, 1999b) reported that the USA Justice Department joined another lawsuit against HCA, in which HCA's physicians were accused of having investment opportunities and acting like free riders. 
The buyback was financed by cash and not debt issuance. Therefore, the $6 \%$ increase in the market leverage ratio was due to a decrease in the number of shares outstanding along with a very small increase (about 1.1\%) in the share price in Equation (3.5).

To study the capital structure changes, we dig into the events that made this change. First, Gazette (Jan 2, 2005) reported stock option expenses would be deducted from earnings starting in June 2005. Therefore, HCA announced acceleration in its employee options vesting. Kahle (2002) examines the relationship between shares buyback and stock options exercise. She finds that firms follow a buyback strategy when employees have a large amount of currently exercisable options. From a firm's point of view, vesting increases the number of shares outstanding and results in dilution which means decreases in the earnings per share. To cope with the EPS reduction due to vesting, a firm needs to lessen its shares outstanding in the market. Therefore, HCA's management repurchased 39.645 million shares which reduced the dilution and increased the earnings per share financial measure. Second, Reuters Significant Developments (January 12, 2005) reported an approximate $6.1 \%$ increase in HCA's fourth quarter earnings in comparison with the previous year's fourth quarter. After this announcement, HCA's share price rose $10.1 \%$ to close at $\$ 43.7$ per share on January 12 . As a result, the market leverage ratio was decreased about $6 \%$ due to the increase in HCA's share price in Equation (3.5).

All in all, we propose the main reason for the Jan 31, 2005 stock repurchase was the employee option vesting that made HCA's management repurchase HCA's stock in order to stop the decrease in earnings per share.

The fourth biggest HCA share buyback (35.167 million shares) was reported on January 31, 2006 and caused a 5.8\% increase in the market leverage ratio. APRS (November 16, 2005) reported that HCA was authorized to repurchase $\$ 2.5$ billion of its stock in a Dutch auction tender offer. ${ }^{32}$ The

\footnotetext{
${ }^{32}$ In a Dutch auction share repurchase, a firm specifies a desired price range and invites its stockholders to tender their shares. By the responses from the shareholders, the firm decides on the purchase price which is the lowest price, allowing the firm to purchase the number of shares stated in the offer. Then the firm pays the purchase price to the shareholders who tendered below or at the chosen purchase price.
} 
auction of about 28.740 million shares (about $\$ 1.5$ billion) took place on November, 14 and the firm was still authorized to repurchase $\$ 1$ billion stock. The buyback of 35.167 million shares reported in January was the result of this $\$ 2.5$ billion stock repurchase. As a result of this buyback, the market leverage ratio was increased due to a decrease in the number of shares outstanding in Equation (3.5).

Another motive for January 2006 share buyback was granting about $\$ 3.3$ million restricted stock and 66,750 stock options to the HCA's chairman and the CEO. ${ }^{33}$ Granting restricted stock and stock options to the CEO of a firm reduces the diluted earnings per share by increasing the denominator of earnings per share measure. A firm reports its diluted earnings per share as a measure of its profit. Therefore, lower diluted earnings per share could affect the share price negatively. By the buyback of 35.167 million shares, diluted EPS was prevented from decreasing. Using the stock buyback to increase earnings per share is consistent with Hribar et al. (2006) and Almeida et al. (2013).

In this section we study the four largest HCA buybacks from 1990 to 2013. The evidence shows several objectives behind these buybacks. HCA's intention behind the 1998 to 2000 buybacks is different to the September 2011 buyback.

For the years 1998 to 2000, HCA planned to send a signal to the market and tried to increase its share price by repurchasing millions of shares after the 1997 fraud investigation. HCA's attempts to increase the share price by share buyback is consistent with the findings of Dann and Mikkelson (1984), DeAngelo et al. (1984) and Asquith and Mullins (1986), which indicate market positive reaction to share repurchase announcements. HCA financed this period of buybacks mostly with the excess cash generated by several divestitures and also a small amount of borrowings. Overall, the decrease in the market leverage ratio in Equation (3.5) was due to the increase in the Equation (3.5) third term (price per share) with a positive sign. Figure 6 shows that for the years 1998 up to 2001, the book leverage ratio was increasing while the market leverage ratio was decreasing. We think the different trend

\footnotetext{
${ }^{33}$ Reported by Dow Jones Corporate Filings Alert (January 31, 2006).
} 
in market and book leverage ratio is due to the buyback of about 135 million shares for the years 1998 to 2001. HCA used the book leverage ratio to stop the market leverage ratio from decreasing below the lower target leverage range of 0.2. After the 1997 fraud investigation, HCA faced a large decrease in its share price. At the same time HCA modified its strategy and started to divest some of its business units, and kept its long-term debt level fairly constant. HCA knew after changing its strategy, the share price would increase. The increase in the share price would have decreased the market leverage below the target lower bound of 0.2 . The buyback of 135 million shares during this period decreased during the second term of Equation (3.6) $(\Delta c e q)$ as a result of the decline in the capital surplus and therefore increased the book leverage ratio. On the other hand, the buyback decreased the second term of Equation (3.5) (the number of shares outstanding) which somehow offset the increase in the share price due to divestitures and as a result, the market leverage ratio did not go below 0.2. My concluding remark is that HCA's management team used the book leverage ratio as a tool to stop the market leverage ratio from decreasing below the lower leverage limit of 0.2 .

On the other hand, the 2011 buyback was not HCA's decision to repurchase its stock, it was Bank of America's decision to focus on its core business. HCA financed this buyback by cash on hand and some borrowings. Therefore, the book leverage ratio increase in Equation (3.6) was due to the increase in HCA's long-term debt, and the variation in the market leverage ratio in Equation (3.5) was due to the decrease in the second term, i.e. the number of shares outstanding.

Moreover, in both the 2005 and 2006 buybacks, HCA was facing dilution due to vesting its employees' options and granting restricted stock and stock options to its CEO, respectively. Therefore, consistent with Hribar et al. (2006) and Almeida et al. (2013), HCA's management team decided to repurchase some shares to cope with dilution as well as the earnings per share deceleration. These buybacks were financed by cash in hand and some borrowings and decreased the market leverage ratio due to a decrease in the second term $(\Delta N)$ and an increase in the third term $(\Delta P)$ of Equation (3.5). 


\subsubsection{Changes in Ownership}

In this section we discuss the two events that change the ownership of a firm, LBOs and public offerings.

\section{insert Table 5}

LBO is the acquisition of a firm by a group of investors where the acquisition costs are covered by a remarkable amount of money borrowed from a bank or bond issuance by the acquired firm. The LBO activities were popular during the 1980s, but declined after the USA early 1990s recession and the bond market crash. Renneboog, Simons and Wright (2007) report that a range of $\$ 1$ billion to $\$ 60$ billion LBOs were completed from 1979 through 1988, and the total value of LBOs in the 1980s was slightly less than $\$ 1.3$ trillion (Shleifer and Vishny, 1991). The second wave of LBOs started in the mid-2000s, and stopped in 2008 following the debt market turbulence and the 2008 financial crisis.

Table 5 lists some of the existing literature on LBOs and public offerings. Kaplan (1989) and Bargeron, Schlingemann, Stulz and Zutter (2008) note that LBOs transactions tend to be completed by a large premium over the existing share price. LBOs in general are financed with a large amount of debt including loans and debt issuance (mostly junk bonds) by the acquired firm. In most of the LBOs the leverage ratio increases drastically. As reported by Bayar, Baker and Kiymaz (2011), during the first wave of LBOs in the 1980 s, the firms' leverage ratios approached $90 \%$, which is higher than firms' leverage ratios during the second LBO wave in the mid-2000s. In addition to the debt financing, the remaining portion of acquisition costs is financed by the acquiring parties, which could be private equity firms or wealthy individual investors.

In July 2006 during the second LBO wave, the Frist family (one of the co-founders of HCA in 1968) and a group of private equity firms including Merrill Lynch Private Equity and Bain Capital and Kohlberg Kravis Roberts proposed to acquire HCA in a $\$ 21$ billion LBO. The $\$ 21$ billion value of the 
deal did not include HCA's $\$ 10.6$ billion debt. ${ }^{34}$

The deal was on and off for some time as the offered price by lending banks and the buyers was not satisfactory for HCA. HCA market capitalization was $\$ 17.6$ billion accompanied by a $\$ 11.7$ billion debt, making its leverage ratio $38.6 \%$ which was not desirable enough for the banks and the buyers to offer a higher price. ${ }^{35}$ Finally, HCA's shareholders approved the largest buyout in USA history on November 16, 2006 (French, 17 November 2006).

To finance the proposed buyout, the prospective buyers invested about $\$ 5.5$ billion in cash, and issued about $\$ 16$ billion new debt (mostly callable junk bonds) in addition to HCA's existing $\$ 11.7$ billion debt. ${ }^{36}$ The on-againoff-again $\$ 33$ billion deal (including HCA's existing debt) was completed on November 17, 2006. Each HCA shareholder received $\$ 51$ in cash for each share they held. The total value of the deal was equal to $\$ 21.3$ billion paid to shareholders in cash plus the $\$ 11.7$ billion HCA debt (French, 17 November 2006). Considering the $\$ 11.7$ billion HCA debt, each HCA shareholder received $\$ 80.53$ for each share they held, with $\$ 29.56$ premium over the last traded share price of $\$ 50.97$ one day before the buyout.

DeAngelo and DeAngelo (1987) indicate tax saving, better performance and competitive positioning as LBOs' merits. On the other hand, they state problems in raising capital and attracting experienced managers as LBOs' demerits. Guo, Hotchkiss and Song (2011) find that in LBOs, the realized returns to capital are affected by tax benefit of debt, industry valuation multiples and changes in operating performance. In addition, Fox and Marcus (1992) find that LBOs increase managers' commitment to profitability. In

\footnotetext{
${ }^{34}$ According to APRS (20 July 2006), at that time HCA Inc. owned 94 surgery centres and 182 hospitals and its 2005 net income was $\$ 1.4$ billion.

${ }^{35}$ Newspapers reported a $10 \%$ difference in the value of the deal between HCA and the buyers.

36 HCA Quarterly report (May 15, 2007, page 21) reported:
}

Due to the Recapitalization, we are highly leveraged and have significant debt service requirements. Our debt totaled $\$ 27.903$ billion at March 31, 2007, which represents a $\$ 16.591$ billion increase from the total debt of $\$ 11.312$ billion at March 31, 2006. Interest expense increased from $\$ 186$ million in the first quarter of 2006 to $\$ 557$ million in the first quarter of 2007 . We expect our interest expense to increase from $\$ 955$ million for the year ended December 31, 2006 to approximately $\$ 2.3$ billion in 2007 . 
general, when firms go private after LBOs they face lower regulations. Private firms could gain benefit from the fact that their management teams have more time and energy to spend on long-term earnings and are not obligated to provide the quarterly earnings' expectations by external analysts. Thus, the private firm senior management team will be able to focus more on the firm's strategic positioning in the market, growth opportunities, and cost-cutting strategies.

What were the reasons behind HCA's 2006 LBO? Generally, an appropriate LBO candidate (the target firm) should have enough potential to maximize the value of acquirers' investment. HCA was a suitable LBO candidate from the HCA acquirers' point of view. First, increase in health care spending due to the USA population aging made the health care industry a lucrative investment target. Second, HCA's strong position in the market made it an appropriate buyout candidate. In addition, the publicly traded HCA was supposed to pay taxes and dividends, while the HCA non-profit competitors had the strength against HCA (a for-profit organization) that they did not have to worry about paying taxes and dividends (Berman, Naik and Winslow, July 25, 2006). Therefore, in order to be competitive in the market, HCA needed to reduce some of its expenses. The 2006 LBO helped HCA to cut some of its expenses and the number of full-time equivalents in comparison with other local hospitals (McCue and Thompson, 2012).

HCA had about $\$ 11.7$ billion debt when it confirmed pursuing the buyout on July 24, 2006. The announcement of pursuing the buyout triggered a huge decline in the value of HCA's long-term bonds.

insert Figure 9

Figure 9 plots HCA's 6.5\% coupon bond prices due Feb 15, 2016, from June 2006 to November 2007. The value of this bond dropped to $\$ 78.12$ on July 26, 2006 after the LBO announcement, as a result of the increase in HCA's default risk after the LBO. Debt rating was also cut accordingly.

insert Figure 10

Figure 10 plots the HCA historical share price from January to November 2006. The price of each HCA share increased to $\$ 49.48$, indicating a $3 \%$ 
premium to the closing price of $\$ 47.84$ on July 21,2006 .

The 2006 LBO increased the HCA capital structure drastically due to the existing and new debt issue in order to finance the buyout. The day before the buyout on November 16, HCA's market leverage was about 0.36 and its book leverage was about 0.6. After the buyout the book leverage increased to 1.67 which indicates a $178 \%$ increase in the book leverage ratio (Equation (3.6)). ${ }^{37}$ The reason for the $178 \%$ increase in the book leverage ratio and the greater than one book leverage (1.67) is explained in Section 3.5.1.

One of the ways a firm can acquire its required funds is to publicly sell its equity. The term IPO refers to a type of offering in which a private firm sells its stock to the public for the first time. The raised capital via the public offerings (the proceeds) may be used for debt repayments, investment opportunities, acquisitions, product developments and distribution to preIPO shareholders (Leone, Rock and Willenborg, 2007). In addition to raising capital, founding individuals or private equity firms may use IPO as an exit strategy.

Panel B of Table 4 shows Columbia/HCA public offerings from 1990 to 2013. The largest offering was the IPO of 515.205 million shares on March 10, 2011. HCA had been privately held from the 2006 LBO to the time it went public again in 2011.

Accompanied by HCA's largest IPO in 2011, Figure 6 shows that the largest debt reduction in the history of HCA occurred in 2011. As stated in HCA's prospectus dated March 9, 2011, HCA intended to use the net proceeds from the 2011 IPO to repay some of its indebtedness including the senior secured revolving credit facility and the asset-based revolving credit facility. As HCA did not hold any debt with 2011 maturity, the 2011 debt reduction refers to calling HCA's callable bonds before their maturity date.

Why 2011? Cowan (19 February 2011) reported that HCA's public offering was the third public offering in 2011 (in the first two months of the year) which raised more than one billion dollars. HCA's 2011 IPO followed public offerings of Kinder Morgan Inc. and Nielsen Holdings N.V. Stock prices, both of which were priced above their range. Private firms issue considerably

\footnotetext{
${ }^{37}$ After buyout market leverage is not available as HCA was privately held until 2011.
} 
more equity and decrease their leverage ratio more in a hot IPO market than a cold IPO market. Alti (2006) examines the impact of market timing on capital structure by studying the number of firms' issued shares when they issue shares in either a hot or a cold market. He shows that firms tend to issue more equity in a hot issue market than they would do if the market was not hot. Demos (23 February, 2011) reported the struggle of private equity IPOs in 2010, as some of them were priced below their range and others were delayed as the potential investors had their doubts regarding the debt repayments by the heavily indebted private equity firms. On the other hand, the evidence shows that the 2011 IPO market could be considered to be a hot IPO market, after the good performance of USA equity markets, since the middle of 2010 .

Figure 6 shows a decrease in HCA's market leverage ratio in 2011 from 2010. This decrease is due to a decrease in the first term $(\Delta D)$ and an increase in the second term $(\Delta c e q)$ of Equation (3.6). The comparison of market leverage ratios in 2010 and 2011 is not possible as market data are not available for the years 2006-2011. However, it is worth mentioning that the downward slope of the market leverage ratio in Figure 6 indicates the HCA management team's attempt to close the gap between HCA's market leverage ratio and its target leverage zone of 0.2 and 0.4 .

Section 3.5.1 points out either the firms' decisions affect their capital structure (changes in both market and book debt ratios) or the outsiders' valuation affects the capital structure (changes in market debt ratio). HCA's decision to go public and use the proceeds to repay some of its debt decreased its book and market debt ratios. Our conjecture is that consistent with the Baker and Wurgler (2002) market timing theory and the Alti (2006) hot vs. cold IPO market findings, HCA chose the perfect timing to go public, as the 2011 IPO market can be considered to be a hot IPO market.

\subsection{Discussion and Summary}

The empirical studies on dynamics of capital structure explore whether firms' capital structures vary over time and what factors affect these capital struc- 
ture variations. This paper is a case study of HCA and its capital structure dynamics for the years 1990 to 2013. The motivation of this case study comes from the fact that in an empirical study with thousands of firms in the sample, we are not able to understand how management teams of firms make their capital structure decisions and how they decide what to do, and how they do it. This case study helps us to understand how firms make capital structure decisions and how the behavior of the accounting-based data is different to the market-based data, and how the HCA management team's decisions affect the capital structure and the data.

In this study, we investigate HCA's capital structure changes due to 1) mergers and acquisitions, and divestitures that change a firm's total assets, 2) buybacks, and 3) LBOs and public offerings that change a firm's ownership. HCA is an interesting case to study as it had several M\&As, divestitures, buybacks, LBOs and public offerings from 1990 to 2013.

Our evidence suggests that in most of the cases except the 2006 LBO which has increased the book leverage ratio dramatically, HCA's management team tried to keep the leverage ratio in a target leverage zone by using both debt and equity financing.

HCA's market leverage ratio had been bounded between 0.2 and 0.4 for the years 1992 to 2006 before the LBO. The 2006 LBO increased HCA's debt drastically and made it a private firm. This paper suggests HCA aimed to keep its market leverage ratio in the target leverage zone. The decreasing trend of the HCA market leverage ratio after the 2011 IPO shows that the market leverage ratio tends to get back to the target leverage zone. The idea of staying in a target leverage zone is consistent with the dynamic trade-off theory and the existence of a target leverage ratio like Leary and Roberts (2005). More interestingly, the evidence suggests that in some cases when the outsiders' valuation pulled the market leverage ratio out of the target leverage zone, HCA used the book leverage ratio as a tool to keep the market leverage ratio inside the target leverage zone. For instance, from 1998 to 2000 the HCA management team decreased the common equity (ceq) to stop the market leverage ratio from decreasing below the target lower bound of 0.2.

The HCA case suggests that the reasons behind the equity financing in 
one situation are different to another situation. Financing events by voluntary debt or equity issuance is different from using available cash from operating activities or selling assets. Both cases cause variations in leverage ratios, but the latter is less expensive than the former. For example repurchasing shares using the available generated cash from selling a business unit is less expensive than repurchasing shares by issuing debt in order to finance the buyback.

In addition, the substantial amount of debt or equity issuance in the case of acquisitions, as well as the substantial amount of available cash in the case of divestitures, leads us to test the relationship between the investment volatility and the level of debt and cash holding outlined in the next chapter. 


\subsection{Figures and Tables}




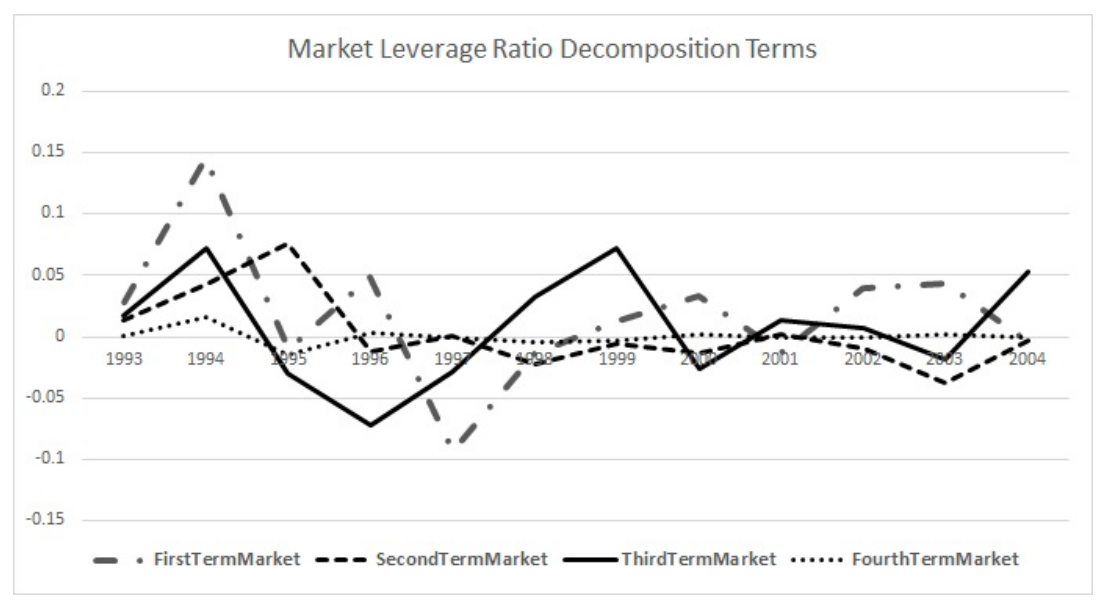

Figure 1: Horizontal axis shows the years 1993-2004. Vertical axis plots the first to the fourth terms of Equation (3.4), the HCA's market leverage ratio decomposition.

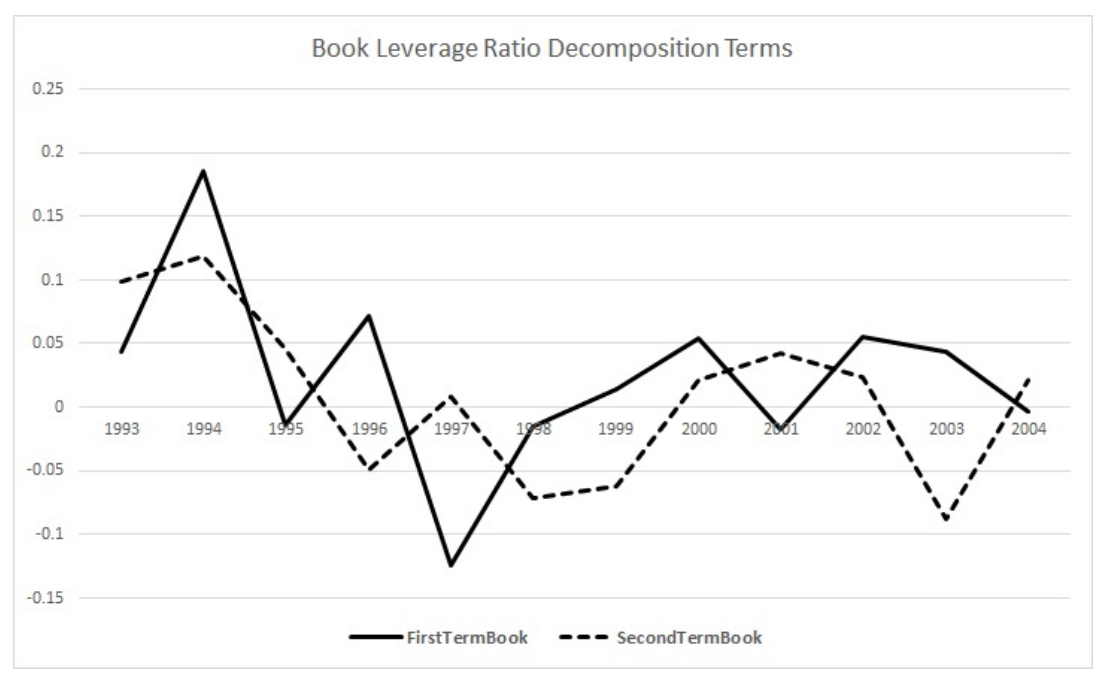

Figure 2: Horizontal axis shows the years 1993-2004. Vertical axis plots the first and the second terms of Equation (3.6), the HCA's book leverage ratio decomposition. 


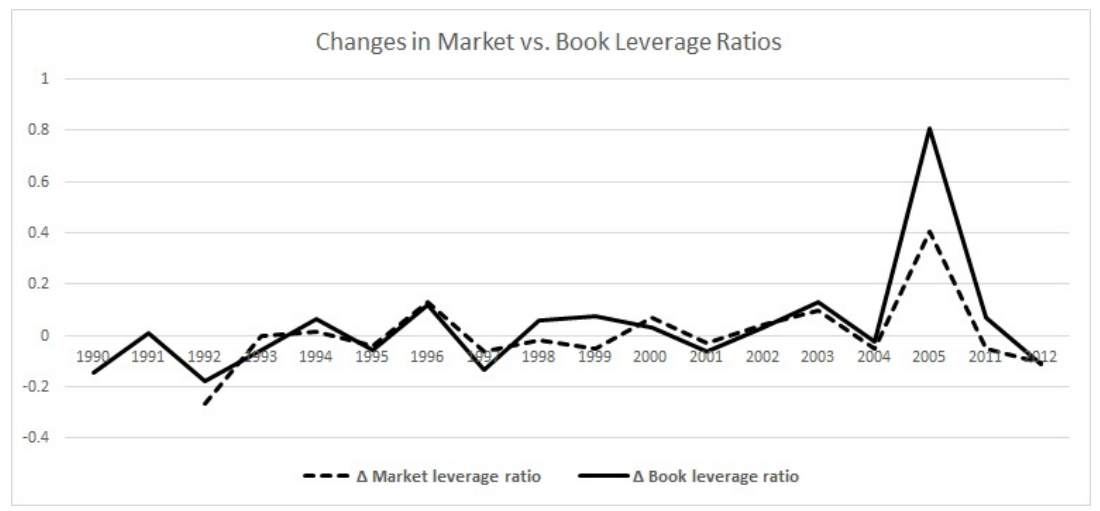

Figure 3: Horizontal axis shows the years 1990-2012. Vertical axis plots the changes in the HCA's market leverage ratio of Equation (3.4), and the changes in the HCA's book leverage ratio of Equation (3.6).

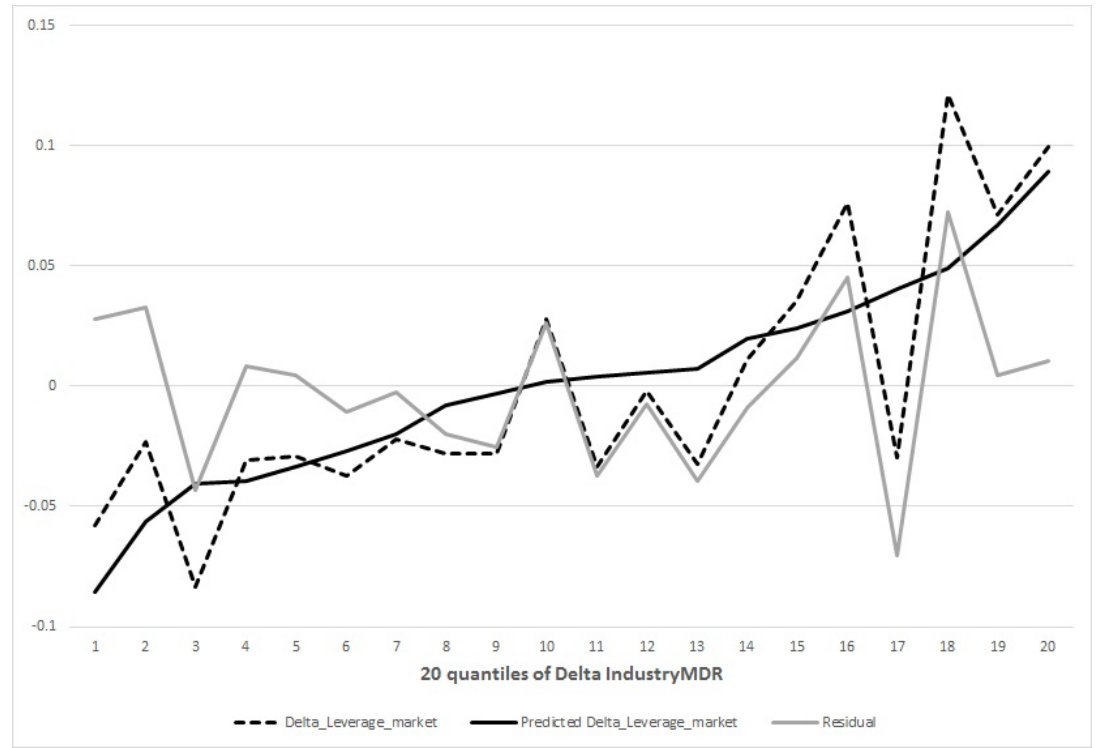

Figure 4: The horizontal axis shows the 20-Quantiles of $\Delta\left(\right.$ Industry $\left.M D R_{t}\right)$. The vertical axis plots the mean of $\Delta\left(L_{t}\right)_{\text {Market }}$, the predicted $\Delta\left(L_{t}\right)_{\text {Market }}$, and the predicted residuals using Equation (3.7). 


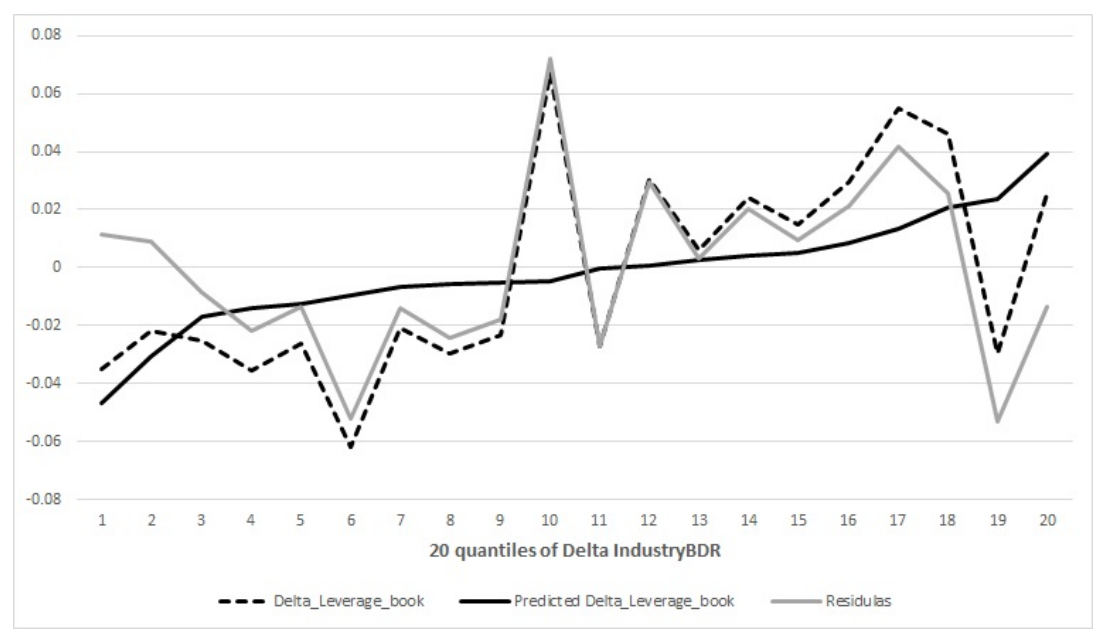

Figure 5: The horizontal axis shows the 20-Quantiles of $\Delta\left(\right.$ Industry $\left.B D R_{t}\right)$. The vertical axis plots the mean of $\Delta\left(L_{t}\right)_{\text {Book }}$, the predicted $\Delta\left(L_{t}\right)_{\text {Book }}$, and the predicted residuals using Equation (3.7).

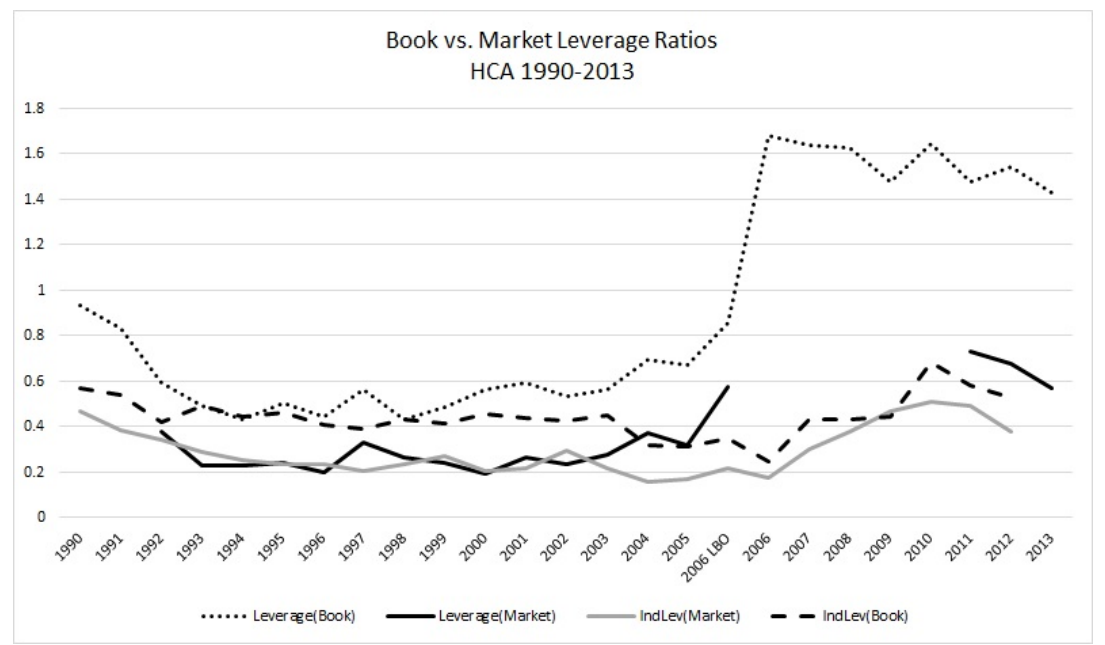

Figure 6: Horizontal axis shows the years 1990-2013. Vertical axis plots the annual market and book leverage ratios of $\mathrm{HCA}$ in each year. Annual market leverage ratios are missing from 1990 to 1992 and from 2007 through 2011, when HCA was privately held. The book leverage ratios are available for all years. 


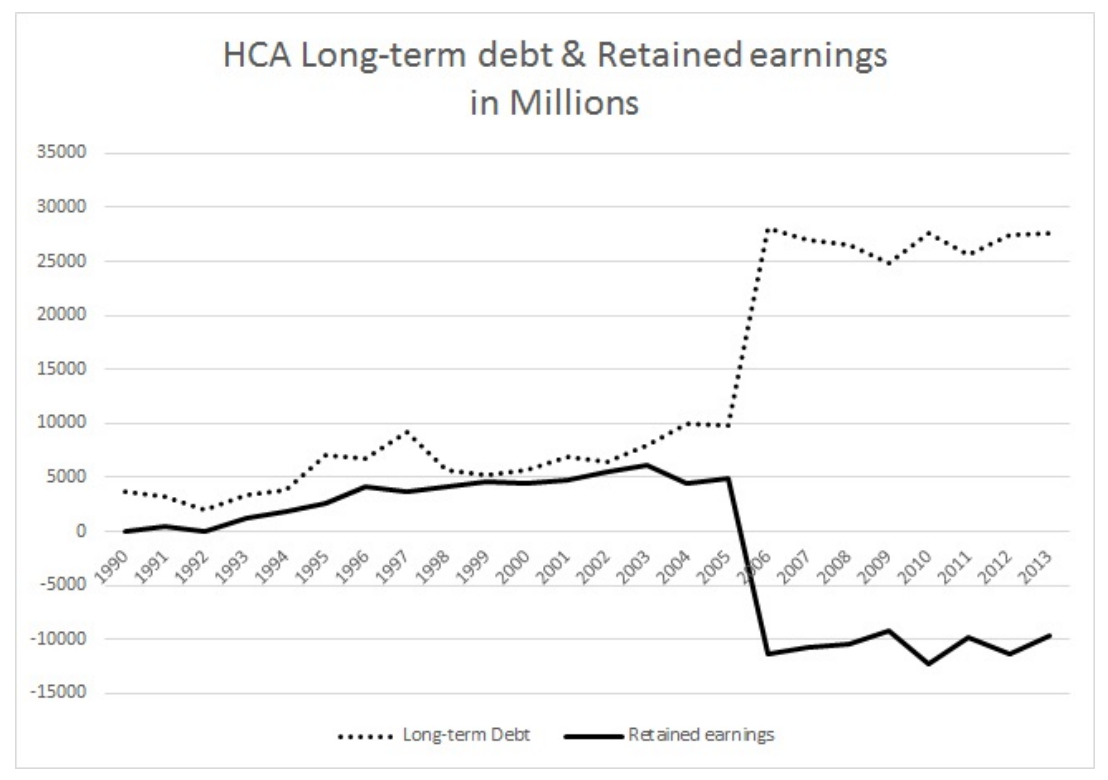

Figure 7: Horizontal axis shows the years 1990-2013. Vertical axis plots the HCA annual long-term debt and retained earnings from 1990 to 2013 in millions.

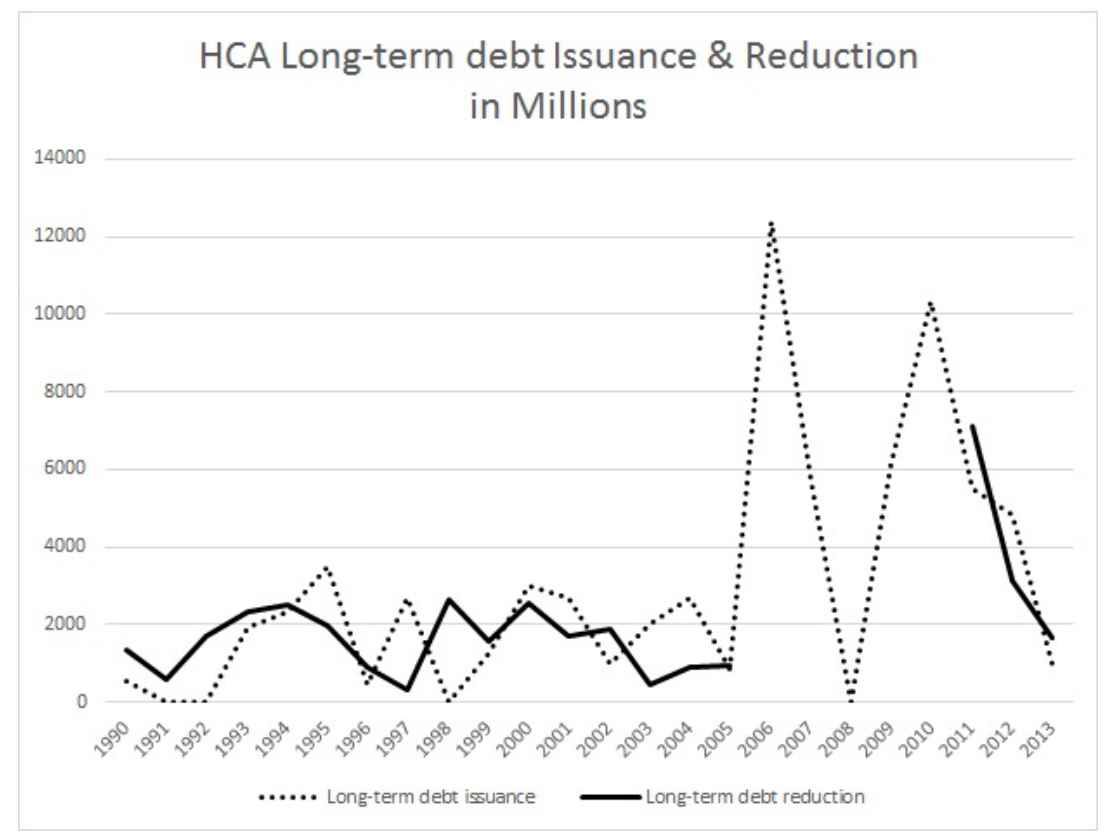

Figure 8: Horizontal axis shows the years 1990-2013. Vertical axis plots the HCA annual long-term debt issuance and reduction from 1990 to 2013 in millions. 


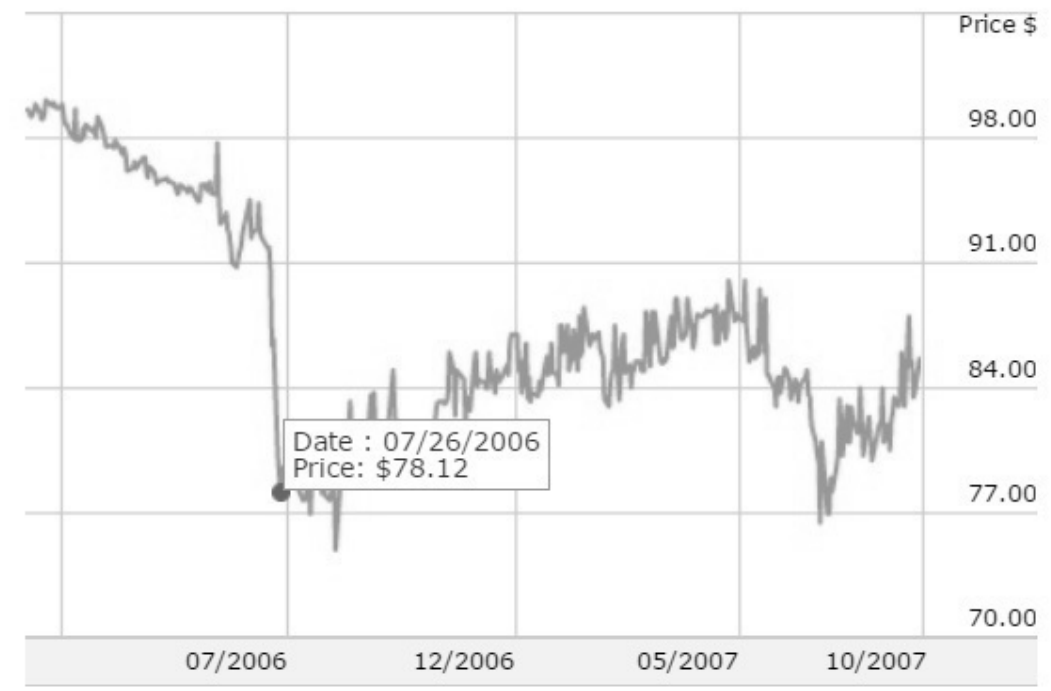

Figure 9: Horizontal axis shows the year 2006. Vertical axis plots HCA 6.5\% coupon bond prices due Feb 15, 2016, from June 2006 to November 2007. Source: Financial Industry Regulatory Authority, Inc. (FINRA) (2015).

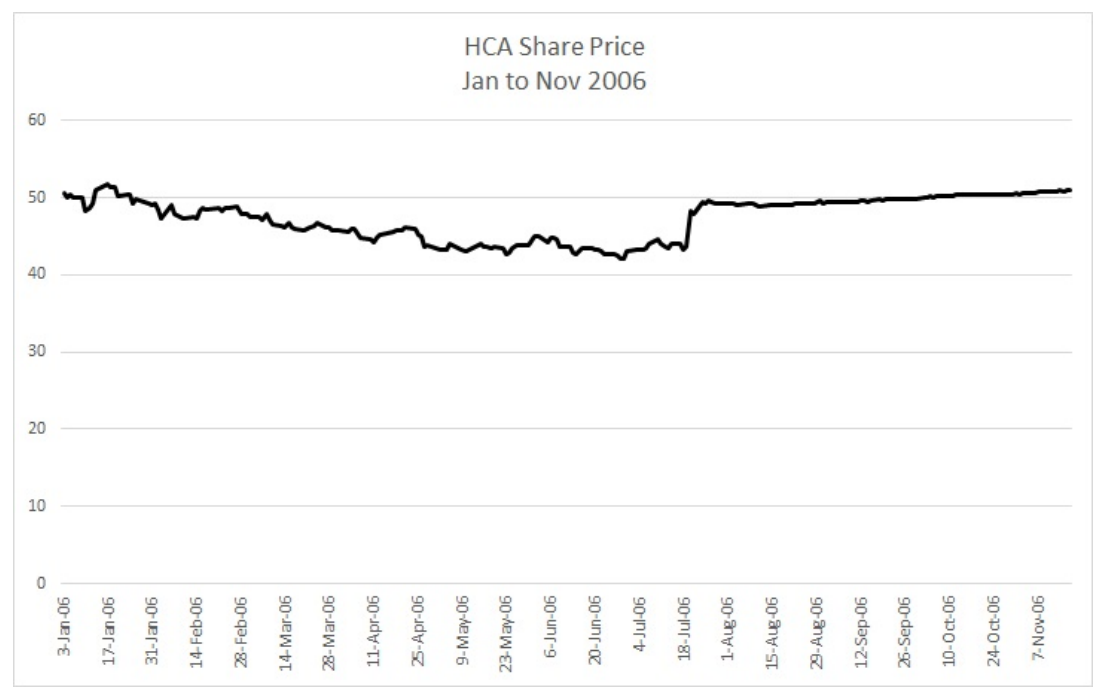

Figure 10: Horizontal axis shows the year 2006. Vertical axis plots HCA historical share price from January to November 2006. 


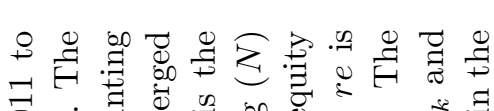
ลี่

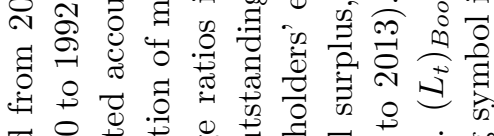

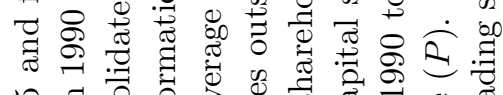

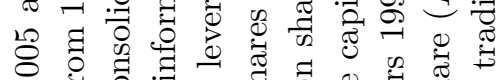

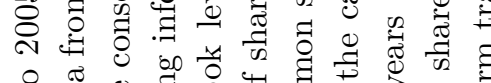

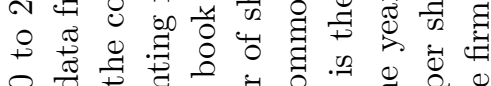

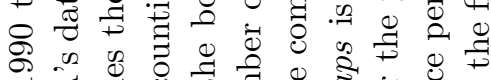

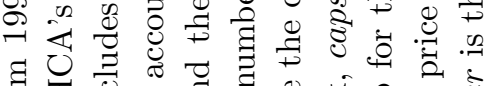

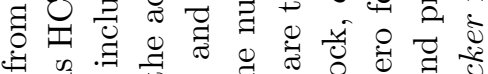

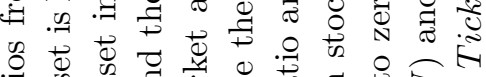
象

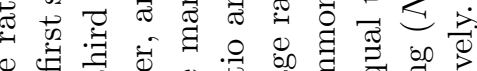

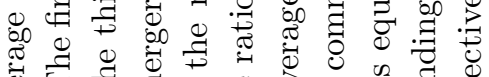

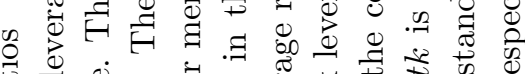

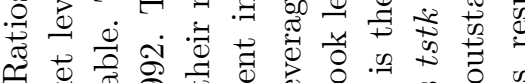

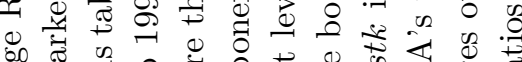

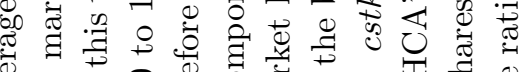

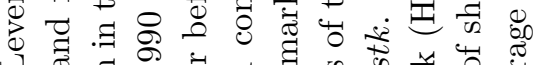

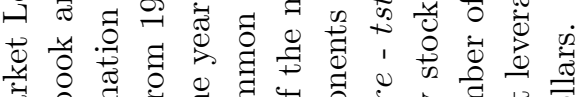

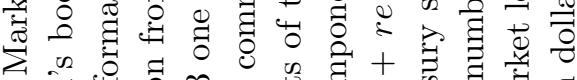

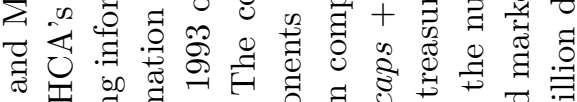

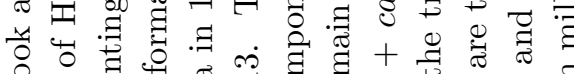

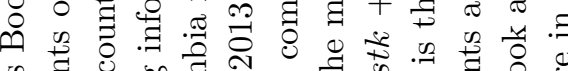

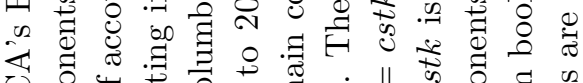

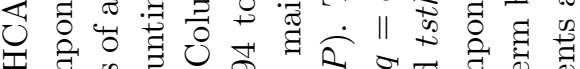

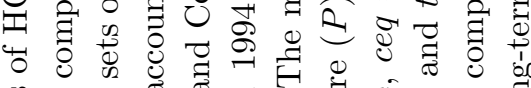

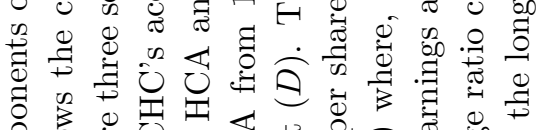

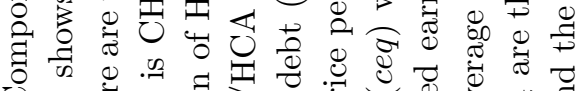
U O

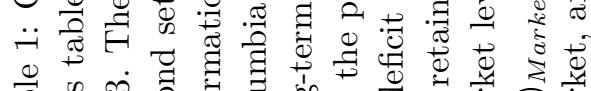

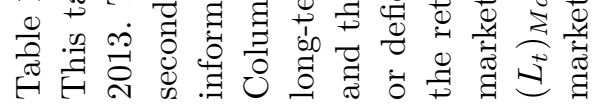

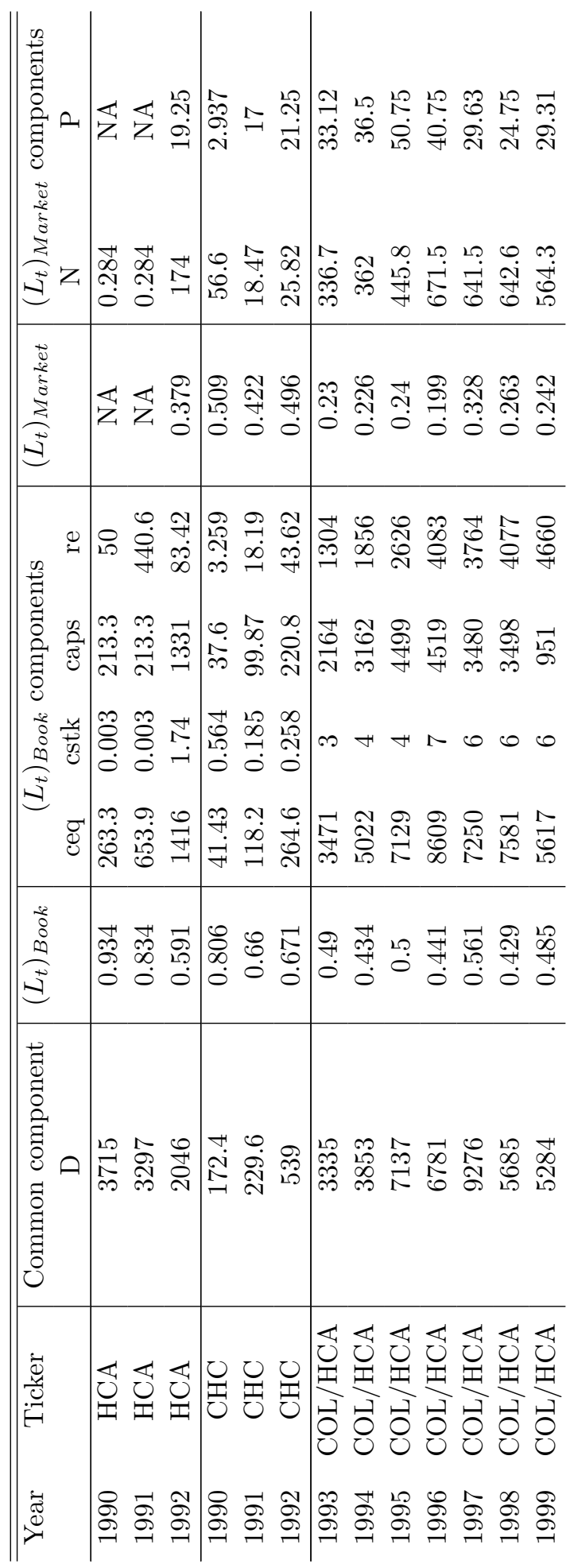




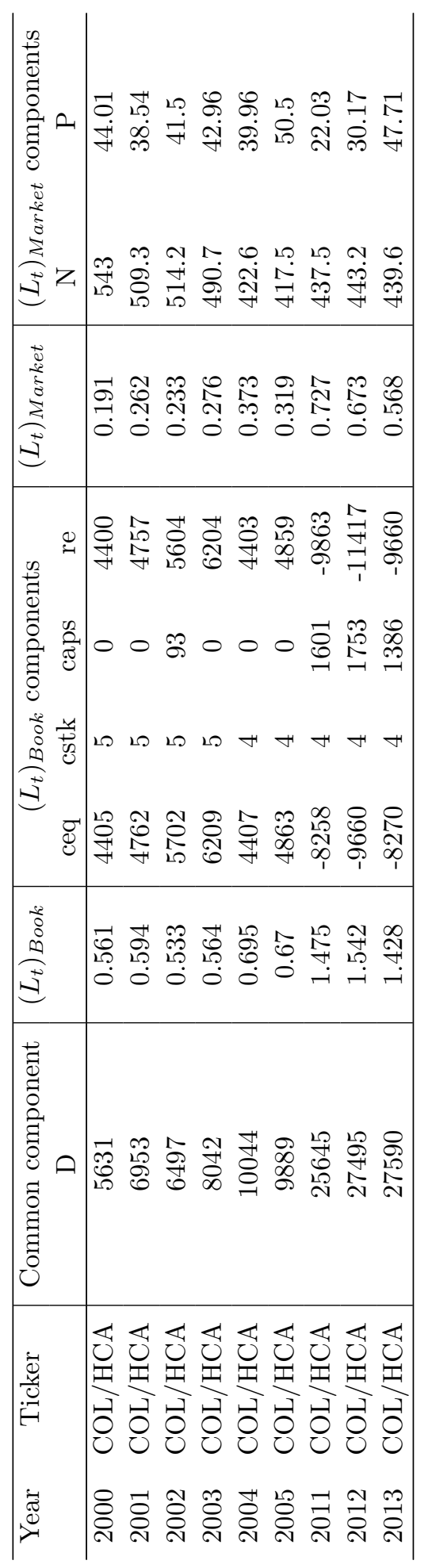




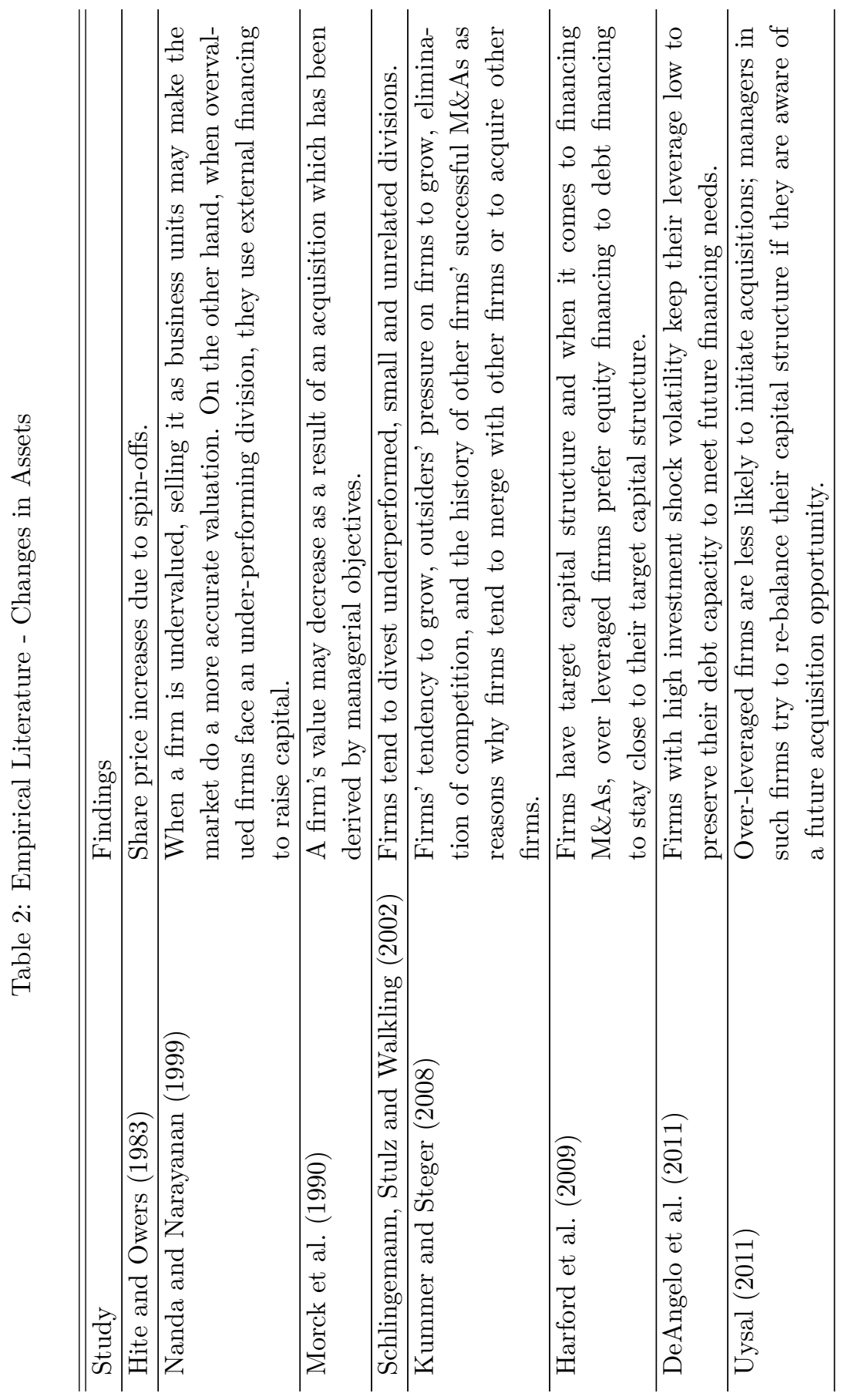




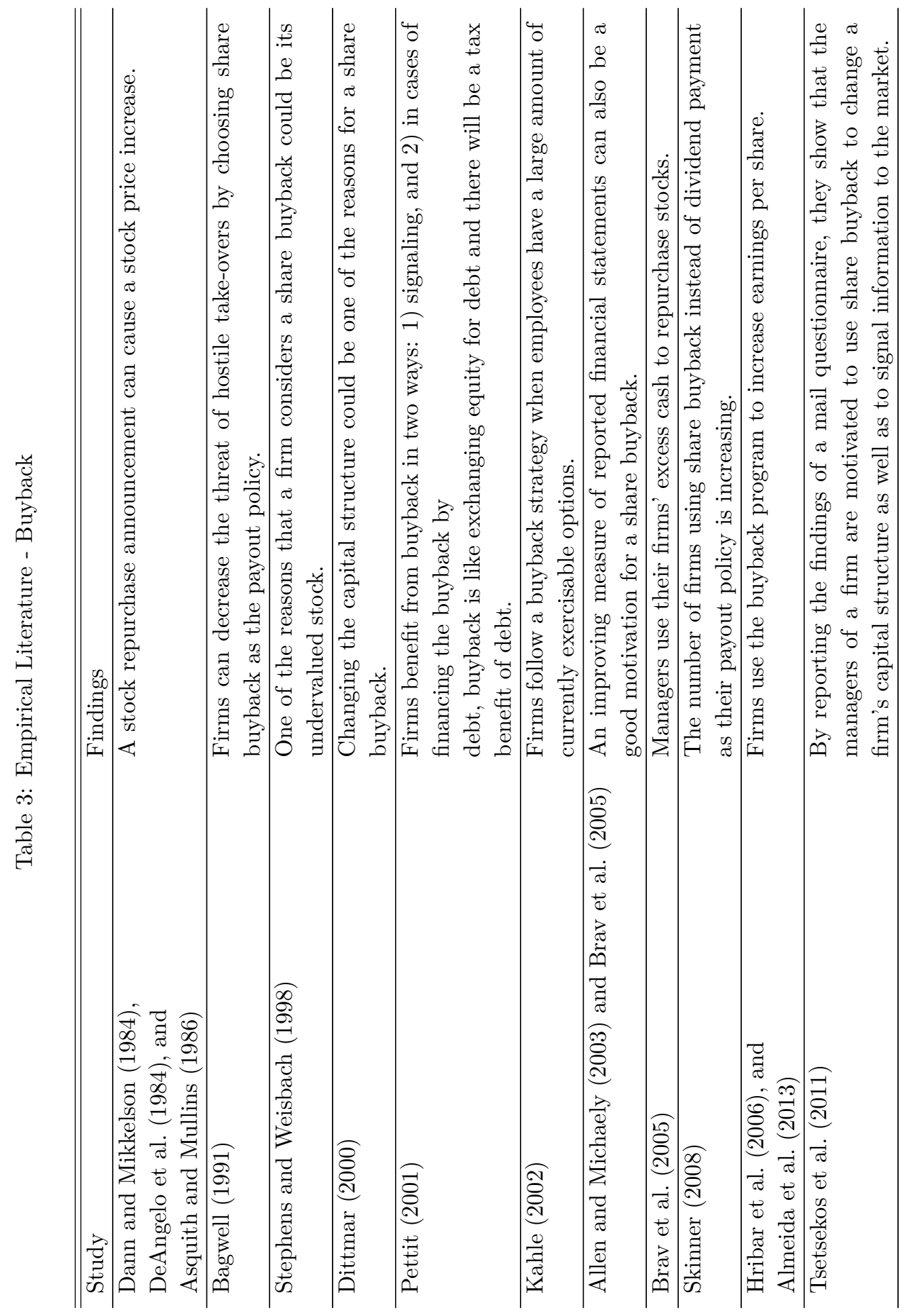


Table 4: Columbia/HCA buybacks and public offerings from 1990 to 2013

Panel A of this table reports Columbia/HCA buybacks from 1990 to 2013, and panel B reports Columbia/HCA public offerings from 1990 to 2013. Columns (1) to (4) represent the date of buyback/public offering, number of shares outstanding, price per share, shareholders' equity. Column (5) in panel A reports the number of the buybacked shares, and panel B reports the number of the offered shares. The numbers in columns (2), (4) and (5) are written in thousands. The negative signs in Column (5) show the decrease in the shares outstanding from the previous day, and the positive signs show the increase in the shares outstanding from the previous day.

\begin{tabular}{lcccc}
\hline \hline Panel A & & & & \\
\hline$(1)$ & $(2)$ & $(3)$ & $(4)$ & $(5)$ \\
Date & N & Prc & SHEquity & Diffshrout \\
\hline $31 / 10 / 11$ & 436409 & 23.45 & 10200000 & -80771 \\
$28 / 05 / 99$ & 547075 & 23.56 & 12900000 & -74159 \\
$31 / 01 / 05$ & 422600 & 44.52 & 18800000 & -39645 \\
$31 / 01 / 06$ & 417500 & 49.08 & 20500000 & -35167 \\
$31 / 03 / 06$ & 386931 & 45.79 & 17700000 & -30582 \\
$30 / 06 / 97$ & 646788 & 39.31 & 25400000 & -26536 \\
$31 / 08 / 01$ & 492662 & 45.74 & 22500000 & -23859 \\
$31 / 03 / 03$ & 490739 & 41.36 & 20300000 & -23261 \\
$31 / 08 / 06$ & 388548 & 49.32 & 19200000 & -20689 \\
$31 / 05 / 11$ & 515646 & 34.89 & 18000000 & -18489 \\
\hline \hline Panel B & & & & \\
\hline $10 / 03 / 11$ & 515205 & 31.02 & 16000000 & 515205 \\
$16 / 10 / 96$ & 670704 & 36.25 & 24300000 & 223568 \\
$11 / 02 / 94$ & 337546 & 38.63 & 13000000 & 161264 \\
$28 / 04 / 95$ & 442079 & 42.13 & 18600000 & 79988 \\
$31 / 05 / 05$ & 446719 & 54.00 & 24100000 & 30853 \\
$28 / 04 / 06$ & 408100 & 43.89 & 17900000 & 21169 \\
$17 / 11 / 06$ & 409800 & 50.97 & 20900000 & 21102 \\
$30 / 09 / 94$ & 358642 & 43.50 & 15600000 & 20573 \\
$29 / 04 / 11$ & 534135 & 32.80 & 17500000 & 18930 \\
$30 / 06 / 93$ & 174256 & 19.50 & 3398000 & 15685 \\
\hline
\end{tabular}




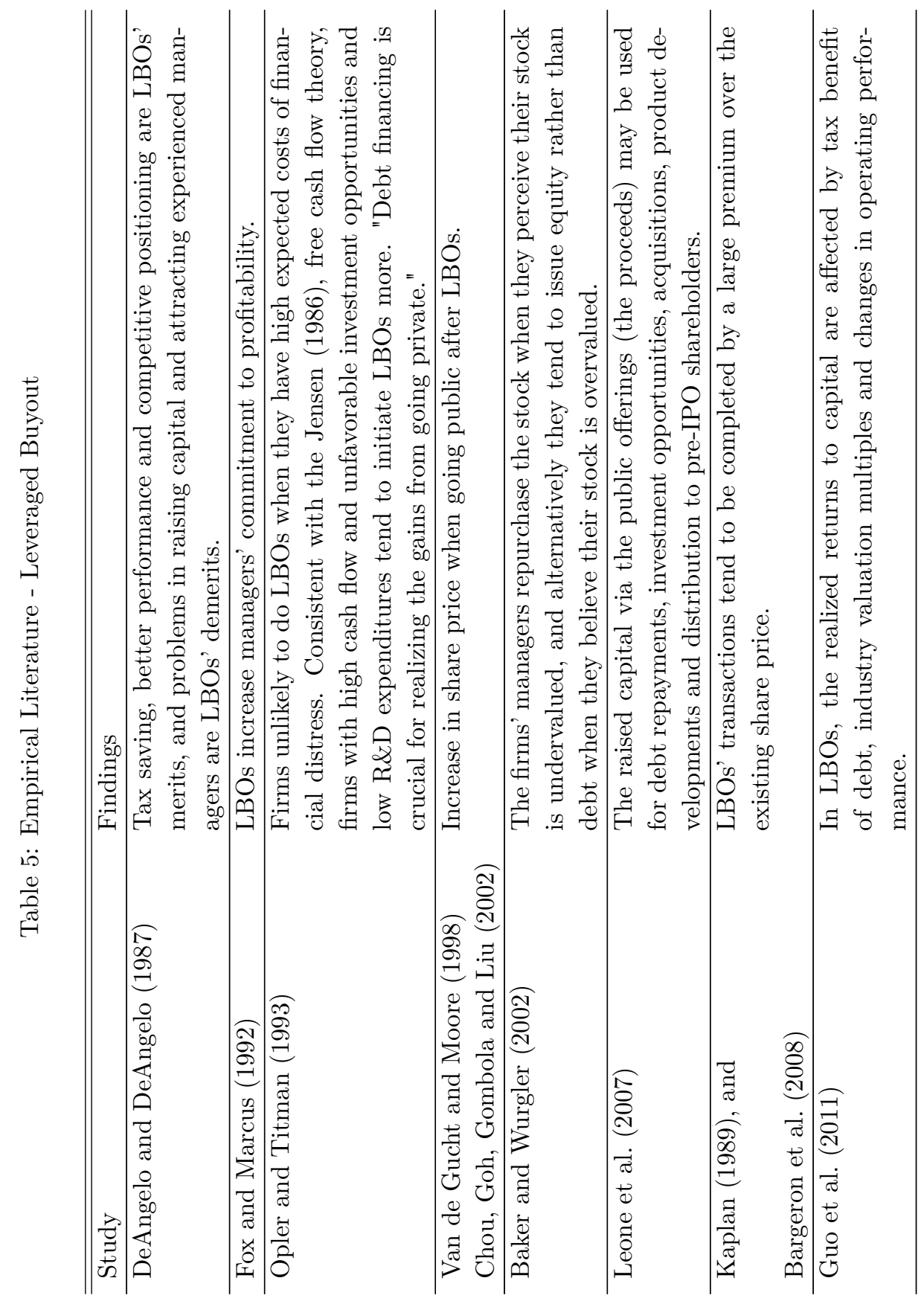




\section{Chapter 4}

\section{The influence of investment volatility on capital structure and cash holdings}

\subsection{Introduction}

The theoretical and empirical academic literature regarding how firms finance their investment opportunities is large (for example Myers and Majluf (1984); Jensen (1986)). However, the relationship between investment volatility and financing is relatively unexplored. DeAngelo et al. (2011) create a dynamic capital structure model, where investment opportunities are not predictable but subject to shocks. Based on model simulations, firms with high shock volatility (relative to low shock volatility firms) have lower levels of debt, higher cash balances, and higher average debt issuance. In a related study, Elsas, Flannery and Garfinkel (2014) study how firms pay for very large investments and conclude that firms issue debt to fund large investments and subsequently pay off the debt with internal cash flows. Both papers empirically examine the influence of investment spikes (large investments) on financing, but to our knowledge there are no papers that test the crosssectional relationship between investment volatility and financing. ${ }^{1}$

\footnotetext{
${ }^{1}$ For example, investment volatility is not tested in Frank and Goyal (2009).
} 
We follow DeAngelo et al. (2011) and define investment as capital expenditures plus acquisitions. However, because firms' policies may differ by investment types, we unbundle their definition and define investment as either capital expenditures or acquisitions and further define research and development as investment. We follow DeAngelo et al. (2011) and scale all investment measures by property, plant and equipment.

We use two methods to construct our variables of interest. First, we use the method of Kim and Sorensen (1986) and estimate the rolling five year standard deviation of investment. Second, we estimate the De Veirman and Levin (2015) conditional volatility measure and use it to construct investment spike variables (large investments). An investment spike occurs when actual investment growth is greater than predicted investment growth and when investment volatility is in the top tercile. The dependent variables are either the short and long-term book debt ratio or cash to total assets ratio. Whereas our investment spike variable is estimated from investment realizations from a conditional volatility estimation, DeAngelo et al. (2011) define investment spikes as investments that are two standard deviations from the two digit SIC code average. As the dependent variables in this study are bounded between zero and one, we test using the GLM (Generalized Linear Model) with logit link function proposed by Kieschnick and McCullough (2003) and used by Keefe and Yaghoubi (2015). We also follow Lemmon et al. (2008) and Flannery and Rangan (2006) and estimate a panel data model that controls for time invariant firm heterogeneity, and use panel GLM to test our hypotheses.

The first hypothesis is about the relationship between the investment volatility and a firm's debt and cash levels. Relative to the relationship between investment volatility and debt levels, our evidence indicates that high capital expenditure and acquisition volatility leads to higher debt levels. Relative to the relationship between investment volatility and cash levels, our estimation results indicate that high acquisition volatility leads to lower levels of cash, but that capital expenditure volatility does not affect cash levels. Our results are statistically significant and economically important. One standard deviation increase from the mean of capital expenditure plus 
acquisition investments volatility variable, leads to a $17.17 \%$ increase in the debt ratio and a $12.06 \%$ decrease in the cash level. All in all, our evidence does not support the DeAngelo et al. (2011) model prediction that firms with high investment volatility keep debt levels low and cash levels high. To our knowledge, we are the first to empirically test the relationship between financing and investment volatility.

The second hypothesis relates to how firms use debt and cash to fund large investments. We find a positive relationship between large investments and use of debt, and a negative relationship between large investments and cash levels. Our variable of interest is the investment spike variable defined earlier. Our evidence supports the ration that firms use debt and cash to fund large investments. Our results are statistically significant and economically important - our evidence suggests a $30.39 \%$ increase in the debt ratio and a $30.59 \%$ decrease in the cash level as a result of an investment spike (large investment). This finding supports the DeAngelo et al. (2011) model prediction and empirical tests that firms issue debt and use cash to fund large capital expenditure and acquisition investments. Unlike the first hypothesis, which has not been previously tested, our contribution relative to the second hypothesis is the use of a firm-level measure of investment spikes.

The third hypothesis is whether, after funding large investments, firms decrease debt levels and increase cash levels. Although rebuilding cash levels is not explicit in the model of DeAngelo et al. (2011), a plausible implication of their model is that firms rebuild their stock of cash after using cash stocks to fund large investments. For both cash and debt levels, our evidence suggests that one year after making large investments firms rebuild their debt and cash capacity by decreasing their debt levels and increasing their cash stocks. Our results are statistically significant and economically important - our evidence suggests a $10.76 \%$ decrease in the debt ratio and a $21.15 \%$ increase in the cash levels one year after the large investment. Overall, our findings support the DeAngelo et al. (2011) model prediction that firms decrease their debt level after the spike year. Our findings that firms increase cash levels after funding investments is novel.

Our evidence suggests firms' financial policies to support research and 
development investments differ from financial policies in support of capital expenditure and acquisition investments. Therefore, we discuss here our findings for all three hypotheses related to research and development. First, our evidence shows that higher research and development volatility leads to lower debt levels and higher cash levels. This result is statistically and economically important - a one standard deviation increase in research and development investment volatility leads to a $5.15 \%$ decrease in the debt ratio and a $10.40 \%$ increase in cash levels. Interestingly, unlike capital expenditure and acquisition volatility, this finding supports the DeAngelo et al. (2011) model prediction that firms with high investment volatility keep debt levels low and cash levels high. Second, our evidence indicates that research and development investment spikes are not important in explaining the level of cash or debt. However, one year after a large research and development investment, firms increase their debt capacity and cash stocks, which mirrors firms' behavior relative to capital expenditure and acquisition spikes. Our findings related to research and development investment volatility are novel.

We also evaluate if our findings are robust to a different measure of debt ratio, cash ratio, and spike measure. In particular, we test our hypotheses using the market short and long-term debt ratio, the ratio of cash over net assets, and a variable representing two consecutive investment spikes (large investments). We test our first hypothesis using the market debt ratio variable and our main results remain unchanged. Then we test all the three cash hypotheses using the ratio of cash over net assets and find that all the results remain unchanged. However, the result that research and development investment volatility leads to high cash levels is no longer statistically significant. We note that we estimate using a linear model. Lastly, using the two consecutive spike variables, we test our second hypothesis and all the main results remain unchanged.

This paper proceeds as follows: Section 4.2 reviews the literature and develops our hypotheses of the study. Section 4.3 reviews the data, constructs the variables, and reports the univariate statistics of the variables. Section 4.4 tests the hypotheses and discusses the results. Section 4.5 tests for robustness to other specifications and econometric methods. Section 4.6 
provides concluding remarks.

\subsection{Literature review and Hypothesis devel- opment}

DeAngelo et al. (2011) create a dynamic model of capital structure where optimal investment requirements are not predictable. Specifically, the marginal productivity of capital is modeled as an auto-regressive (AR1) process, where the error term represents shocks to marginal productivity. These shocks imply that optimal investment is uncertain. The model suggests a firm's debt structure and cash levels are influenced by the need to fund uncertain investments. Using a Simulated Method of Moments (SMM), DeAngelo et al. (2011) show their model predicts that firms with higher versus lower standard deviation of investment shocks tend to have higher (lower) standard deviation of investment outlays, lower (higher) debt ratios, higher (lower) cash holdings, and higher (lower) deviation from target debt ratio. Essentially, a firm with uncertain future investment maintains financing capacity by keeping its debt ratio low and its cash level high.

DeAngelo et al. (2011) advance their dynamic model which implies firms with high investment shock volatility hold less debt. Intuitively, a firm with high investment shocks maintains low debt ratios to preserve debt capacity in order to fund uncertain investments. Although we cannot observe marginal productivity shocks in the DeAngelo et al. (2011) model, we can observe firm level investment volatility. To the extent that investment volatility is a proxy for marginal productivity shocks, firms with high investment volatility maintain lower debt ratios than would be optimal under a static trade-off model.

Hypothesis 3a. Firms with high investment volatility have lower debt ratios, caeteris paribus.

Opler, Pinkowitz, Stulz and Williamson (1999) state that firms set cash holding levels where the marginal benefits of holding cash are equal or greater 


\subsection{LITERATURE REVIEW AND HYPOTHESIS DEVELOPMENT 111}

than the marginal cost of it. ${ }^{2}$ One of the benefits of cash holdings is having the option to finance investment opportunities using cash when other sources of financing are costly. Also, Kim, Kim and Woods (2011) find a positive relationship between a firm's cash holding level and investment opportunities. The model DeAngelo et al. (2011) advances that a higher fraction of investments in firms with high investment shock volatility are funded from cash balances, which implies:

Hypothesis 3b. Firms with high investment volatility hold more cash, caeteris paribus.

The model of DeAngelo et al. (2011) implies that firms temporarily diverge from their target capital structure to finance investments, where the difference between the target capital structure and the actual capital structure is the "transitory debt." DeAngelo et al. (2011) refer to large investments as investment spikes, and analyze debt issuances that associated with investment spikes for a sample of Compustat firms. Empirical tests show that investment spikes are accompanied by large debt issuances. In a related note, Denis and McKeon (2012) discuss how firms evaluate the financing of investment opportunities, and if there is a financing deficit they deviate from the target capital structure. They find that increases in the debt levels are primarily the result of the investment needs. In addition, Elsas et al. (2014) conclude that firms issue debt to fund large investments.

Hypothesis 4a. Firms with large investments have higher debt ratios, caeteris paribus.

The model of DeAngelo et al. (2011) implies firms with large uncertain investments have a higher beginning-of-year than end-of-year cash to assets ratio, indicating that such firms use cash to find large uncertain investments. Therefore, investment spikes are financed by a decrease in a firm's cash level, which implies:

Hypothesis 4b. Firms with large investments have lower cash levels, caeteris paribus.

\footnotetext{
${ }^{2}$ Examples of the drawbacks of holding cash are incremental taxes on interest income and lower rates of return.
} 
The DeAngelo et al. (2011) model predicts firms fund large uncertain investments by issuing debt, after which, firms decrease their debt level back toward their target capital structure. In a related study, Elsas et al. (2014) conclude that firms issue debt to fund large investments and subsequently pay off the debt with internal cash flows. Both studies advance:

Hypothesis 5a. After making large investments, firms decrease debt, caeteris paribus.

The DeAngelo et al. (2011) model advances that firms hold cash to fund uncertain investments. Although not explicit in their model, a plausible implication is that after depleting cash stocks to fund a large investment, the firm will rebuild their stock of cash, which implies:

Hypothesis 5b. After making large investments, firms increase cash, caeteris paribus.

These hypotheses test the relationship between the volatility of investments and large realization of investment on debt and cash levels. Prior literature uses several investment definitions including capital expenditures $(C a p x)$, acquisitions $(A c q)$, and the sum of capital expenditures and acquisitions $(C a p x+A c q)$. This paper contributes to the literature both in terms of the hypotheses tested and the range of our definitions of investment. To our knowledge, Hypotheses 3a, 3b and 5b have not been tested for any of these four investment volatilities. For some investment types some hypotheses have been tested. Hypothesis 4a has been empirically tested by DeAngelo et al. (2011) for large Capx + Acq and by Elsas et al. (2014) for large Capx and $A c q$, Hypothesis 4b has been empirically tested by DeAngelo et al. (2011) for large Capx $+A c q$, and Hypothesis 5 a has been empirically tested by DeAngelo et al. (2011) for large Capx + Acq. Lastly, research and development expenditures $(R \& D)$ has not been used as a measure of investment. 


\subsection{Sample, variable construction, and uni- variate statistics}

\subsubsection{Sample}

To test these hypotheses we obtain annual data from 1974 through 2015 of the US corporations from the Compustat-CRSP Merged database. Following Bates, Kahle and Stulz (2009), we exclude financial firms, utilities, nonUS firms and firms with missing or negative total assets or sales. We also follow Denis and Sibilkov (2010) and exclude firms with missing or negative cash. Following Kale and Shahrur (2007), all the variables are winsorized at $0.1 \%$ level in both tails of the distribution before calculating the summary statistics.

\subsubsection{Variable Construction}

\section{Dependent variables}

To test the relationship between investment volatility and capital structure, we construct both book and market debt ratios. In Section 4.4, we test using the book debt ratio and in the robustness section, we test using the market debt ratio. Our preferred measure is the book debt ratio because of possible simultaneity between market value and investment. ${ }^{3}$

In constructing our leverage measures, we address the Welch (2011) critique related to the treatment of non-financial liabilities. Welch (2011) states that by using financial debt over total assets ratio, researchers treat the nonfinancial liabilities as equity. To be consistent with DeAngelo et al. (2011), we use the total long plus short-term debt (financial-debt) in the numerator of our debt ratio measures, but we do not use the DeAngelo et al. (2011) debt ratio's denominator as they used the total assets. Following the Welch (2011) critique, we modify the denominator of our debt measures and use the below book and market debt ratios used by Rajan and Zingales (1995). For

\footnotetext{
${ }^{3}$ Investment might affect both the market value of the equity and the need for the firm to issue more debt to fund the investment.
} 
replication purposes, we use Compustat variable names in our definitions.

i) The short and long-term book debt ratio is the sum of short and longterm debt over the sum of common shareholders' equity, the total longterm debt and the total short-term debt.

$$
B D R=\frac{d l t t+d l c}{c e q+d l t t+d l c}
$$

ii) The long-term market debt ratio is the sum of short and long-term debt divided by the sum of the long-term debt, short-term debt and the market value of equity.

$$
M D R=\frac{d l t t+d l c}{d l t t+d l c+c s h o * p r c c \_f} .
$$

Note that both the numerator and the denominator exclude the non-financial liabilities.

To test the relationship between investment volatility and cash holdings, we construct a ratio of cash and short-term investments over total assets (DeAngelo et al., 2011; Bates et al., 2009; Almeida, Campello and Weisbach, 2004; DeAngelo, DeAngelo and Stulz, 2006).

$$
\text { Cash }=\frac{\text { che }}{a t} .
$$

\section{Variables of Interest}

We employ four measures of investment. First, we follow Guay (1999), Eisfeldt and Rampini (2006) and DeAngelo et al. (2011), who define a firm's investment as the sum of its capital expenditures plus acquisitions, Inv $=$ $C a p x+A c q .{ }^{4}$ Second, we use the components of the aforementioned investment definition which are capital expenditure Capx and acquisitions $A c q$ as the investment measures. Third, we use the research and development expenses $X r d$ as a measure of investment following Brown and Petersen (2011).

\footnotetext{
${ }^{4}$ Note that Compustat item capital expenditure Capx excludes the acquisitions Acq.
} 
We follow DeAngelo et al. (2011) and scale our investment measures by property, plant and equipment. ${ }^{5}$

We employ two volatility estimation methods from the literature. For our first volatility estimation method, we follow the volatility estimation method of Kim and Sorensen (1986) and used by Keefe and Yaghoubi (2015). We estimate the ratio of the five years rolling standard deviation of Inv, Capx, $A c q$ and $X r d$ to the five years rolling average of property, plant and equipment and construct $\operatorname{InvVol}_{t-5, t}, \mathrm{CapxVol}_{t-5, t}, \mathrm{Acq}_{\mathrm{V}} \mathrm{l}_{t-5, t}$ and $X r d V o l_{t-5, t}$ investment volatility measures; where, for example, InvVol ${ }_{t-5, t}$ is the investment volatility measure using Inv as the investment measure and the Kim and Sorensen (1986) estimation method. To denote five years as the length of the rolling window we use $(t-5, t)$ in the volatility measure.

To closely match the normal distribution of the investment volatility measures, we take the natural logarithm of the volatility measures. For example, the skewness and the kurtosis of Inv $o_{t-5, t}$ before taking the natural logarithm are 3.93 and 20.97, respectively. After taking the natural logarithm the skewness and the kurtosis decrease to 0.25 and 2.98 , respectively. ${ }^{6}$

For our second investment volatility measure, we follow the De Veirman and Levin (2015) volatility estimation method and used by Keefe and Yaghoubi (2015) and Keefe and Tate (2013). To construct the De Veirman and Levin (2015) investment volatility measure, we estimate

$$
\omega_{i, t}=\alpha_{i}+Y e a r \beta_{1}+\epsilon_{i, t}
$$

where $\omega_{i, t}$ represents the first difference of an investment measure scaled by property, plant and equipment from $t-1$ to $t$ for firm $i$ and $Y e a r$ is a matrix of year dummies. The residual $\epsilon_{i, t}$ represents the difference between the observed and the estimated investment growth of firm $i$ when controlling for time and firm's fixed effects. De Veirman and Levin (2015) show that $\hat{\sigma}_{i, t}$ is

\footnotetext{
${ }^{5}$ Except for research and development which is scaled by sales.

${ }^{6}$ Note that the skewness and the kurtosis of a normal distribution is 0 and 3, respectively.
} 
an unbiased estimator of the true conditional volatility

$$
\hat{\sigma}_{i, t}=\sqrt{\pi / 2} *\left|\hat{\epsilon}_{i, t}\right|
$$

where $\hat{\epsilon}_{i, t}$ is the estimated residual from Equation (4.4). We construct InvVol $_{t}$, CapxVol $_{t}, A c q V o l_{t}$ and $X r d V o l_{t}$ investment volatility measures. For example, CapxVol is the investment volatility for year $t$ estimated using Capx as the investment measure.

We construct our investment spike measure, using the De Veirman and Levin (2015) measure of volatility. For investment to be defined as a spike, it must meet two conditions. First, $\hat{\epsilon}_{i, t}$, which is estimated from Equation (4.4) must be positive. This implies that actual investment growth is greater than predicted investment growth from Equation (4.4). Second, the De Veirman and Levin (2015) measure of volatility $\hat{\sigma}_{i, t}$ in Equation (4.5) must be in the top tercile for each year. In summary, an investment spike occurs for those observations where $\hat{\sigma}_{i, t}$ is in the top tercile and where the deviation from predicted investment is positive. For example, CapxSpike ${ }_{i, t}$ is set to one when actual capital expenditure growth is higher than predicted from Equation (4.4) and capital expenditure volatility from Equation (4.5) is in the highest tercile.

\section{Control Variables}

To control for variables that influence a firm's debt ratio, we follow Frank and Goyal (2009) and use the following control variables.

i) MarketToBook is the proxy for a firm's growth opportunities and is the ratio of market value of asset to total assets.

ii) Tangibility is the asset tangibility. The assets tangibility of a firm is the ratio of net property, plant, and equipment over book value of total assets.

iii) FirmSize is a proxy for firms' size. It is the natural logarithm of total assets. 
iv) Profitability is the firm's operating income before depreciation divided by total assets.

v) FirmAge is the number of years a firm has been listed in the Compustat.

vi) $L n R n D$ is the natural $\log$ of $(1+$ research and development expenses divided by revenue).

vii) IndustLev is the ratio of median industry leverage ratio by SIC code to the total market debt ratio in each year.

viii) CreditRating is an indicator variable, equals to one if $\mathrm{S} \& \mathrm{P}$ rates the debt as investment grade (BBB) debt and zero otherwise.

ix) Inflation is the expected variation of CPI over the coming year.

We also control for cash flow volatility and follow Keefe and Yaghoubi (2015) and use:

x) $C F V_{t-5, t}$ is the natural log of a firm's cash flow volatility using a five-year window for years $t-5$ to $t$.

To control for variables that influence a firm's cash level, we follow Opler et al. (1999), Bates et al. (2009), and Pinkowitz and Williamson (2007) and use the following controls:

xi) DPfirms is a dummy variable set to one if the firm pays a dividend in year $t$, and zero otherwise.

xii) $N W C$ is the working capital minus cash and marketable securities over total assets.

Lastly, we control for the investment variables that are used to construct our investment volatility measures.

xiii) Acquisitions is the natural logarithm of the ratio of acquisition spending to property, plant and equipment (ppegt).

xiv) Capx is the natural logarithm of the ratio of capital expenditure to property, plant and equipment (ppegt). 
Because we already control for research and development using the Frank and Goyal (2009) measure, we do not add an additional control for research and development. To mitigate possible omitted variable bias we use all of the control variables in all tests.

\section{Sample and Univariate Statistics}

Table 1 reports summary statistics. The table reports that for most variables there are 146,668 firm-year observations. The mean of the book debt ratio $B D R$ is greater than the mean of the market debt ratio. This is consistent with the mean of market to book ratio $M t B$ being greater than one. In addition, Table 1 shows that on average the cash holding level of the sample firms is about $18 \%$ of the total assets, with a standard deviation of 0.22 . The table also shows that on average $35.4 \%$ of the firm-year observations are the dividend paying firms and have been listed in Compustat for about 9 years.

\section{insert Table 1}

Table 2 reports the correlation coefficients between our volatility measures, MarketToBook and our four investment measures. All the investment measures are positively correlated and among all of them Capx and Inv are highly correlated, with a correlation coefficient of 0.89 . However, the correlation coefficient between Capx and $A c q$ is only 0.22. This suggests Capx dominates the combined measure of investment used by DeAngelo et al. (2011). The correlation coefficients between MarketToBook and Inv, Capx and Acq are small and negative, while the correlation between $\mathrm{Xrd}$ and MarketToBook ratio is small and positive. All the investment volatility measures as well as MarketToBook are positively correlated. Also, all investment volatility and investment spike variables are positively correlated. The highest correlation coefficient of 0.83 is between $\operatorname{InvVol}_{t-5, t}$ and $A c q V o l_{t-5, t}$. This suggests most of the variation in the compound measure of investment is driven by acquisitions.

insert Table 2 


\subsection{Testing}

\subsubsection{Estimation approach}

To test our hypotheses, we consider the fact that our dependent variables are proportional variables that are bounded between zero and one, which implies a nonlinear relationship between our dependent variables and explanatory variables. To address this issue, we follow Cook et al. (2008) and use the following GLM (Generalized Linear Model):

$$
E\left(\text { Ratio }_{i, t} \mid X_{i, t-1}, I\right)=G\left(\alpha_{i}+X_{i, t-1} \beta_{1}+\beta_{2} I+\epsilon\right)
$$

where

- $\mathrm{G}($.$) is the logistic link function,$

- Ratio ${ }_{i, t}$ is the book debt ratio BDR for Hypotheses 3a, 4a and 5a; and is the cash ratio Cash for Hypotheses $3 \mathrm{~b}, 4 \mathrm{~b}$ and $5 \mathrm{~b}$.

- $X_{i, t-1}$ is a matrix of lagged control variables listed in Section 4.3.2, and

- $I$ is the variable of interest. For Hypotheses $3 \mathrm{a}$ and $3 \mathrm{~b}, I$ is the lag of one of the investment volatility variables $\operatorname{InvVol}_{t-5, t}, \mathrm{CapxVol}_{t-5, t}$, $A c q V o l_{t-5, t}$ and $X r d V o l_{t-5, t}$; for Hypotheses $4 \mathrm{a}$ and $4 \mathrm{~b}, I$ is one of the the dummy spike variables InvSpike ${ }_{t}$, CapxSpike $_{t}$, AcqSpike $_{t}$ and $X r d$ Spike $_{t}$; for Hypotheses $5 \mathrm{a}$ and $5 \mathrm{~b}, I$ is the first lag and the first lead of one of the spike variables.

In addition to our cross-sectional regression, we follow Lemmon et al. (2008) and Flannery and Rangan (2006) and estimate a panel data model which controls for time invariant firm heterogeneity, implying identification comes through investment volatility variations within a firm over time. Because our dependent variables are proportional variables bounded between zero and one, we use the GLM panel data model as follows:

$$
E\left(\text { Ratio }_{i, t} \mid X_{i, t-1}, I\right)=G\left(\alpha_{i}+X_{i, t-1} \beta_{1}+\beta_{2} I+\epsilon_{i, t-1}\right)
$$

where 
- $\mathrm{G}($.$) is the logistic link function,$

- Ratio $i_{i, t}$ is the book debt ratio $B D R$ for Hypotheses 3a, 4a and 5a; and is cash ratio Cash for Hypotheses 3b, 4b and 5b.

- $X_{i, t-1}$ is a matrix of lagged control variables listed in Section 4.3.2, and

- $I$ is the variable of interest. For Hypotheses $3 \mathrm{a}$ and $3 \mathrm{~b}, I$ is the lag of one of the investment volatility variables $\operatorname{InvVol}_{t-5, t}, \mathrm{CapxVol}_{t-5, t}$, $A c q V o l_{t-5, t}$ and $X r d V o l_{t-5, t}$; for Hypotheses $4 \mathrm{a}$ and $4 \mathrm{~b}, I$ is one of the the dummy investment spike variables InvSpike $e_{t}$, CapxSpike $_{t}$, AcqSpike $_{t}$ and XrdSpike ; $_{t}$ for Hypotheses 5a and 5b, I is the first lag and the first lead of one of the investment spike variables.

Table 3 through Table 8 report estimation results. In each table, Columns (1) to (4) report the estimation results of Equation (4.6) and Columns (5) to (8) report the estimation results of Equation (4.7), where the dependent variable is either book debt ratio $B D R$ or the cash to assets ratio Cash. In addition, Table 3 through Table 8 report that all the control variables are statistically significant with signs predicted from the literature.

\subsubsection{Hypotheses 3a and 3b - Effect of investment volatility on a firm's debt and cash levels.}

Table 3 reports estimation results that test Hypothesis $3 \mathrm{a}$, which posits that investment volatility implies low levels of debt. The intuition behind this hypothesis is that firms with high investment volatility keep debt levels low to maintain debt capacity to fund uncertain future investments. Table 3 shows:

- The coefficient associated with capital expenditure volatility CapxVol ${ }_{t-5, t}$ is positive and statistically significant at less than the $1 \%$ level, which is opposite to the predicted relationship.

- The coefficient associated with acquisitions volatility $A c q V o l_{t-5, t}$ is positive and statistically significant at less than the $1 \%$ level, which is 
opposite to the predicted relationship. We note that compound investment volatility $\operatorname{InvVol}_{t-5, t}$, which is highly correlated with acquisition volatility, has the same sign and statistically significance.

- The coefficient associated with research and development volatility $X r d V o l_{t-5, t}$ is negative and statistical significant at less than the $1 \%$ level, which is consistent with the predicted relationship.

Our evidence suggests that firms with high capital expenditures and acquisitions investment volatility do not keep debt levels low. Rather, high investment volatility appears to lead to higher debt levels. In contrast, firms with high research and development investment volatility use less debt. All in all, our evidence does not seem to support the DeAngelo et al. (2011) model prediction that firms with high investment volatility keep debt levels low.

\section{insert Table 3}

Table 4 reports estimation results test Hypothesis 3b, which advances that investment volatility implies high levels of cash. The intuition behind this hypothesis is firms with high investment volatility keep cash levels high to fund uncertain future investments. Table 4 shows:

- The coefficient associated with capital expenditure volatility CapxVol ${ }_{t-5, t}$ is positive, but not statistically significant.

- The coefficient associated with acquisitions volatility $A c q V o l_{t-5, t}$ is negative and statistically significant at less than the $1 \%$ level, which is opposite to the predicted relationship. We note that compound investment volatility $I_{n v} \mathrm{Vol}_{t-5, t}$, which is highly correlated with acquisitions, has the same sign and statistical significance.

- The coefficient associated with research and development volatility $X r d V o l_{t-5, t}$ is positive and statistically significant at less than the $1 \%$ level, which is consistent with the predicted relationship.

Our estimation results testing with acquisition volatility are contrary, research and development volatility is in support and capital expenditure 
volatility is ambiguous relative to Hypothesis 3b. This evidence provides mixed support of the DeAngelo et al. (2011) model.

insert Table 4

\subsubsection{Testing Hypotheses $4 \mathrm{a}$ and $4 \mathrm{~b}$ - Effect of invest- ment spikes on a firm's debt and cash levels.}

Table 5 reports estimation results that test Hypothesis 4a, which proposes that an investment spike leads to higher levels of debt. The intuition behind this hypothesis is a firm's issue debt to fund large investments. Table 5 shows:

- The coefficient associated with capital expenditures spike is positive and statistically significant at less than the $1 \%$ level, which is consistent with the predicted relationship.

- The coefficient associated with the acquisitions spike is positive and statistically significant at less than the $1 \%$ level, which is consistent with the predicted relationship. We note that the compound invest-

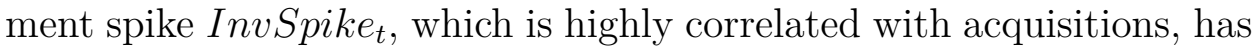
the same sign and statistical significance.

- The coefficient associated with research and development spike $\mathrm{XrdSpike}_{t}$ is positive, but not statistically significant.

With the exception of research and development, our evidence supports using debt to fund large investments. All in all, our findings support the DeAngelo et al. (2011) model prediction that firms issue debt to fund large investments.

\section{insert Table 5}

Table 6 reports estimation results that test Hypothesis 4b, which posits that an investment spike implies lower levels of cash. The intuition behind this hypothesis is that firms use cash to fund large investments. Table 6 shows:

- The coefficient associated with capital expenditures spike CapxSpike t $_{t}$ is negative and statistically significant at less than the $1 \%$ level, which is consistent with the predicted relationship. 
- The coefficient associated with acquisitions spike AcqSpike $e_{t}$ is negative and statistically significant at less than the $1 \%$ level, which is consistent with the predicted relationship. We note that compound investment

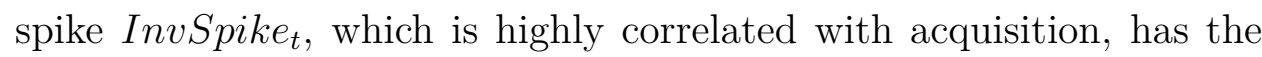
same sign and statistical significance.

- The coefficient associated with research and development spike $\mathrm{XrdSpike}_{t}$ is negative, but not statistically significant.

With the exception of research and development, our evidence supports using cash to fund large investments. All in all, our findings support the DeAngelo et al. (2011) model prediction that firms use cash to fund large investments.

insert Table 6

\subsubsection{Hypotheses 5a and 5b - The intertemporal effect of investment spikes on firm debt and cash levels.}

Table 7 reports estimation results that test Hypothesis 5a, which advances that firms decrease debt levels after funding large investments. The intuition behind this hypothesis is that after large investments, firms decrease debt levels to maintain debt capacity to fund future investment. Table 7 shows:

- The coefficient associated with the lead of capital expenditures spike Capx $_{\text {Spike }}{ }_{t+1}$ is negative and statistically significant at less than the $1 \%$ level, which is consistent with the predicted relationship.

- The coefficient associated with acquisitions spike AcqSpike $e_{t+1}$ is negative and statistically significant at less than the $1 \%$ level, which is consistent with the predicted relationship. We note that the compound investment spike InvSpike $e_{t+1}$, which is highly correlated with acquisition, has the same sign and statistical significance.

- The coefficient associated with research and development spike $X r d$ Spike $_{t+1}$ is negative and statistically significant at less than the $1 \%$ level, which is consistent with the predicted relationship. 
Our evidence suggests that after large investments firms decrease their debt levels. All in all, our findings seem to support the DeAngelo et al. (2011) model prediction that firms decrease their debt level after the spike year.

\section{insert Table 7}

Table 8 reports estimation results that test Hypothesis 5b, which puts forward that firms increase cash levels after funding large investments. The intuition behind this hypothesis is that after large investments, firms rebuild cash stock to maintain cash capacity to fund future investment. Table 8 shows:

- The coefficient associated with the lead of capital expenditures spike CapxSpike $_{t+1}$ is positive and statistically significant at less than the $1 \%$ level, which is consistent with the predicted relationship.

- The coefficient associated with acquisitions spike AcqSpike $e_{t+1}$ is positive and statistically significant at less than the $1 \%$ level, which is consistent with the predicted relationship. We note that the compound

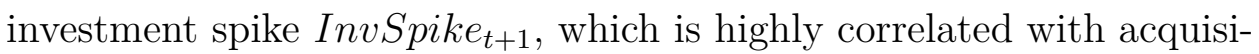
tion, has the same sign and statistical significance.

- The coefficient associated with research and development spike $X_{r d S}$ ike $_{t+1}$ is positive and statistically significant at less than the $1 \%$ level, which is consistent with the predicted relationship.

Our evidence suggests that after large investments firms rebuild their cash stock. Although not explicit in the model of DeAngelo et al. (2011), our evidence supports the plausible implication of their model that firms rebuild their stock of cash after depleting cash stocks to fund large investments.

insert Table 8

\section{Economic Importance}

Table 9 reports the predicted percentage change in dependent variables (BDR and Cash) of our three Hypotheses using both cross-sectional and panel data models. The predicted percentage changes for Hypotheses $3 \mathrm{a}$ 
and $3 \mathrm{~b}$ are the result of one standard deviation increase from the mean of the investment volatility variables, where other control variables are evaluated at their means. For example, to obtain the economic importance of $I_{n} v \operatorname{Vol}_{t-6, t-1}$, we estimate the change in the dependent variable $(B D R)$ due to a one standard deviation increase in $I_{n v} \mathrm{Vol}_{t-6, t-1}$ using Equations (4.6) and (4.7). Predicted $B D R$ at the mean of $I_{n v V o l_{t-6, t-1}}$ is 0.297 and at the mean plus one standard deviation of $\operatorname{InvVol}_{t-6, t-1}$ is 0.348 , implying a $17.17 \%$ increase in debt ratio as a result of one standard deviation increase in $\operatorname{InvVol}_{t-6, t-1} \cdot{ }^{7}$ For Hypotheses $4 \mathrm{a}, 4 \mathrm{~b}, 5 \mathrm{a}$ and $5 \mathrm{~b}$ the predicted percentage changes are the result of the change in the dummy spike variables from zero to one, where other control variables are evaluated at their means. For example, the predicted $B D R$ when InvSpike $=0$ is 0.306 and when InvSpike $=1$ is 0.399 , implying a $30.39 \%$ increase in debt ratio as a result of a large investment spike.

insert Table 9

Table 9 shows a $17.17 \%$ increase in the debt ratio as a result of a one standard deviation increase from the mean of $\operatorname{InvVol}_{t-6, t-1}$ which is mainly derived by $A c q V o l_{t-6, t-1}$. The table also shows the economic importance is slightly lower using the panel data model. The second part of Table 9 reports the predicted percentage change in Cash of Hypothesis 3b. For example, the table reports a $12.02 \%$ decrease in a firm's cash level as a result of a one standard deviation increase from the mean of $I_{n v} \operatorname{Vol}_{t-6, t-1}$. Like $B D R$ changes, the Cash changes are mainly derived by $A c q V o l_{t-6, t-1}$. Note that Inv $=$ Capx + Acq.

\subsection{Discussion and Robustness}

In this section we investigate if our findings are robust to alternative measure of the debt ratio, the cash ratio and the investment volatility measure. Table 10 summarizes our robustness tests.

insert Table 10

\footnotetext{
${ }^{7}$ PercentageChange $=\frac{0.348-0.297}{0.297}=+17.17 \%$.
} 
To evaluate if our findings are robust to a different measure of debt ratio, we use the market short and long-term debt ratio constructed in Section 4.3.2. Panel A tests Hypothesis 3a using the short and long-term market debt ratio and reports the coefficients associated with our main investment volatility variables using both GLM and Panel GLM. Testing Hypotheses 3a, 4a and 5a using the market debt ratio, our main results remain qualitatively unchanged.

We also follow Opler et al. (1999) and construct another cash ratio Cash_na $=$ che/at - che where che is cash and marketable securities and at is total assets. Because our Cash_na variable is not bounded between zero and one, we can not use the GLM model. Therefore, we use the linear panel firm fixed-effect model. Panel B tests Hypotheses 3b, 4b and 5b and reports the coefficients associated with investment volatility. Re-testing our three cash hypotheses using Cash_na, our main results remain qualitatively unchanged for Hypotheses $4 \mathrm{~b}$ and $5 \mathrm{~b}$, and remain qualitatively unchanged for Hypothesis 3a using capital expenditure and acquisition volatility but not research and development volatility.

In addition to our main investment spike variable that represents firms with large investments, we construct a two consecutive investment spikes variable that represents firms with two consecutive large investments. Panel $\mathrm{C}$ tests Hypotheses $4 \mathrm{a}$ and $4 \mathrm{~b}$ using two consecutive spike variables. As can be seen in Panel D of Table 10, our main results remain qualitatively unchanged. The use of two investment spikes magnifies the magnitude of the coefficients associated with all the spike variables in Hypothesis 4a, and the coefficient associated with CapxSpike in Hypothesis 4b.

\subsection{Conclusion}

The empirical literature on the relationship between firms' financing options and the volatility of investment is narrow. Prior literature uses several investment definitions including capital expenditures, acquisitions, and the sum of capital expenditures and acquisitions. Specifically, research and development expenditures have not been tested as a measure of investment. We also con- 
sider the non-linear relationship between our proportional dependent variables and the explanatory variables and use both a cross-sectional and panel GLM with logit link function. Thus, the paper contributes to the literature both in terms of the hypotheses tested and the range of our definition of investments.

The first hypothesis investigates if firms with higher investment volatility have lower debt levels and higher cash levels. Our results indicate that firms with high capital expenditure and acquisition volatility have higher debt levels and firms with high research and development expenditure have lower debt levels. In addition, our evidence suggests that firms with high acquisitions volatility hold less cash. Our results are economically important - we predict the percentage change in debt and cash ratios by one standard deviation increase from the mean of all four investment volatility variables. For example, our evidence suggests a $17.17 \%$ increase in the debt ratio and a $12.06 \%$ decrease in the cash level as a result of one standard deviation increase from the mean of capital expenditure plus acquisition volatility. All in all, our evidence does not support the model of DeAngelo et al. (2011) prediction that firms with high investment volatility have low debt levels and high cash levels.

The second hypothesis tests the effect of large investments on firms' debt and cash levels. The intuition behind this hypothesis is that firms issue debt and use their cash holdings to fund large investments. We construct investment spike variables using our four measures of investment. Our results are economically important - we predict the percentage change in debt and cash ratios by the change in the investment spike dummy variable from zero to one. For example, our evidence suggests a $30.39 \%$ increase in the debt ratio and a $30.59 \%$ decrease in the cash level as a result of an investment spike (large investment). Our evidence supports the prediction of the DeAngelo et al. (2011) model and the findings of Elsas et al. (2014) that firms finance their large investments by issuing debt and using their cash holdings.

The third hypothesis investigates if firms rebuild their debt capacity and cash stocks following the large investments. To test this hypothesis we use the first lead of the investment spike variables. Our results are economically 
important - we predict the percentage change in debt and cash ratios by the change in the lead of investment spike dummy variable from zero to one. For example, our evidence suggests a $10.76 \%$ decrease in the debt ratio and a $21.15 \%$ increase in the cash levels, one year after the large investment. Our evidence supports the prediction from the DeAngelo et al. (2011) model and findings of Elsas et al. (2014) that firms decrease their debt level a year after the spike year. In addition, these firms rebuild their cash stock one year after funding large investments. Our findings that firms increase cash levels after funding investments is novel.

Our evidence suggests different firms' financial policies relative to research and development volatility. Our findings suggest that high research and development investment volatility is accompanied by lower debt and higher cash levels. Plausibly, research and development investment volatility may be a reasonable proxy for shocks to the marginal productivity of capital, the latent variable in the DeAngelo et al. (2011) model. In addition, our evidence suggests that a research and development spike is not an important determinant of a firm's debt and cash level. However, following a research and development investment spike, firms increase their debt capacity and cash levels. This supports the DeAngelo et al. (2011) model prediction. 


\subsection{Appendices}

\subsubsection{Variable Definitions}

Variable Definitions

This table provides variable definitions. Column (1) provides the variable name. Column (2) defines the variable. Column (3) shows the variable construction using system variable names. Column (4) provides the data source.

\begin{tabular}{|c|c|c|c|}
\hline Variable & Definition & Construction & Data Sources \\
\hline$M D R$ & $\begin{array}{l}\text { The ratio of short plus } \\
\text { long-term debt to short plus } \\
\text { long-term debt plus common } \\
\text { shareholder equity, (Rajan and } \\
\text { Zingales, 1995). }\end{array}$ & $\frac{d l t t+d l c}{d l t t+d l c+c s h o * p r c c \_f}$ & Compustat \\
\hline$B D R$ & $\begin{array}{l}\text { The ratio of short plus } \\
\text { long-term debt to the sum of } \\
\text { common shareholders' equity, } \\
\text { the total long-term debt and the } \\
\text { total short-term debt, (Rajan } \\
\text { and Zingales, 1995). }\end{array}$ & $\frac{d l t t+d l c}{d l t t+d l c+c e q}$ & Compustat \\
\hline Cash & $\begin{array}{l}\text { The ratio of cash and short-term } \\
\text { investments over total assets, } \\
\text { (DeAngelo et al., 2011; Bates } \\
\text { et al., 2009; Almeida et al., } \\
\text { 2004; DeAngelo et al., 2006). }\end{array}$ & $\frac{c h e}{a t}$ & Compustat \\
\hline$C F V_{t-5, t}$ & $\begin{array}{l}\text { Natural logarithm of cash flow } \\
\text { volatility. }\end{array}$ & $\begin{array}{l}\text { See the (Keefe and } \\
\text { Yaghoubi, 2015) paper }\end{array}$ & Compustat \\
\hline Tangibility & $\begin{array}{l}\text { The assets tangibility of a firm } \\
\text { is the ratio of(ppent) net } \\
\text { property, plant, and } \\
\text { equipment(at) toatal assets, } \\
\text { (Lemmon et al., 2008) and } \\
\text { (Frank and Goyal, 2009). }\end{array}$ & $\frac{p p e n b}{a t}$ & Compustat \\
\hline IndustLev & $\begin{array}{l}\text { The median industry leverage of } \\
\text { the sector a firm is classified by } \\
\text { four-digit SIC code, (Frank and } \\
\text { Goyal, 2009). }\end{array}$ & The median of $\frac{L T}{M V A}^{8}$ & Compustat \\
\hline FirmSize & The proxy for a firm size. & $\ln (a t)$ & Compustat \\
\hline Profitability & Shows the profitability of a firm. & $\frac{o i b d p}{a t}$ & Compustat \\
\hline
\end{tabular}

${ }^{8}$ Market value of assets $(M V A)=$ debt in current liabilities $(d l c)+$ long-term debt $(d l t t)+$ preferred stock $(p s t k l)+$ market value of equity $(c s h o * p r c c-f)-$ balance sheet deferred taxes and investment tax credit (txditc). 


\begin{tabular}{|c|c|c|c|}
\hline Variable & Definition & Construction & Data Sources \\
\hline MarketToBook & $\begin{array}{l}\text { The proxy for a firm's growth } \\
\text { opportunities and is the ratio of } \\
\text { market value of asset to total } \\
\text { assets. }\end{array}$ & $\frac{M V A}{a t}$ & Compustat \\
\hline Inflation & $\begin{array}{l}\text { The expected change in the } \\
\text { consumer price index (CPI) over } \\
\text { the coming year, (Frank and } \\
\text { Goyal, 2009). }\end{array}$ & $\frac{\text { Forecast } 12 \text { Month-BasePeriod }}{\text { BasePeriod }}$ & $\begin{array}{l}\text { Livingston } \\
\text { Survey }\end{array}$ \\
\hline $\operatorname{LnRnD}$ & $\begin{array}{l}\text { The ratio of R\&D expenses to } \\
\text { sales of a firm, (Frank and } \\
\text { Goyal, 2009). }\end{array}$ & $\ln \left(1+\frac{x r d}{r e v t}\right)$ & Compustat \\
\hline CreditRating & $\begin{array}{l}\text { Indicator variable: One if a firm } \\
\text { is listed as investment grade by } \\
\text { S\&P, and zero otherwise. }\end{array}$ & $\begin{array}{l}=1 \text { if } S P L T I C R M \text { or } \\
S P S D R M<13\end{array}$ & Compustat \\
\hline FirmAge & $\begin{array}{l}\text { The number of years a firm has } \\
\text { had data in Compustat. }\end{array}$ & $\begin{array}{l}\text { fyear-First year in } \\
\text { Compustat }\end{array}$ & Compustat \\
\hline DPfirms & $\begin{array}{l}\text { A dummy variable set to one if } \\
\text { a firm pays dividend in year } t, \\
\text { and zero otherwise, (Opler } \\
\text { et al., 1999) }\end{array}$ & $=1$ if $d v c \neq 0$ & Compustat \\
\hline Acquisitions & $\begin{array}{l}\text { The ratio of acquisitions } \\
\text { spending to the total assets, } \\
\text { (Bates et al., 2009) }\end{array}$ & $\frac{a q c}{a t}$ & Compustat \\
\hline Capx & $\begin{array}{l}\text { The ratio of capital expenditure } \\
\text { to the total assets, (Bates et al., } \\
2009 \text { ) }\end{array}$ & $\frac{c a p x}{a t}$ & Compustat \\
\hline$N W C$ & $\begin{array}{l}\text { The working capital minus cash } \\
\text { and marketable securities over } \\
\text { total assets, (Bates et al., 2009) }\end{array}$ & $\frac{w c a p-c h e}{a t}$ & Compustat \\
\hline InvVol $_{t-5, t}$ & $\begin{array}{l}\text { The capital expenditures plus } \\
\text { acquisitions investment } \\
\text { volatility measure estimated } \\
\text { using (Kim and Sorensen, 1986) } \\
\text { method }\end{array}$ & $\begin{array}{l}\text { SD of Capx }+A c q \text { over } \\
\text { the last five years divided } \\
\text { by the five years moving } \\
\text { average of ppegt }\end{array}$ & Compustat \\
\hline $\mathrm{CapxVol}_{t-5, t}$ & $\begin{array}{l}\text { The capital expenditures } \\
\text { investment volatility measure } \\
\text { estimated using (Kim and } \\
\text { Sorensen, 1986) method }\end{array}$ & $\begin{array}{l}\text { SD of Capx over the last } \\
\text { five years divided by the } \\
\text { five years moving average } \\
\text { of ppegt }\end{array}$ & Compustat \\
\hline $\mathrm{AcqVol}_{t-5, t}$ & $\begin{array}{l}\text { The acquisitions investment } \\
\text { volatility measure estimated } \\
\text { using (Kim and Sorensen, 1986) } \\
\text { method }\end{array}$ & $\begin{array}{l}\text { SD of } A c q \text { over the last } \\
\text { five years divided by the } \\
\text { five years moving average } \\
\text { of ppegt }\end{array}$ & Compustat \\
\hline
\end{tabular}




\begin{tabular}{|c|c|c|c|}
\hline Variable & Definition & Construction & Data Sources \\
\hline$X r d V o l_{t-5, t}$ & $\begin{array}{l}\text { The research and development } \\
\text { investment volatility measure } \\
\text { estimated using (Kim and } \\
\text { Sorensen, 1986) method }\end{array}$ & $\begin{array}{l}\text { SD of } X r d \text { over the last } \\
\text { five years divided by the } \\
\text { five years moving average } \\
\text { of ppegt }\end{array}$ & Compustat \\
\hline InvSpike $_{t}$ & $\begin{array}{l}\text { An investment spike of } \\
\text { Capx }+A c q\end{array}$ & See Section 4.3 .2 & Compustat \\
\hline CapxSpike $_{t}$ & An investment spike of Capx & See Section 4.3 .2 & Compustat \\
\hline AcqSpike $_{t}$ & An investment spike of $A c q$ & See Section 4.3 .2 & Compustat \\
\hline XrdSpike $_{t}$ & An investment spike of $X r d$ & See Section4.3.2 & Compustat \\
\hline
\end{tabular}




\subsection{Figures and Tables}

Table 1: Summary Statistics

This table shows summary statistics of variables of the study for non-financial and non-utility US companies from 1974-2015. All variables are winsorized at $0.1 \%$ level in both tails of the distribution before the summary statistics are calculated. The table reports the number of observations, mean, 25th percentile, median, 75th percentile and standard deviation. Appendix 4.7.1 defines the variables.

\begin{tabular}{|c|c|c|c|c|c|c|c|c|}
\hline Variable & $\mathrm{N}$ & mean & p25 & p50 & p75 & $\max$ & $\min$ & sd \\
\hline$M D R$ & 146668 & 0.230 & 0.0195 & 0.157 & 0.376 & 0.877 & 0 & 0.236 \\
\hline$B D R$ & 146668 & 0.291 & 0.0488 & 0.262 & 0.466 & 0.924 & 0 & 0.250 \\
\hline Cash & 146668 & 0.181 & 0.0274 & 0.0876 & 0.251 & 0.923 & 0.000325 & 0.219 \\
\hline Tangibility & 146455 & 0.276 & 0.103 & 0.222 & 0.390 & 0.894 & 0.00367 & 0.219 \\
\hline FirmSize & 146668 & 4.693 & 3.192 & 4.541 & 6.074 & 10.04 & 0.472 & 2.086 \\
\hline FirmAge & 146668 & 9.098 & 2 & 6 & 13 & 38 & 0 & 8.779 \\
\hline Profitability & 146342 & 0.0637 & 0.0314 & 0.114 & 0.176 & 0.404 & -0.993 & 0.218 \\
\hline MarketToBook & 142098 & 1.674 & 0.725 & 1.082 & 1.861 & 11.10 & 0.279 & 1.740 \\
\hline IndustLev & 146668 & 0.341 & 0.199 & 0.323 & 0.465 & 0.907 & 0.0104 & 0.175 \\
\hline$R n D$ & 144689 & 0.0910 & 0 & 0 & 0.0500 & 2.202 & 0 & 0.300 \\
\hline Inflation & 146668 & 0.0437 & 0.0238 & 0.0379 & 0.0560 & 0.121 & 0.0166 & 0.0246 \\
\hline CreditRating & 146668 & 0.0683 & 0 & 0 & 0 & 1 & 0 & 0.252 \\
\hline$N W C$ & 141986 & 0.459 & -0.0120 & 0.259 & 0.729 & 6.123 & -3.462 & 1.162 \\
\hline DPfirms & 146668 & 0.354 & 0 & 0 & 1 & 1 & 0 & 0.478 \\
\hline$C F V_{t-5, t}$ & 95179 & 1.892 & 1.250 & 1.822 & 2.448 & 4.933 & -0.191 & 0.958 \\
\hline $\operatorname{InvVol}_{t-5, t}$ & 94914 & 2.265 & 1.474 & 2.206 & 2.999 & 5.377 & -0.422 & 1.154 \\
\hline InvSpike $_{t}$ & 128897 & 0.136 & 0 & 0 & 0 & 1 & 0 & 0.342 \\
\hline $\mathrm{CapxVol}_{t-5, t}$ & 94914 & 1.669 & 1.021 & 1.662 & 2.323 & 3.981 & -0.766 & 0.961 \\
\hline CapxSpike $_{t}$ & 128897 & 0.143 & 0 & 0 & 0 & 1 & 0 & 0.350 \\
\hline $\mathrm{AqcVol}_{t-5, t}$ & 54910 & 1.983 & 0.940 & 2.092 & 3.161 & 5.341 & -8.035 & 1.699 \\
\hline AqcSpike $_{t}$ & 128897 & 0.123 & 0 & 0 & 0 & 1 & 0 & 0.329 \\
\hline$X r d V o l_{t-5, t}$ & 51370 & 1.076 & -0.261 & 1.083 & 2.458 & 5.140 & -6.791 & 1.908 \\
\hline XrdSpike ${ }_{t}$ & 128897 & 0.124 & 0 & 0 & 0 & 1 & 0 & 0.329 \\
\hline
\end{tabular}




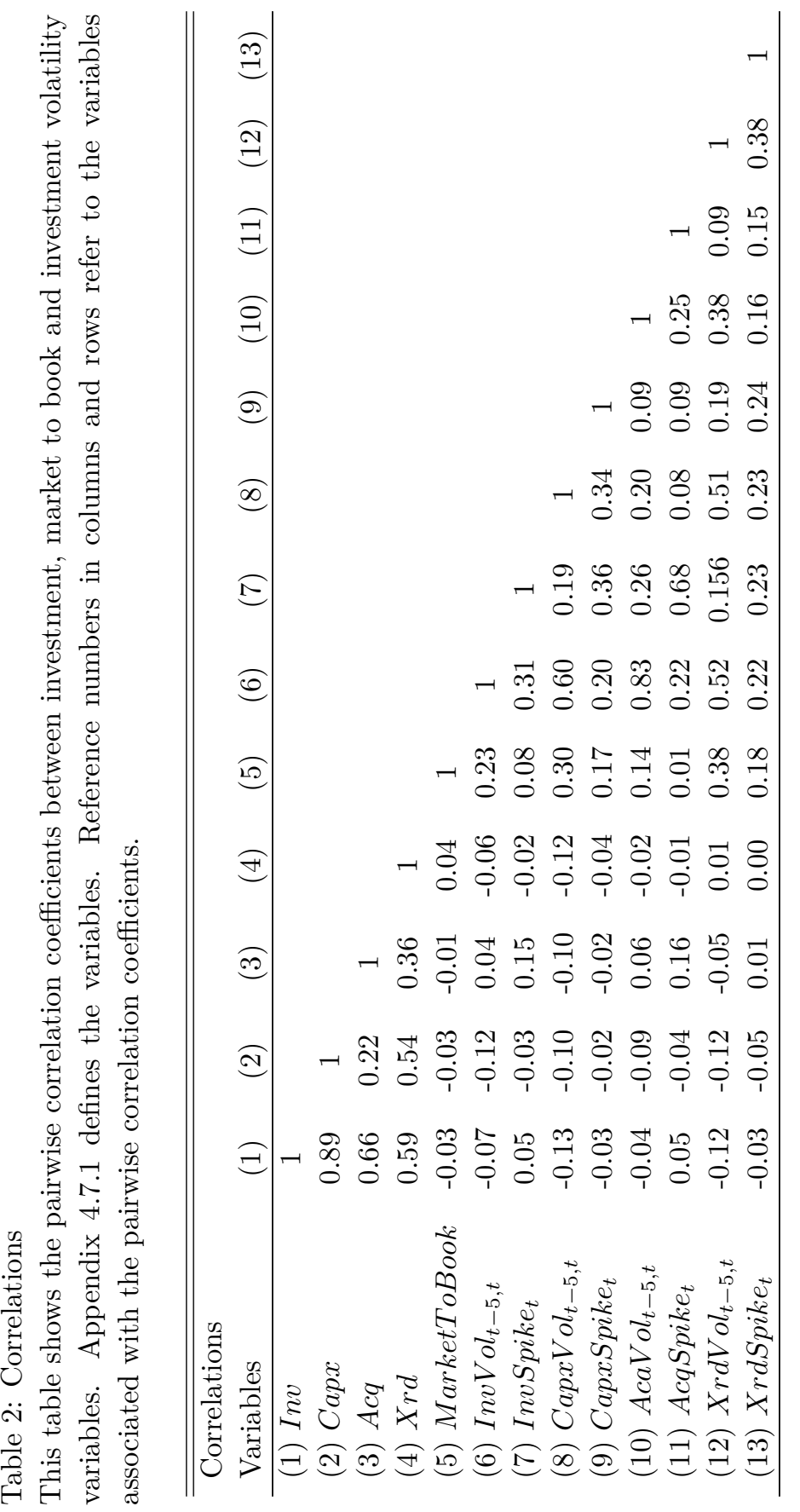




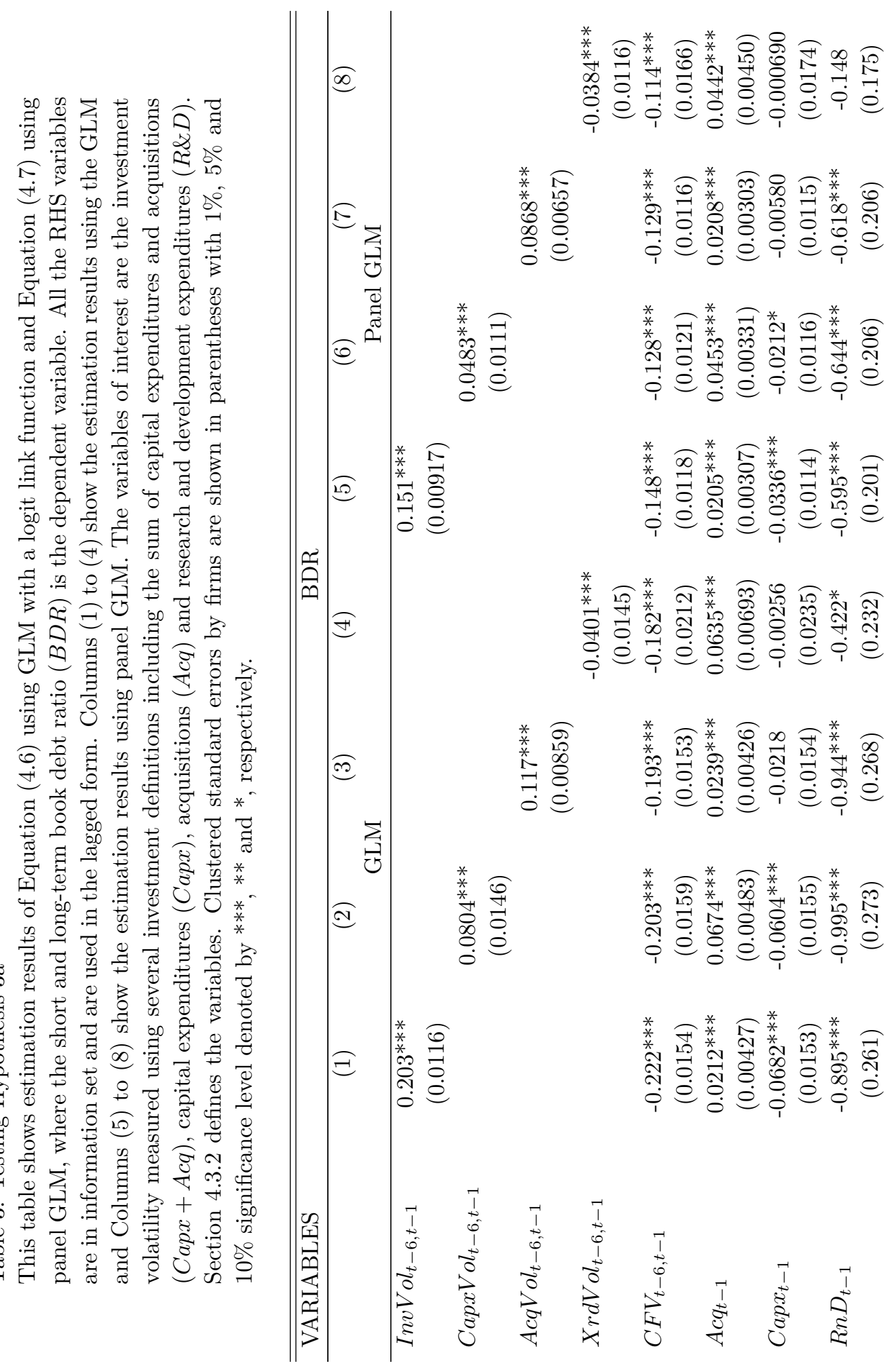




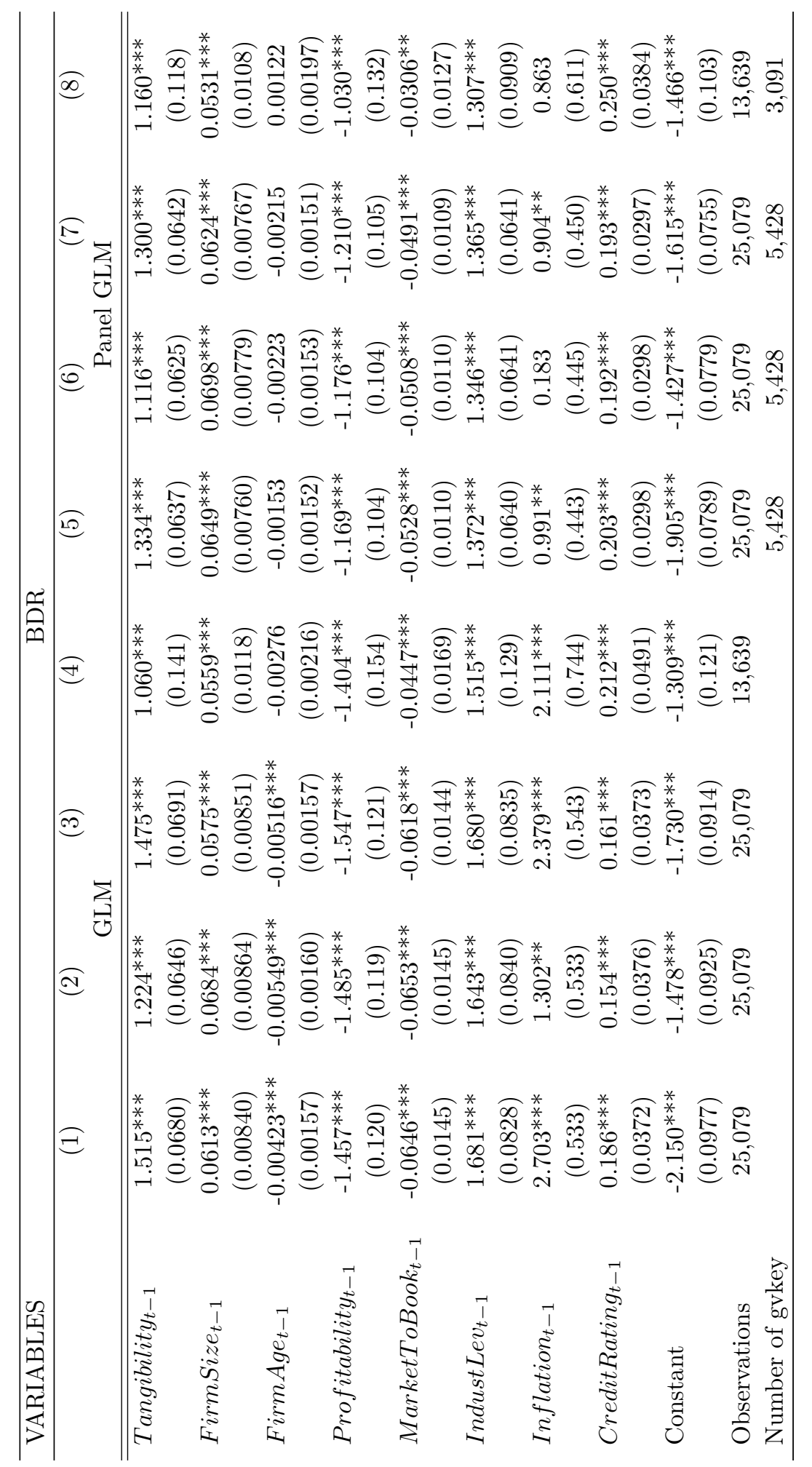




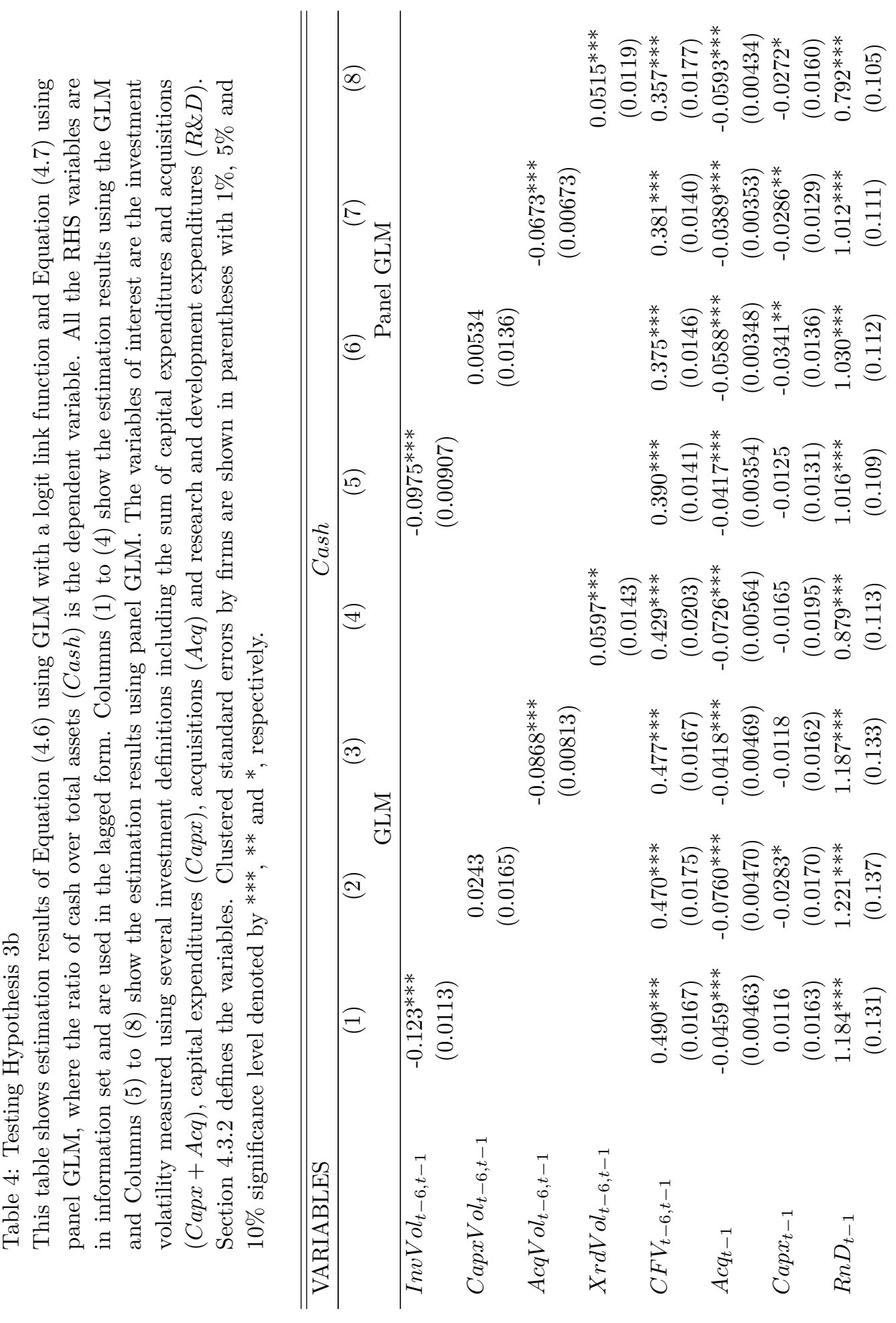




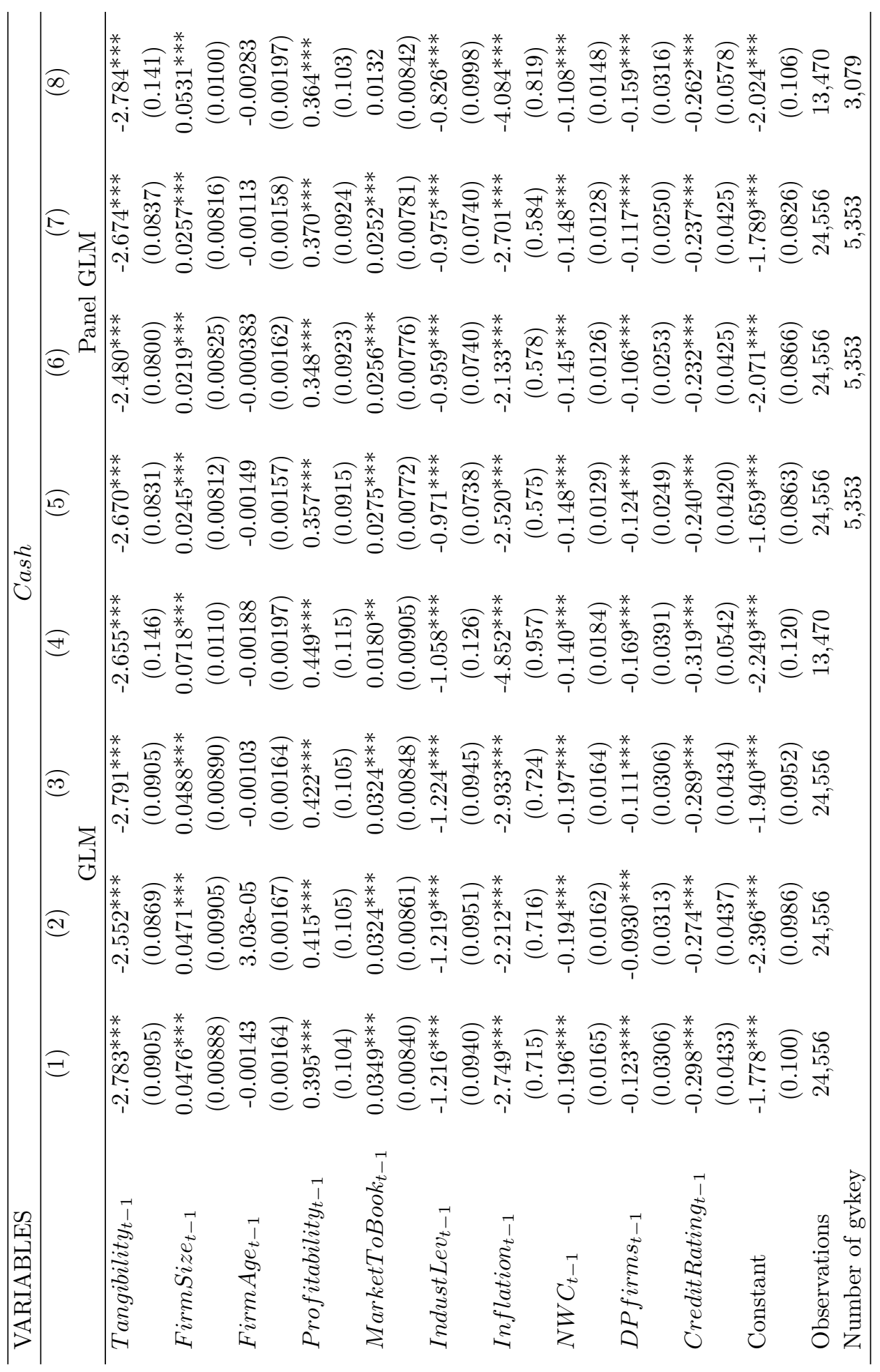




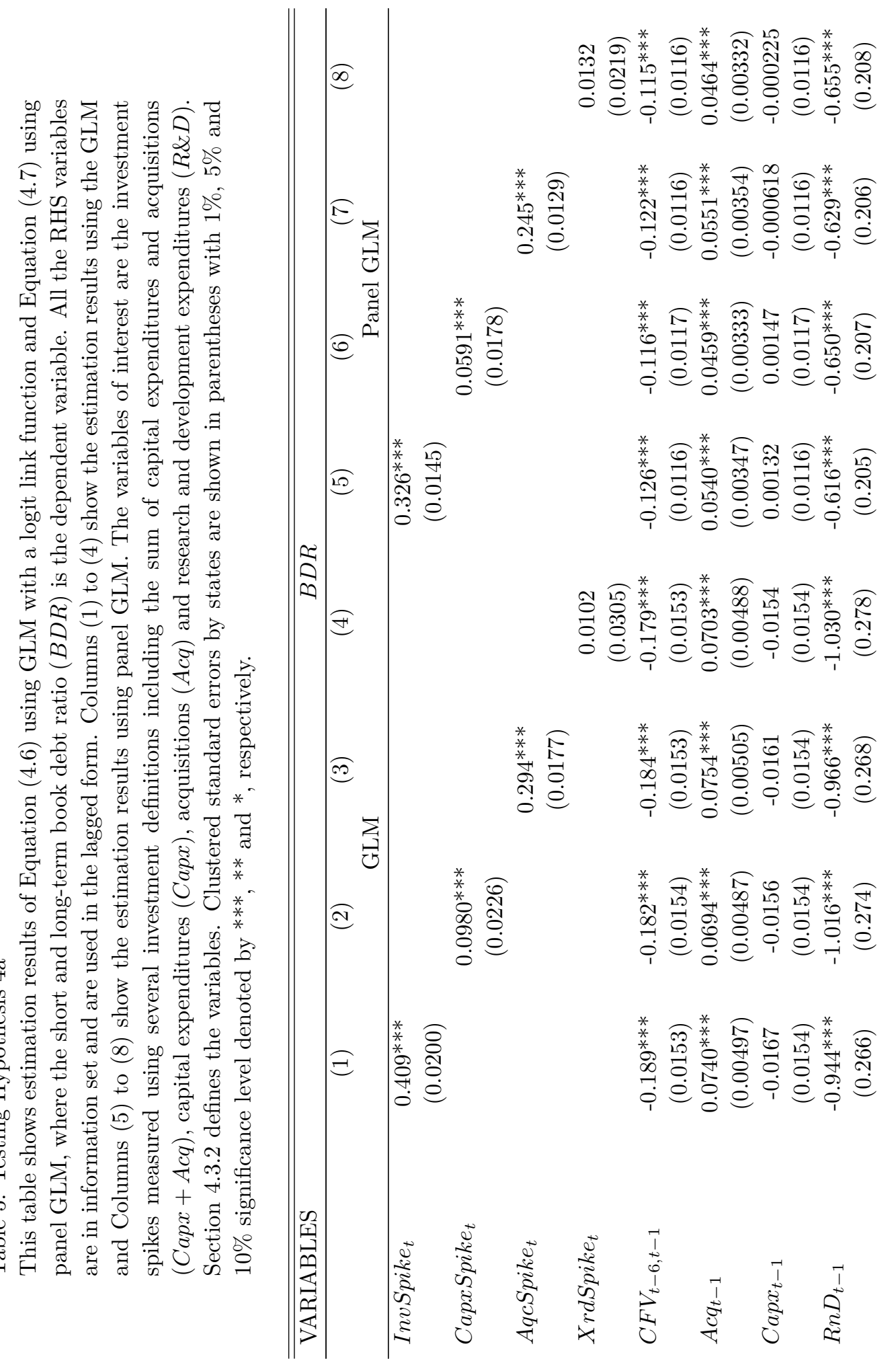




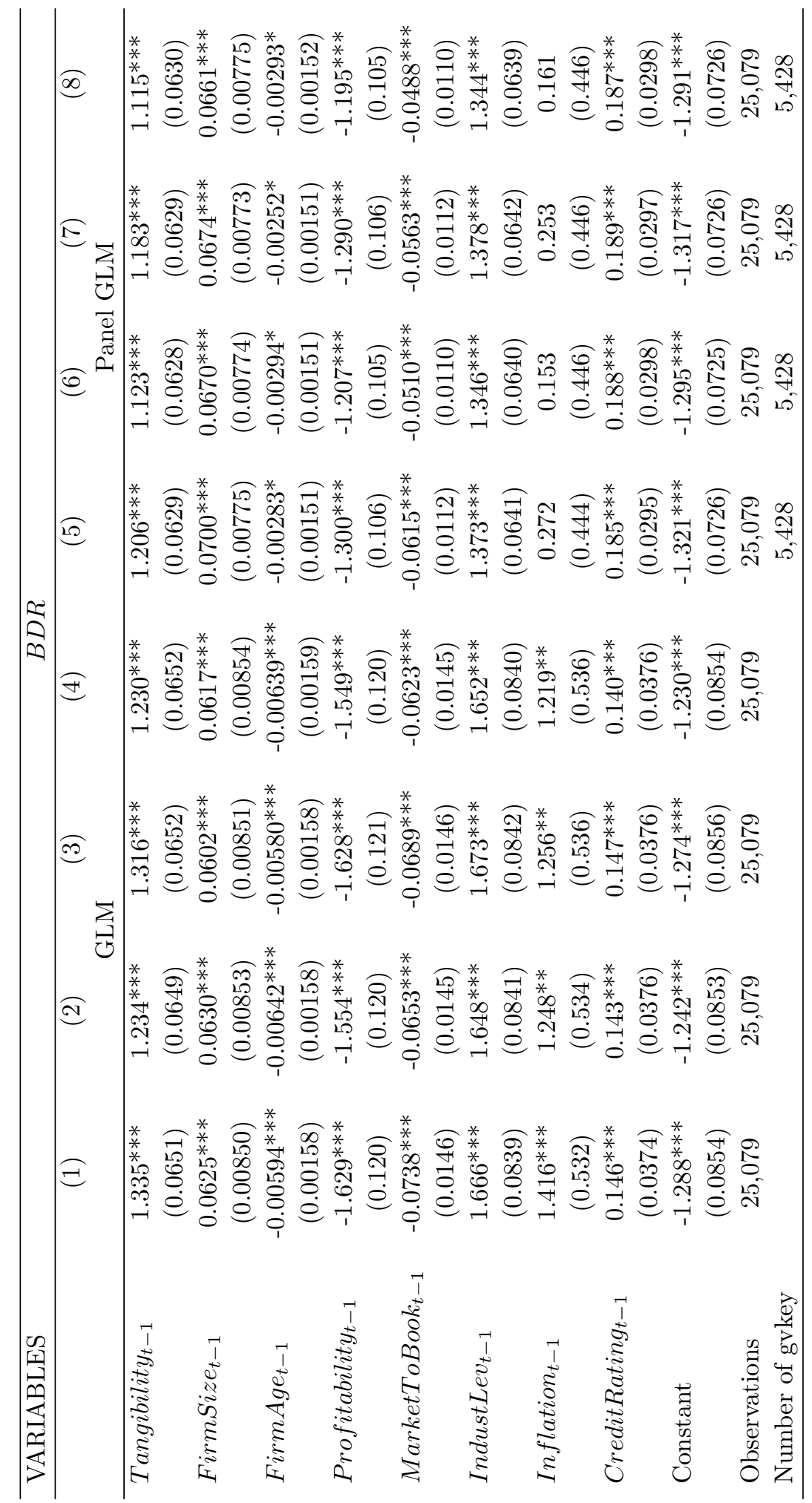




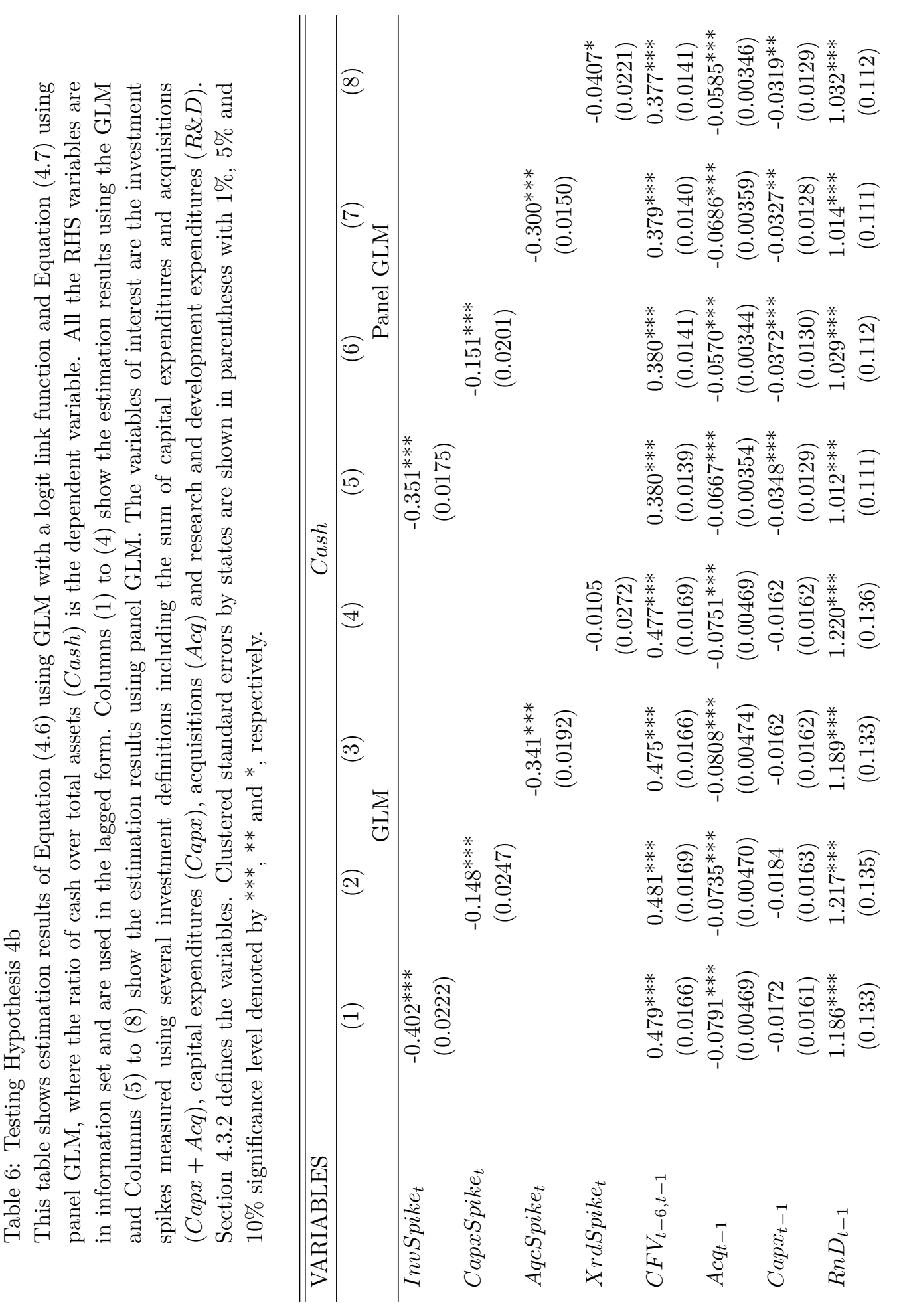




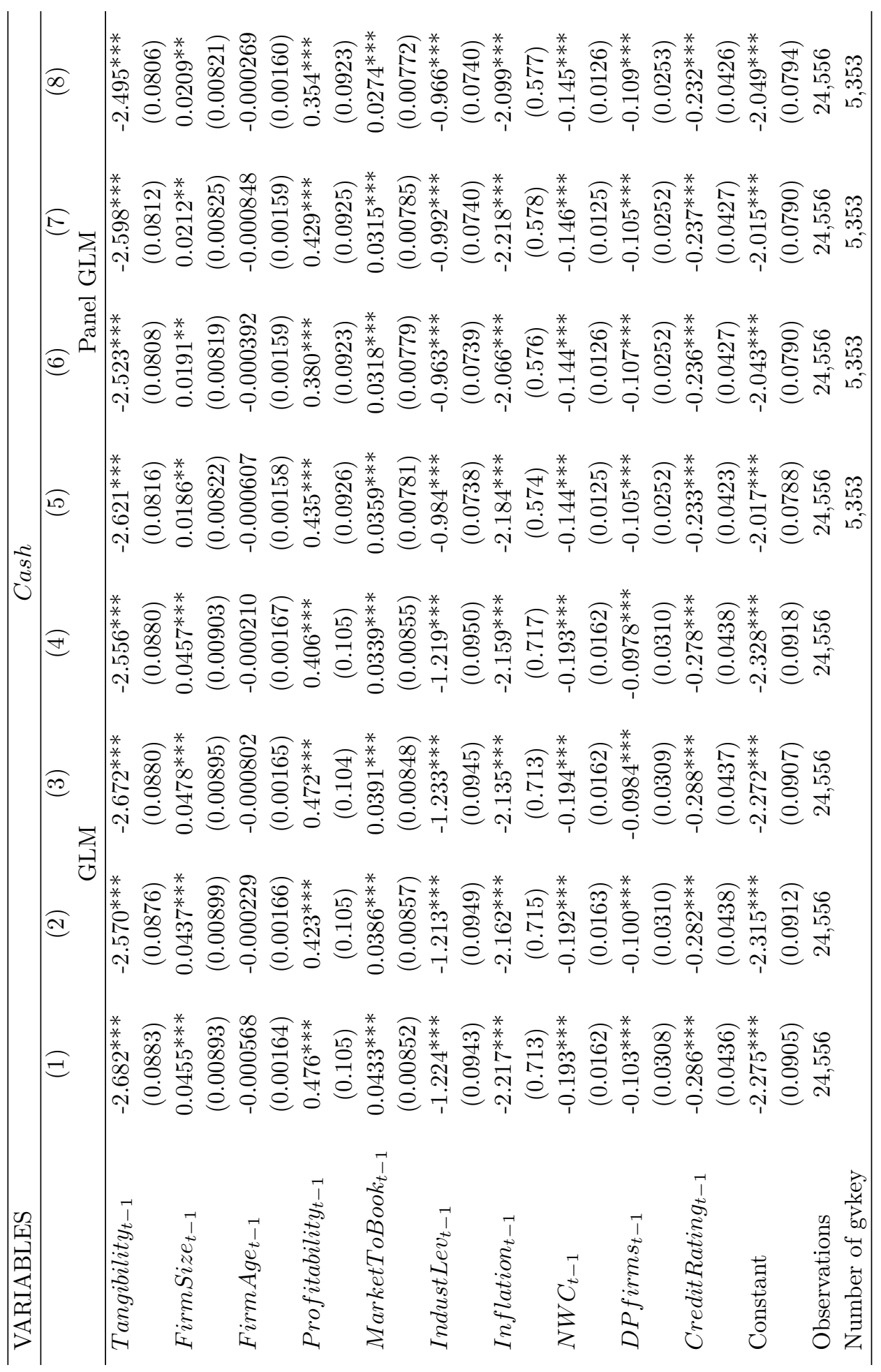




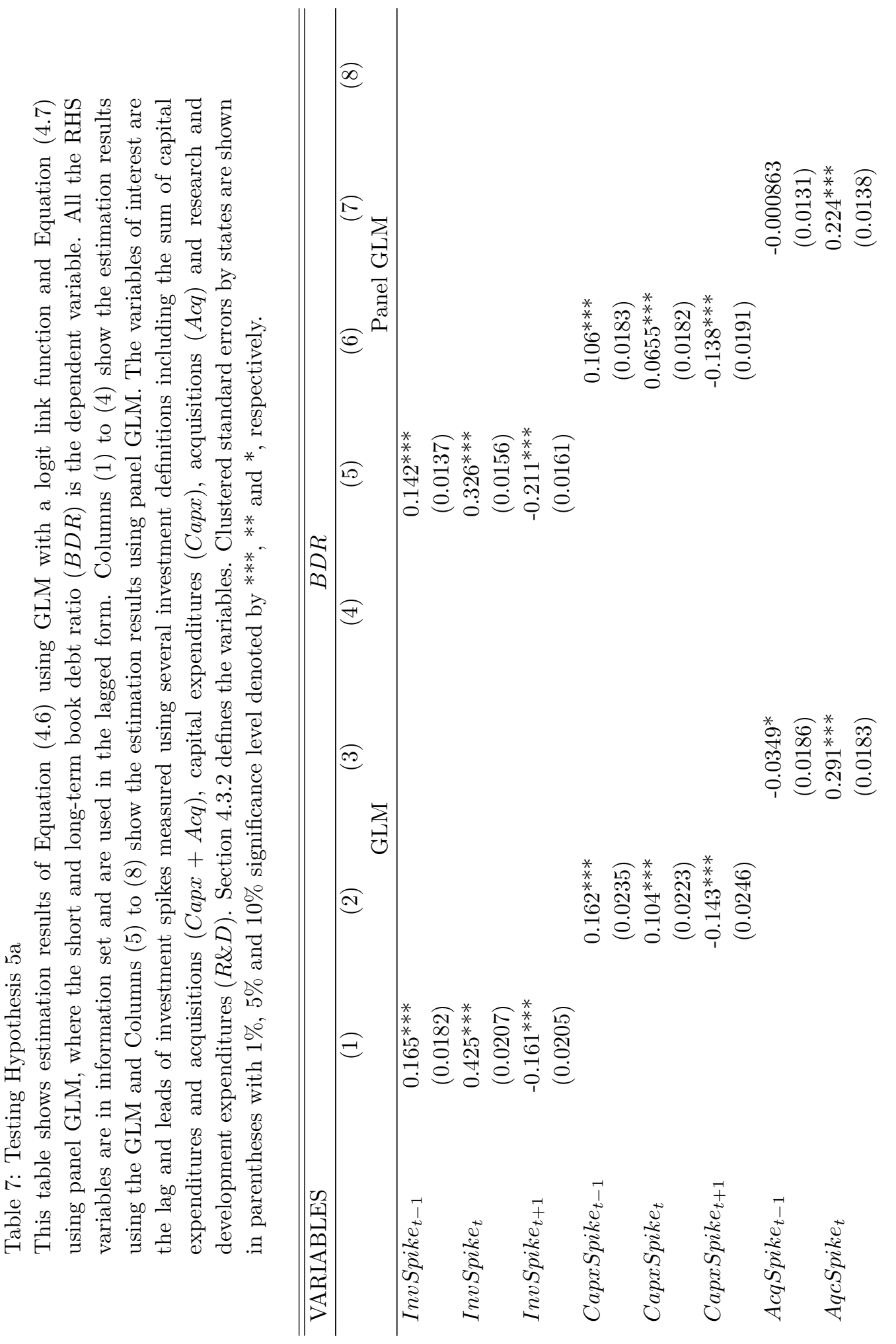




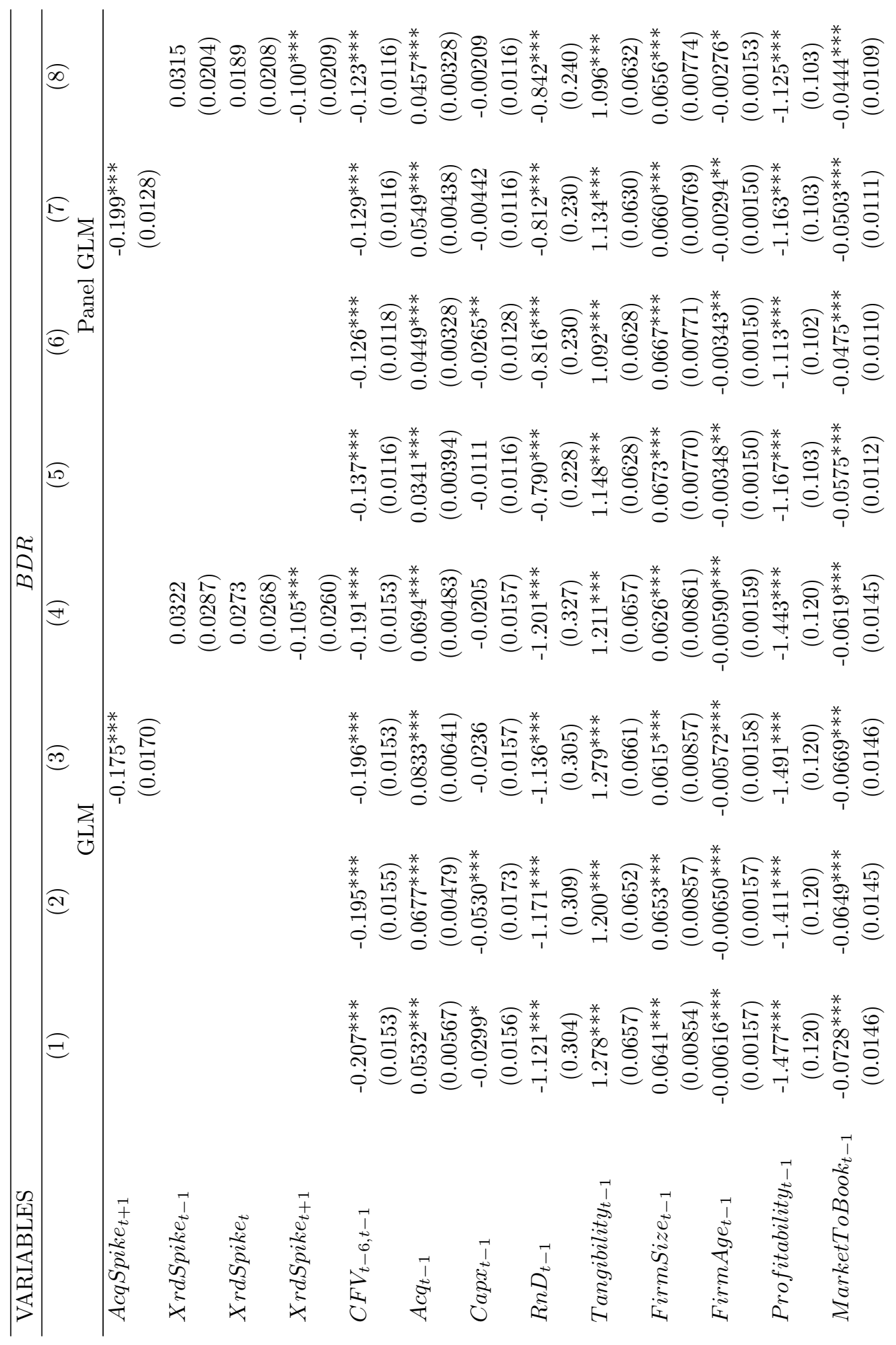




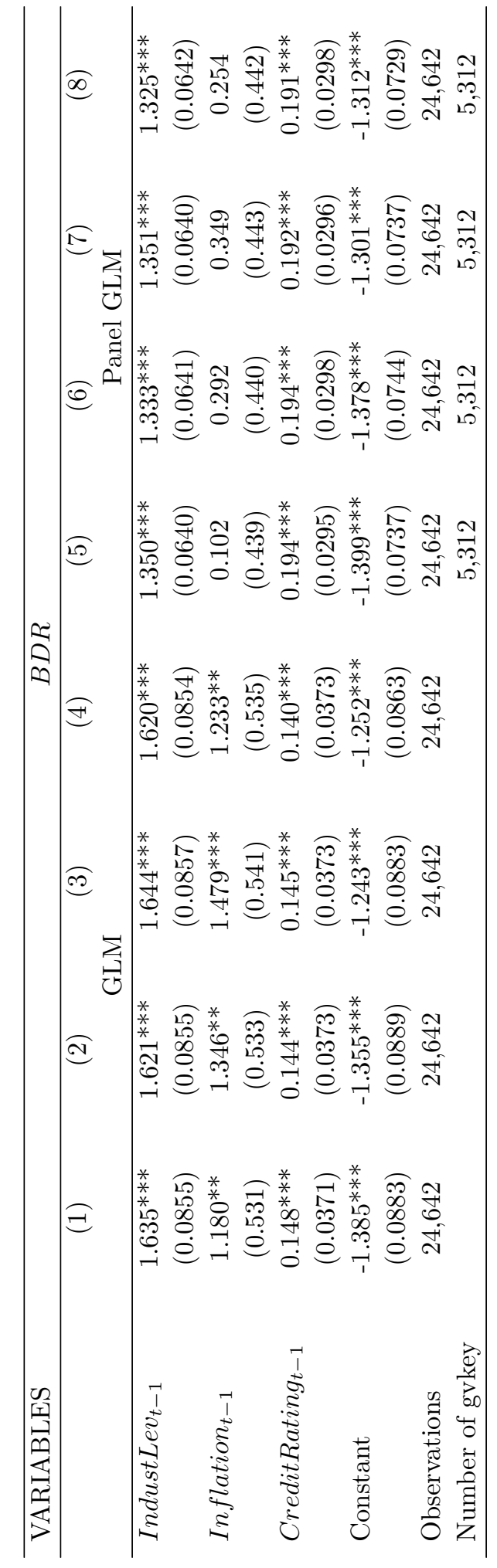




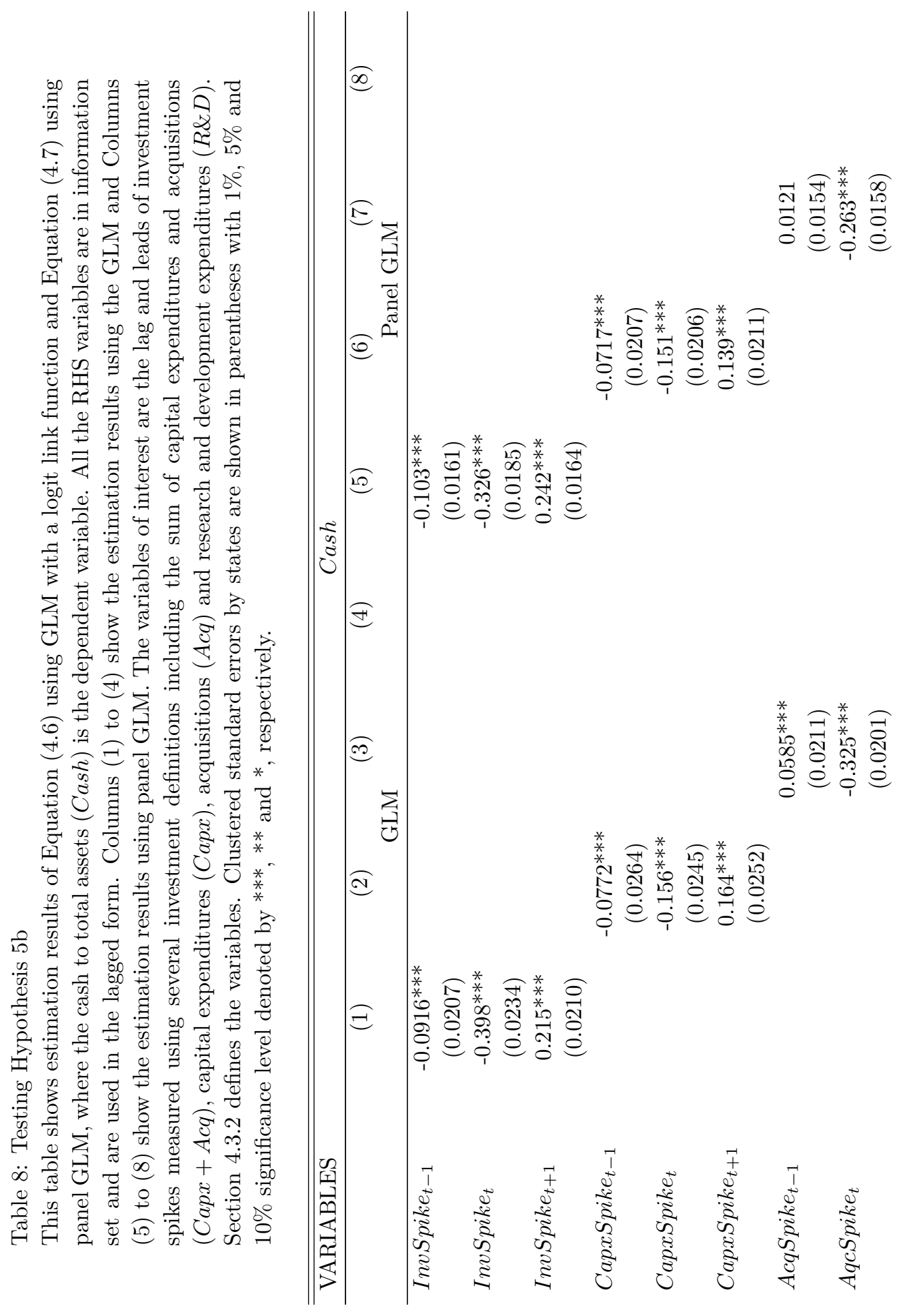




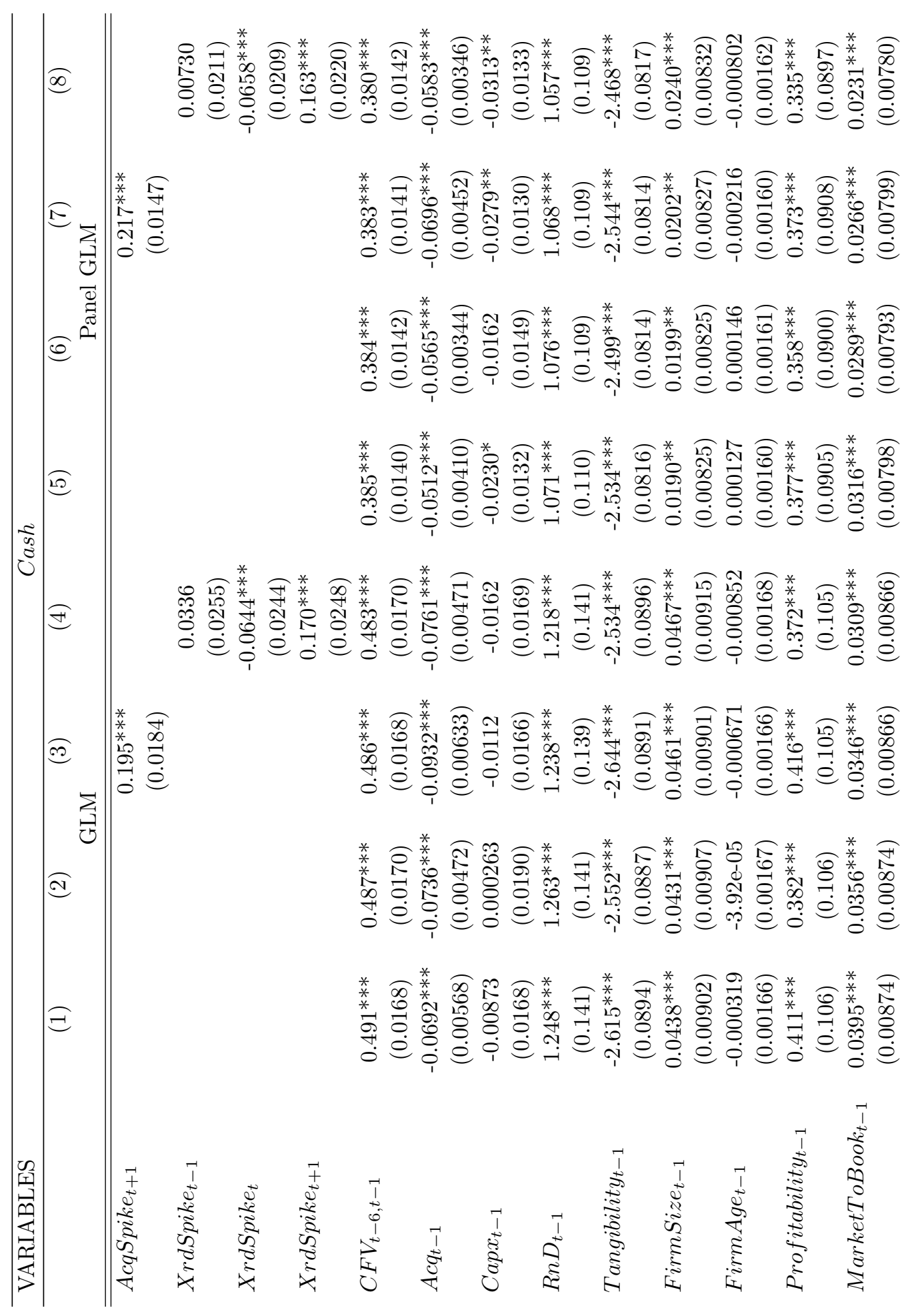




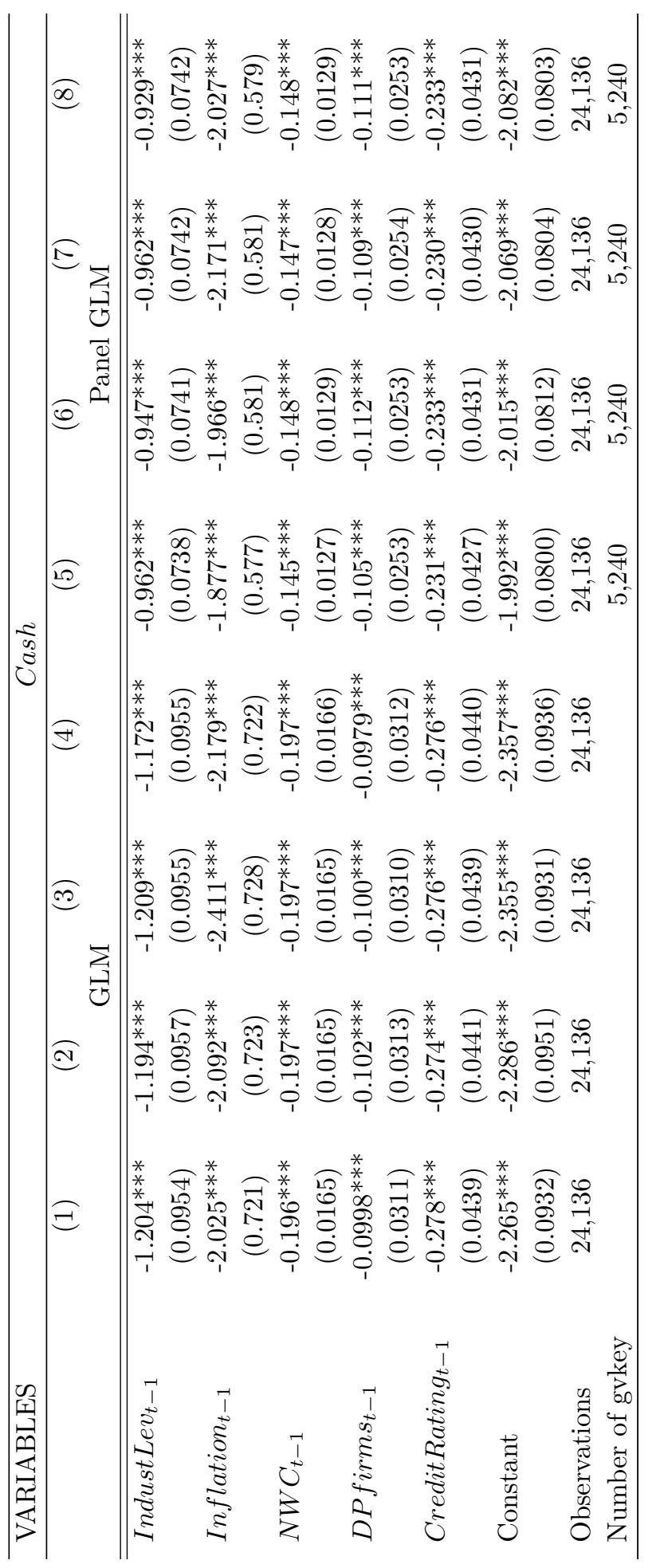




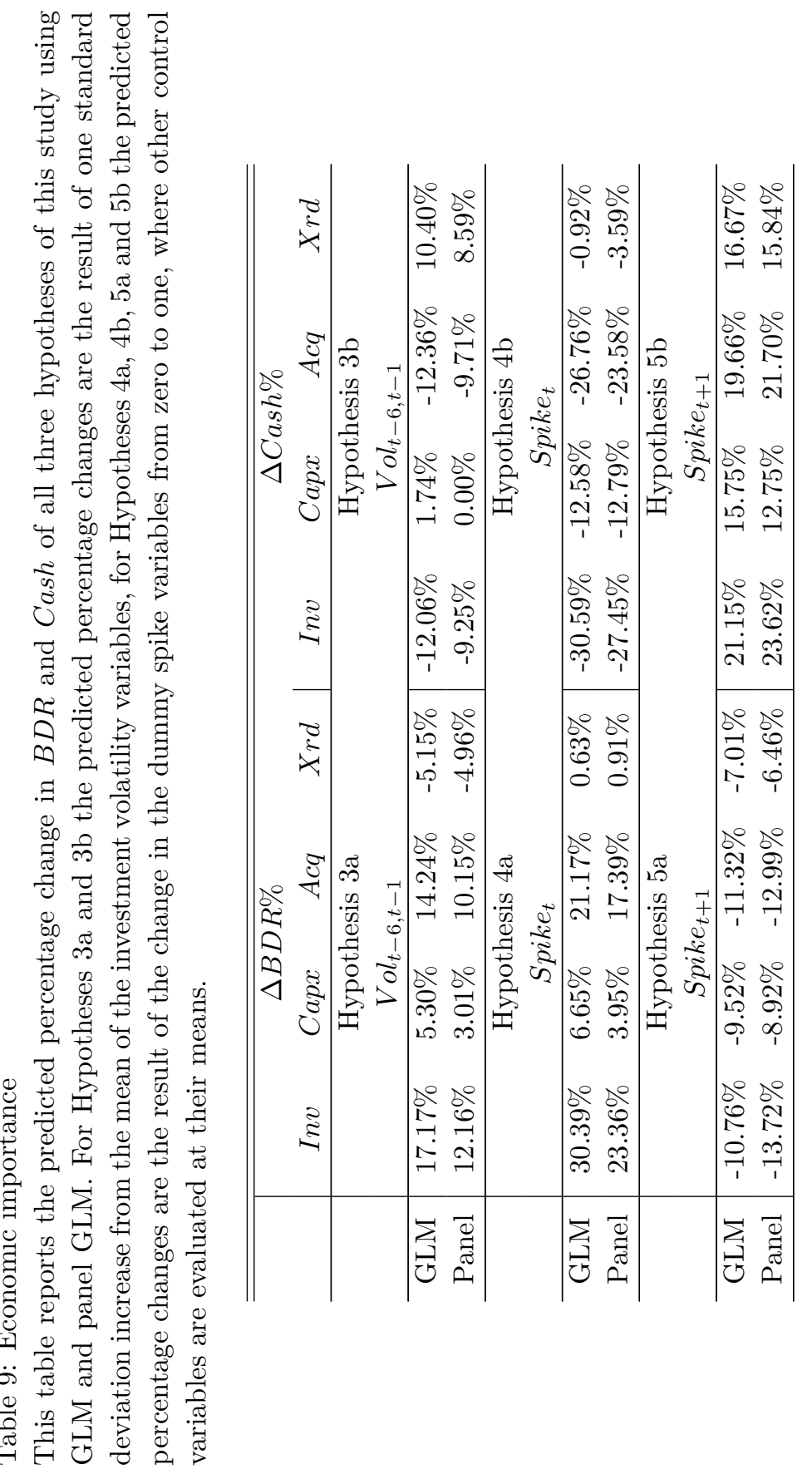




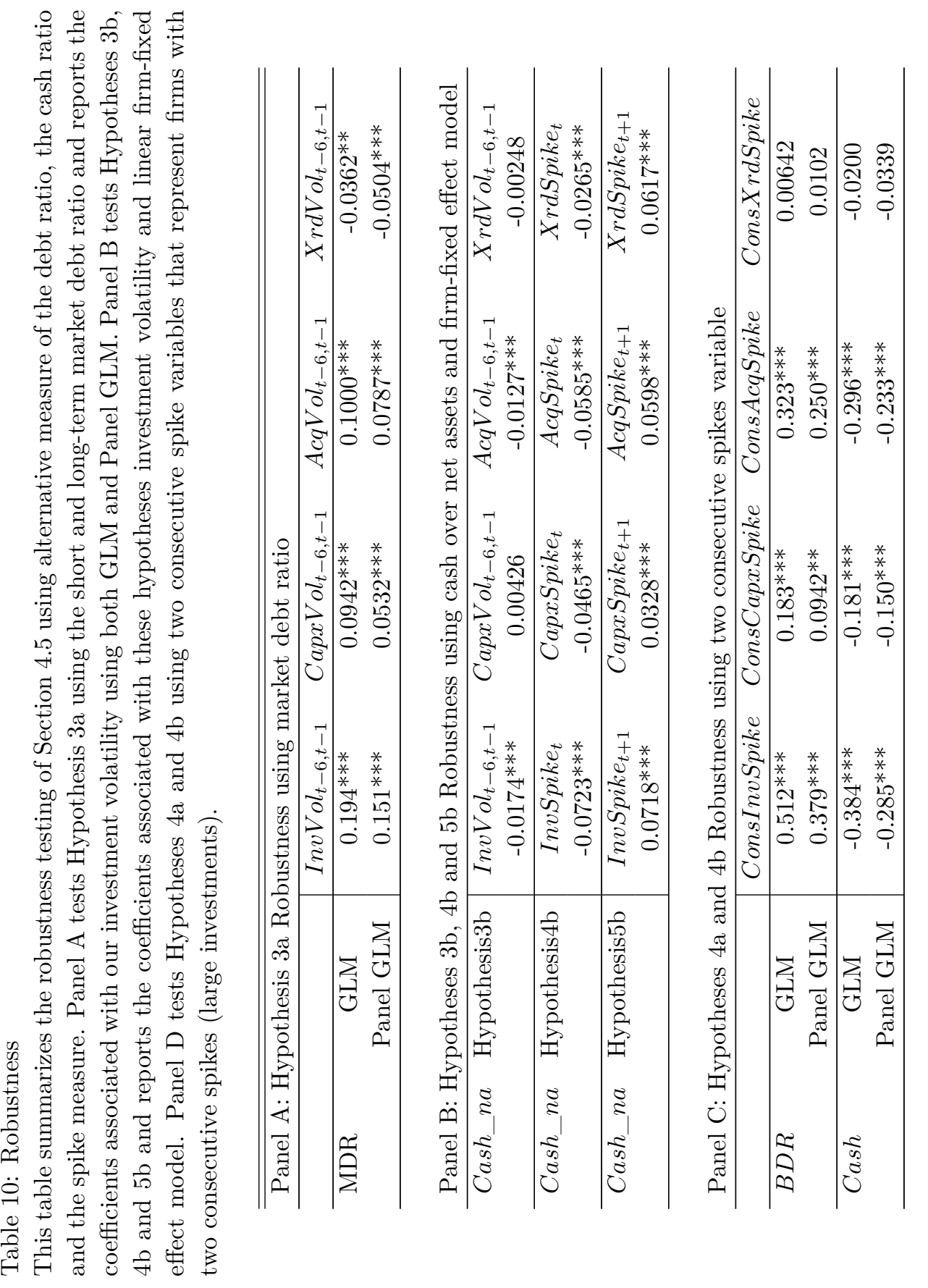




\section{Bibliography}

Allen, F. and Michaely, R. (2003), 'Payout policy', Handbook of the Economics of Finance 1, 337-429.

Almeida, H., Campello, M. and Weisbach, M. S. (2004), 'The cash flow sensitivity of cash', The Journal of Finance 59(4), 1777-1804.

Almeida, H., Fos, V. and Kronlund, M. (2013), 'The real effects of share repurchases', Available at SSRN 2276156.

Alti, A. (2006), 'How persistent is the impact of market timing on capital structure?', The Journal of Finance 61(4), 1681-1710.

Antoniou, A., Guney, Y. and Paudyal, K. (2008), 'The determinants of capital structure: Capital market-oriented versus bank-oriented institutions', The Journal of Financial and Quantitative Analysis 43(1), 59-92.

APRS, . (20 July 2006), 'Report: Proposed leveraged buyout of HCA unravels'.

APRS, . (November 16, 2005), 'HCA to repurchase $\$ 1.5$ billion of stock'.

Asquith, P. and Mullins, D. W. (1986), 'Equity issues and offering dilution', Journal of Financial Economics 15(1), 61-89.

Associated Press, . (October 05, 1994), 'Columbia/HCA to merge with healthtrust in $\$ 5.4$ billion deal : Health care: Columbia is already the nation's largest hospital operator. the new firm would have 311 facilities.'

Bagwell, L. S. (1991), 'Share repurchase and takeover deterrence', The Rand Journal of Economics pp. 72-88.

Baker, M. and Wurgler, J. (2002), 'Market timing and capital structure', Journal of Finance $\mathbf{5 7}(1), 1-32$. 
Ball, R., Gerakos, J., Linnainmaa, J. T. and Nikolaev, V. V. (2015), 'Accruals, cash flows, and operating profitability in the cross section of stock returns', Journal of Financial Economics, forthcoming (15-12).

Barclay, M. J. and Smith, C. W. (1995), 'The maturity structure of corporate debt', The Journal of Finance 50(2), 609-631.

Bargeron, L. L., Schlingemann, F. P., Stulz, R. M. and Zutter, C. J. (2008), 'Why do private acquirers pay so little compared to public acquirers?', Journal of Financial Economics 89(3), 375-390.

Bates, T. W., Kahle, K. M. and Stulz, R. M. (2009), 'Why do U.S. firms hold so much more cash than they used to?', Journal of Finance 64(5), 1985-2021.

Bayar, O., Baker, H. K. and Kiymaz, H. (2011), Going Private and Leveraged Buyouts, The Art of Capital Restructuring, John Wiley and Sons, Inc., pp. 419-435.

Bergstresser, D. and Philippon, T. (2006), 'CEO incentives and earnings management', Journal of Financial Economics 80(3), 511-529.

Berman, D., Naik, G. and Winslow, R. (July 25, 2006), 'Behind $\$ 21$ billion buyout of HCA lies a high-stakes bet on growth', Wall Street Journal.

Bewley, E. (October 28, 2011), 'HCA lobbies 'super committee", Gannett News Service .

BIIDEP, . (July 18, 1997), 'Value health, US-merger with Columbia/HCA approved..

Black, F. and Scholes, M. (1973), 'The pricing of options and corporate liabilities', Journal of Political Economy 81(3), 637-654.

Bradley, M., Jarrell, G. A. and Kim, E. H. (1984), 'On the existence of an optimal capital structure: Theory and evidence', The Journal of Finance 39(3), 857-878.

Brav, A., Graham, J. R., Harvey, C. R. and Michaely, R. (2005), 'Payout policy in the 21st century', Journal of Financial Economics 77(3), 483-527.

Brown, J. R. and Petersen, B. C. (2011), 'Cash holdings and R\&D smoothing', Journal of Corporate Finance 17(3), 694-709.

Business Wire, . (October 29, 2011), 'Robbins Geller Rudman and Dowd LLP files class action suit against HCA Holdings Inc.'

Chen, H., Wang, H. and Zhou, H. (2014), 'Stock return volatility and capital structure decisions', Working paper, available at SSRN: http://ssrn.com/abstract=2346642 pp. 142. 
Chou, D., Goh, J., Gombola, M. and Liu, F. (2002), 'Earnings management preceding reverse leveraged buyouts', Drexel University working paper available at: http://jobfunctions.bnet.com/abstract.aspx .

Columbia/HCA Healthcare Corporation (1996), International Directory of Company Histories. Retrieved April 13, 2015 from Encyclopedia.com:http://www.encyclopedia.com/doc/1G2-2841900039.html .

Cook, D., Kieschnick, R. and McCullough, B. D. (2008), 'Regression analysis of proportions in finance with self selection', Journal of Empirical Finance 15(5), 860-867.

Cowan, L. (19 February 2011), 'HCA IPO: \$30 a share?', The Wall Street Journal Online

Cox, C. (1996), 'Nonlinear quasi-likelihood models: applications to continuous proportions', Computational Statistics \& Data Analysis 21(4), 449-461.

Dang, V. A. (2013), 'An empirical analysis of zero-leverage firms: New evidence from the UK', International Review of Financial Analysis 30, 189-202.

Dann, L. Y. and Mikkelson, W. H. (1984), 'Convertible debt issuance, capital structure change and financing-related information: Some new evidence', Journal of Financial Economics 13(2), 157-186.

De Veirman, E. and Levin, A. (2015), 'Cyclical changes in firm volatility', Journal of Money, Credit and Banking, forthcoming .

De Veirman, E. and Levin, A. T. (2012), 'When did firms become more different? Timevarying firm-specific volatility in japan', Journal of the Japanese and International Economies 26(4), 578-601.

DeAngelo, H. and DeAngelo, L. (1987), 'Management buyouts of publicly traded corporations', Financial Analysts Journal 43(3), 38-49.

DeAngelo, H., DeAngelo, L. and Rice, E. M. (1984), 'Going private: Minority freezeouts and stockholder wealth', JL \& Econ. 27, 367.

DeAngelo, H., DeAngelo, L. and Stulz, R. M. (2006), 'Dividend policy and the earned/contributed capital mix: a test of the life-cycle theory', Journal of Financial Economics 81(2), 227-254.

DeAngelo, H., DeAngelo, L. and Whited, T. M. (2011), 'Capital structure dynamics and transitory debt', Journal of Financial Economics 99(2), 235-261. 
DeAngelo, H. and Roll, R. (2015), 'How stable are corporate capital structures?', The Journal of Finance $\mathbf{7 0}(1), 373-418$.

Demos, T. (23 February, 2011), 'HCA eyes $\$ 4.3$ bn offering next week', Financial Times .

Denis, D. J. and McKeon, S. B. (2012), 'Debt financing and financial flexibility evidence from proactive leverage increases', Review of Financial Studies 25(6), 1897-1929.

Denis, D. J. and Sibilkov, V. (2010), 'Financial constraints, investment, and the value of cash holdings', Review of Financial Studies 23(1), 247-269.

Department of Justice, . (June 26, 2003), 'Largest health care fruad case in US history setteled ; HCA investigation nets record total $\$ 1.7$ billion'.

Dierker, M. J., Kang, J.-K., Lee, I. and Seo, S. W. (2015), 'Do Firms Adjust Capital Structures to Manage Risk?', KAIST College of Business Working Paper Series No. 2013-031. available at http://ssrn.com/abstract=2360903; pp. 1-64.

Dittmar, A. K. (2000), 'Why do firms repurchase stock?', The Journal of Business $\mathbf{7 3}(3), 331-355$.

Dow Jones Corporate Filings Alert, . (January 31, 2006), 'HCA Inc. CEO gets restricted stk valued at $3.3 M^{\prime}$.

Eisfeldt, A. L. and Rampini, A. A. (2006), 'Capital reallocation and liquidity', Journal of Monetary Economics 53(3), 369-399.

Elsas, R., Flannery, M. J. and Garfinkel, J. A. (2014), 'Financing major investments: Information about capital structure decisions', Review of Finance 18(4), 1341-1386.

Fahlenbrach, R. and Stulz, R. M. (2009), 'Managerial ownership dynamics and firm value', Journal of Financial Economics 92(3), 342-361.

Financial Industry Regulatory Authority, Inc. (FINRA), . (2015), Available at : http://finra-markets.morningstar.com/BondCenter/.

Fischer, E., Heinkel, R. and Zechner, J. (1989), 'Dynamic capital structure choice: Theory and tests', The Journal of Finance 44(1), 19-40.

Flannery, M. J. and Rangan, K. P. (2006), 'Partial adjustment toward target capital structures', Journal of Financial Economics 79(3), 469-506.

Flower, J. (1995), 'Rick scott and the Columbia/HCA healthcare system : icon of greed or prophet of true reform?', Healthcare Forum Journal 38. 
Fox, I. and Marcus, A. (1992), 'The causes and consequences of leveraged management buyouts', The Academy of Management Review 17(1), 62-85.

Frank, M. Z. and Goyal, V. K. (2007), 'Trade-off and pecking order theories of debt', Available at SSRN: http://papers.ssrn.com/sol3/papers.cfm?abstract ${ }_{i} d=670543$.

Frank, M. Z. and Goyal, V. K. (2009), 'Capital structure decisions: Which factors are reliably important?', Financial Management 38(1), 1-37.

French, R. (17 November 2006), 'HCA shareholders approve $\$ 21.3 \mathrm{~b}$ buyout to take company private', APRS .

Friend, I. and Lang, L. H. P. (1988), 'An empirical test of the impact of managerial self-interest on corporate capital structure', The Journal of Finance 43(2), 271-281.

Gazette, C. (Jan 2, 2005), 'Companies try to reduce stock option costs', APRS .

Gilpin, K. (January 8, 1998), 'Dr. Thomas Frist Sr., HCA founder, dies at 87', The New York Times .

Graham, J. R. and Leary, M. T. (2011), 'A review of empirical capital structure research and directions for the future', Annual Review of Financial Economics 3.

Guay, W. R. (1999), 'The sensitivity of CEO wealth to equity risk: An analysis of the magnitude and determinants', Journal of Financial Economics 53(1), 43-71.

Guo, S., Hotchkiss, E. and Song, W. (2011), 'Do buyouts (still) create value?', The Journal of Finance 66(2), 479-517.

Harford, J., Klasa, S. and Walcott, N. (2009), 'Do firms have leverage targets? evidence from acquisitions', Journal of Financial Economics 93(1), 1-14.

Haug, M. and Hirschey, M. (2006), 'The january effect', Financial Analysts Journal 62(5), 78-88.

HCA History, . (2015), 'Our history', HCA history available at http://hcahealthcare.com/about/our-history.dot .

HCA Quarterly report (May 15, 2007), Quarterly report available at :http://investor.hcahealthcare.com/sec-filings .

Hite, G. L. and Owers, J. E. (1983), 'Security price reactions around corporate spin-off announcements', Journal of Financial Economics 12(4), 409-436.

Hribar, P., Jenkins, N. T. and Johnson, W. B. (2006), 'Stock repurchases as an earnings management device', Journal of Accounting and Economics 41(1), 3-27. 
Jalilvand, A. and Harris, R. S. (1984), 'Corporate behavior in adjusting to capital structure and dividend targets: An econometric study', The Journal of Finance 39(1), 127-145.

Jensen, M. C. (1986), 'Agency costs of free cash flow, corporate finance, and takeovers', American Economic Review 76(2), 323-329.

Kahle, K. M. (2002), 'When a buyback isn't a buyback: open market repurchases and employee options', Journal of Financial Economics 63(2), 235-261.

Kale, J. R. and Shahrur, H. (2007), 'Corporate capital structure and the characteristics of suppliers and customers', Journal of Financial Economics 83(2), 321-365.

Kane, A., Marcus, A. J. and McDonald, R. L. (1985), 'Debt policy and the rate of return premium to leverage', Journal of Financial \& Quantitative Analysis 20(4), 479-499.

Kaplan, S. (1989), 'The effects of management buyouts on operating performance and value', Journal of Financial Economics 24(2), 217-254.

Kayhan, A. and Titman, S. (2007), 'Firms' histories and their capital structures', Journal of Financial Economics 83(1), 1-32.

Keefe, M. O. and Tate, J. (2013), 'Is the relationship between investment and conditional cash flow volatility ambiguous, asymmetric or both?', Accounting \& Finance 53(4), 913947.

Keefe, M. and Yaghoubi, M. (2015), 'The influence of cash flow volatility on capital structure and the use of debt of different maturities', Journal of Corporate Finance.

Kester, W. C. (1986), 'Capital and ownership structure: A comparison of united states and japanese manufacturing corporations', Financial Management 15(1), 5-16.

Kieschnick, R. and McCullough, B. D. (2003), 'Regression analysis of variates observed on $(0,1)$ : Percentages, proportions and fractions', Statistical Modelling: An International Journal 3(3), 193.

Kim, J., Kim, H. and Woods, D. (2011), 'Determinants of corporate cash-holding levels: An empirical examination of the restaurant industry', International Journal of Hospitality Management 30(3), 568-574.

Kim, W. S. and Sorensen, E. H. (1986), 'Evidence on the impact of the agency costs of debt on corporate debt policy', The Journal of Financial and Quantitative Analysis 21(2), 131-144.

Kraus, A. and Litzenberger, R. H. (1973), 'A state-preference model of optimal financial leverage', The Journal of Finance 28(4), 911-922. 
Kummer, C. and Steger, U. (2008), 'Why merger and acquisition (M\&A) waves reoccur: the vicious circle from pressure to failure', Strategic Management Review 2(1), 44-63.

Leary, M. and Roberts, M. (2005), 'Do firms rebalance their capital structures?', The Journal of Finance 60(6), 2575-2619.

Leary, M. T. and Roberts, M. R. (2014), 'Do peer firms affect corporate financial policy?', The Journal of Finance 69(1), 139-178.

Lee, H. and Moon, G. (2011), 'The long-run equity performance of zero-leverage firms', Managerial Finance (10), 872.

Lemmon, M. L., Roberts, M. R. and Zender, J. F. (2008), 'Back to the beginning: Persistence and the cross-section of corporate capital structure', Journal of Finance 63(4), 1575-1608.

Leone, A. J., Rock, S. and Willenborg, M. (2007), 'Disclosure of intended use of proceeds and underpricing in initial public offerings', Journal of Accounting Research 45(1), 111153.

Levine, O. and Wu, Y. (2016), 'Asset volatility and financial policy: Evidence from corporate mergers', Working paper available at SSRN: http://ssrn.com/abstract=2399154

Ma, J. (15 Sep 2011), 'HCA buys back 15.6\% stake from Bank of America', Investor's Business Daily .

MarketWatch, . (September 20, 2011), 'Hospitals feel stronger pinch in Obama plan some firms down $7 \%$ in effort to cut medicare overpayment'.

McCue, M. and Thompson, J. (2012), 'The impact of HCA's 2006 leveraged buyout on hospital performance', Journal of healthcare management / American College of Healthcare Executives 57(5), 342-56; discussion 357.

Merton, R. C. (1973), 'Theory of rational option pricing', The Bell Journal of Economics and Management Science 4(1), 141-183.

Merton, R. C. (1974), 'On the pricing of corporate debt: The risk structure of interest rates', The Journal of Finance 29(2), 449-470.

Modern Healthcare, . (August 15, 2007), 'HCA plans to pay $\$ 20$ million to settle lawsuits'.

Morck, R., Shleifer, A. and Vishny, R. (1990), 'Do managerial objectives drive bad acquisitions?', The Journal of Finance 45(1), 31-48. 
Myers, S. C. (1977), 'Determinants of corporate borrowing', Journal of Financial Economics 5(2), 147-175.

Myers, S. C. and Majluf, N. S. (1984), 'Corporate financing and investment decisions when firms have information that investors do not have', Journal of Financial Economics $\mathbf{1 3}(2), 187-221$.

Myerson, A. (May 24, 1994), 'Another big merger in health care', The New York Times .

Nanda, V. and Narayanan, M. (1999), 'Disentangling value: Financing needs, firm scope, and divestitures', Journal of Financial Intermediation 8(3), 174-204.

Norris, F. (October 6, 1994), 'Market place; efficiencies of scale are taken to the nth degree at Columbia.', The New York Times .

Opler, T., Pinkowitz, L., Stulz, R. and Williamson, R. (1999), 'The determinants and implications of corporate cash holdings', Journal of Financial Economics 52(1), 3-46.

Opler, T. and Titman, S. (1993), 'The determinants of leveraged buyout activity: Free cash flow vs. financial distress costs', The Journal of Finance 48(5), 1985-1999.

Paolino, P. (2001), 'Maximum likelihood estimation of models with beta-distributed dependent variables', Political Analysis 9(4), 325-346.

Papke, L. E. and Wooldridge, J. M. (1996), 'Econometric methods for fractional response variables with an application to $401(\mathrm{k})$ plan participation rates', Journal of Applied Econometrics 11(6), 619-632.

Pederson, J. P. (2001), 'International directory of company histories', St. James Press 38.

Pettit, J. (2001), 'Is a share buyback right for your company?', Harvard business review $\mathbf{7 9}(4), 141-170$.

Pinkowitz, L. and Williamson, R. (2007), 'What is the market value of a dollar of corporate cash?', Journal of Applied Corporate Finance 19(3), 74-81.

PRNewswire, . (November 5, 1996), 'Columbia completes acquisition of Central Health Services, Inc. and affiliated Home Health Agencies.'.

Rajan, R. G. and Zingales, L. (1995), 'What do we know about capital structure? Some evidence from international data', The Journal of Finance 50(5), 1421-1460.

Reindl, J., Stoughton, N. and Zechner, J. (2013), 'Market implied costs of bankruptcy', Working paper available at SSRN: http://papers.ssrn.com/sol3/papers.cfm?abstract_id=2324097. 
Renneboog, L., Simons, T. and Wright, M. (2007), 'Why do public firms go private in the UK? the impact of private equity investors, incentive realignment and undervaluation', Journal of Corporate Finance 13(4), 591-628.

Reuters News, . (10 June 1993), 'Columbia Hos. to merge with Galen..

Reuters News, . (21 April, 1999a), 'Columbia/HCA Q1 net up on lower revs..

Reuters News, . (August 7, 1997a), 'Columbia/HCA proposes fundumental changes'.

Reuters News, . (July 26, 1997b), 'Top 2 Columbia/HCA executives resign..'

Reuters News, . (March 21, 1997c), 'U.S. expands Columbia/HCA investigation-NYT..

Reuters News, . (May 26, 1999b), 'U.S. Justice Dept. joins another Columbia/HCA suit'.

Reuters Significant Developments, . (January 12, 2005), 'HCA Inc. raises Q4 EPS guidance'.

Schlingemann, F., Stulz, R. and Walkling, R. (2002), 'Divestitures and the liquidity of the market for corporate assets', Journal of Financial Economics 64(1), 117-144.

Shleifer, A. and Vishny, R. W. (1991), 'The takeover wave of the 1980s', Journal of Applied Corporate Finance 4(3), 49-56.

Skinner, D. J. (2008), 'The evolving relation between earnings, dividends, and stock repurchases', Journal of Financial Economics 87(3), 582-609.

Stephens, C. P. and Weisbach, M. S. (1998), 'Actual share reacquisitions in open-market repurchase programs', The Journal of Finance 53(1), 313-333.

Stohs, M. H. and Mauer, D. C. (1996), 'The determinants of corporate debt maturity structure', The Journal of Business 69(3), 279-312.

Stoll, H. R. (1969), 'The relationship between put and call option prices', The Journal of Finance 24(5), 801-824.

Strebulaev, I. A. (2007), 'Do tests of capital structure theory mean what they say?', Journal of Finance 62(4), 1747-1787.

Strebulaev, I. and Yang, B. (2013), 'The mystery of zero leverage firms', Journal of Financial Economics 109(1), 1-23.

StreetInsider, . (September 15, 2011), 'HCA Holdings enters into 80.77M buyback plan with BofA for $\$ 18.61$ share', StreetInsider.com . 
Sundaresan, S. (2013), 'A review of merton s model of the firm s capital structure with its wide applications', Annual Review of Financial Economics 5(1).

The New York Times, . (3 October 1993), '2 largest hospital chains in U.S. merge'.

Titman, S. and Wessels, R. (1988), 'The determinants of capital structure choice', The Journal of Finance 43(1), 1-19.

Tsetsekos, G., Kaufman Jr, D. and Gitman, L. (2011), 'A survey of stock repurchase motivations and practices of major US corporations', Journal of Applied Business Research (JABR) $\mathbf{7}(3), 15-21$.

Uysal, V. B. (2011), 'Deviation from the target capital structure and acquisition choices', Journal of Financial Economics 102(3), 602-620.

Van de Gucht, L. and Moore, W. (1998), 'Predicting the duration and reversal probability of leveraged buyouts', Journal of Empirical Finance 5(4), 299-315.

Welch, I. (2004), 'Capital structure and stock returns', Journal of Political Economy 112(1), 106-132.

Welch, I. (2007), 'Common flaws in empirical capital structure research', AFA 2008 New Orleans Meetings Paper pp. 1-33.

Welch, I. (2011), 'Two common problems in capital structure research: The financialdebt-to-asset ratio and issuing activity versus leverage changes', International Review of Finance 11(1), 1-17.

Zengerle, P. (May 2, 1999b), 'US to start fraud trial for Columbia/HCA exexecs.', Reuters News.

Zengerle, P. (May 5, 1999a), 'Focus-lawyers spar at start of Columbia/HCA trial.', Reuters News . 